\title{
Cracks, Microcracks and Fracture in Polymer Structures: Formation, Detection, Autonomic Repair
}

\author{
Firas Awaja $^{\mathrm{a}^{*} \text {, Shengnan Zhang }}{ }^{\mathrm{b}}$, Manoj Tripathi ${ }^{\mathrm{a}}$, Anton Nikiforov ${ }^{\mathrm{d}}$, Nicola \\ Pugno ${ }^{\mathrm{a}, \mathrm{d}, \mathrm{e}}$ \\ ${ }^{\text {a }}$ Center for Materials and Microsystems, PAM-SE, Fondazione Bruno Kessler, Trento, Italy \\ ${ }^{\mathrm{b}}$ School of Aerospace, Mechanical and Mechatronic Engineering, The University of Sydney, \\ Sydney, NSW, 2006, Australia \\ 'Department of Applied Physics, Ghent University, Sint-Pietersnieuwstraat 41 B4, 9000 Ghent, \\ Belgium \\ ${ }^{\mathrm{d}}$ Laboratory of Bioinspired and Graphene Nanomechanics, University of Trento, Italy \\ ${ }^{\mathrm{e}}$ School of Engineering and Materials Science, Queen Mary University of London, Mile End \\ Road, London, E1 4NS, UK
}

*Author for Correspondence, awaja@fbk.eu. Tel: +39 0461314645

\begin{abstract}
:
Polymers and polymer composites are susceptible to premature failure due to the formation of cracks and microcracks during their service time. Evolution of cracks and microcracks could induce catastrophic material failure. Therefore, the detection/diagnostics and effective repair of cracks and microcracks are vital for ensuring the performance reliability, cost effectiveness and safety for polymer structures. Cracks and microcracks, however, are difficult to detect and often repair processes are complex. Biologically inspired self-healing polymer systems with inherent ability to repair damage have the potential to autonomically repair cracks and microcracks. This article is a review on the latest developments on the topics of cracks and microcracks initiation and propagation in polymer structures and it discusses the current techniques for detection and 1
\end{abstract}


observation. Furthermore, cracks and microcrack repair through bio-mimetic self- healing techniques is discussed along with surface active protection. A separate section is dedicated to fracture analysis and discusses in details Fracture mechanics and formation.

Keywords: polymer composites, cracks, microcracks, polymer structures, self-repair 


\section{Table of Contents}

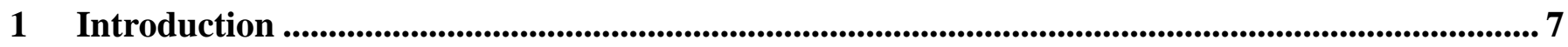

2 Crack and microcrack: Formation; initiation and propagation....................................................9

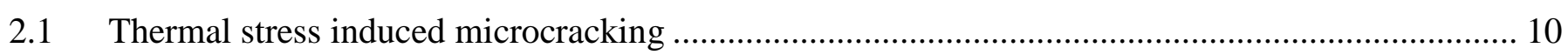

2.2 Mechanical fatigue induced microcracking (mechanical cycling) ................................................. 13

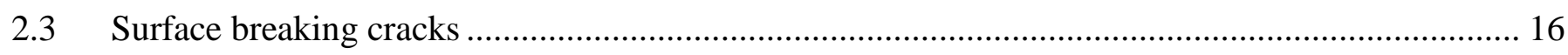

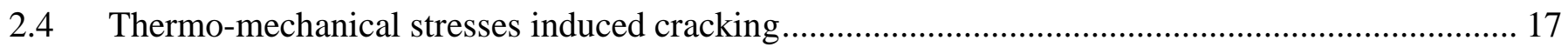

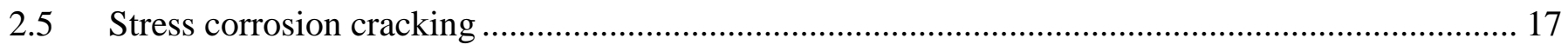

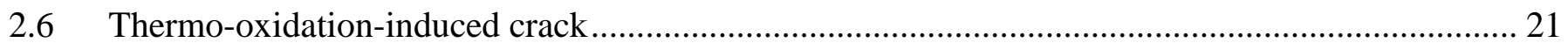

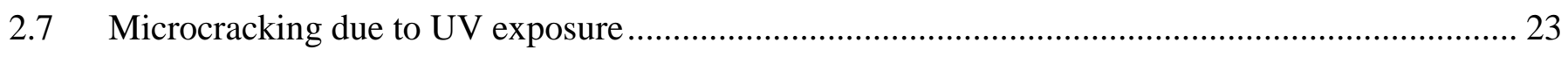

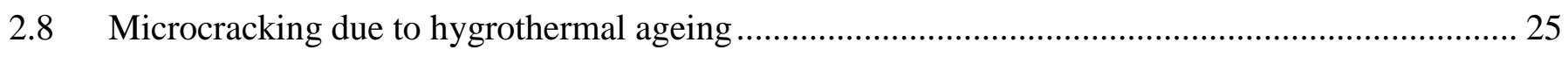

3 Crack and microcrack detection: non-destructive evaluation ............................................................... 28

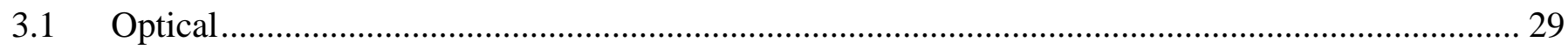

3.2 Optical Coherence Tomography (OCT) …………......................................................................... 30

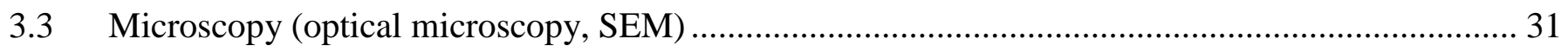

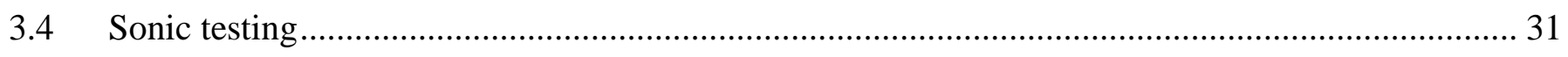

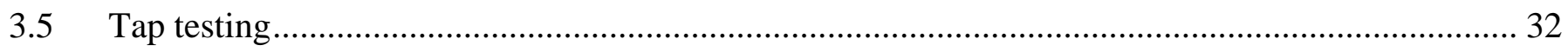

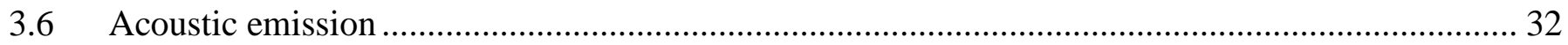

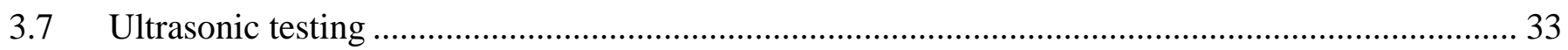

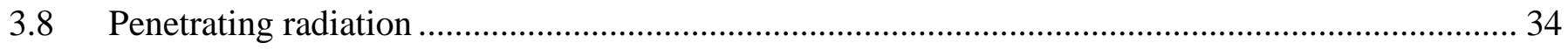

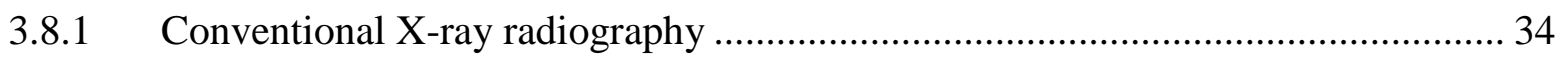

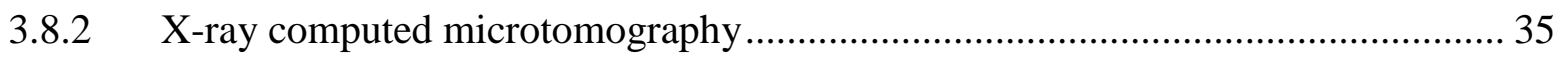




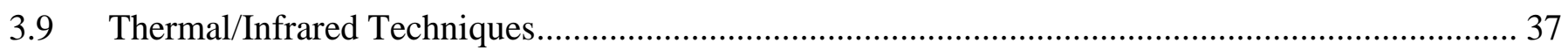

4 Self Healing: Autonomic Repair and Manufacturing techniques.....................................................38

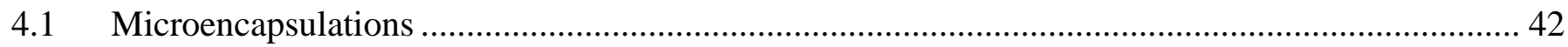

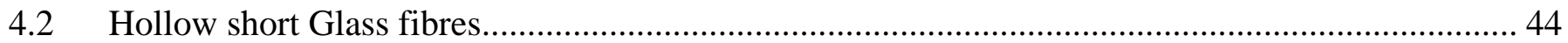

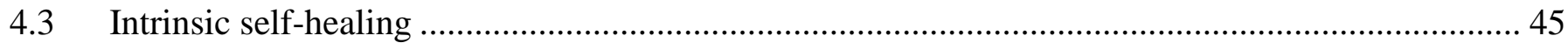

5 Active protection .................................................................................................................................................... 47

6 Fracture mechanics for polymer composites. …................................................................................. 48

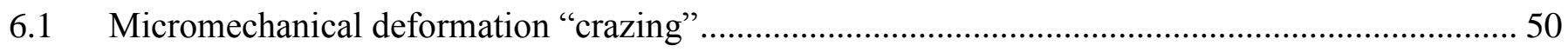

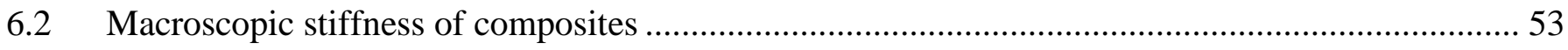

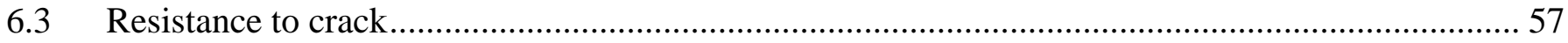

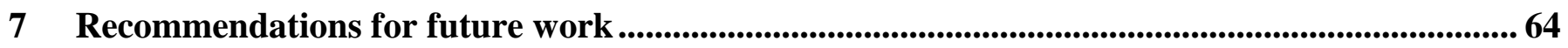

(List of Equations, Tables and Figures:)

$\sigma f(2 l)=\sigma p 1+r 2 \Delta l 1+2 l \Delta l 2 w \pi l \tan \pi l 2 w 12$

$\left.\left.\mathrm{G}=\left(\mathrm{K}_{I(\text { model })}\right)^{2} \mathrm{E}^{\prime}\right)+\left(\mathrm{K}_{I(\text { modelI })}{ }^{2} \mathrm{E}^{\prime}\right)+\mathrm{K}_{I(\text { modeIII })}{ }^{2} / \mathrm{E}\right)$

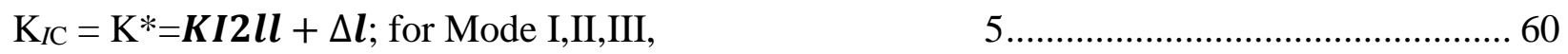

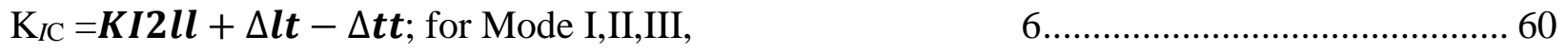

Table 1. Some applications of fibre reinforced composites and their crack susceptibility........... 85

Table 2. Some examples of various causes of defects in composites and their detection methods 
Table 3: Thermal and Oxidative shrinkage in polymer composites

Table 4: Hydrolysis aging of polymer composites 88

Table 5: Comparison of different non-destructive testing methods for composites 89

Table 6: Quantitative measurements of defects in polymer composites using x-ray tomography 91

Table 7: Comparisons of crack detections for polymer structures and composites..... 93

Table 8: Cracks and Micro cracks self-repair and healing mechanisms 94

Table 9: Craze initiation stress (MPa) for different polymers (from left to right are Polypropylene, polystyrene, polycarbonate, polyvinyl chloride, poly-methyl methacrylate) and composites ..... 96

Table 10: Fracture toughness of Epoxy polymer composite tested from different methods. Fracture toughness shows here represent the mean values from different literatures. 97

Figure 1 Stress corrosion cracks formation in combined aggressive chemical environment and mechanical stress. Copyright 2014. Reprint from [85]. 99

Figure 2 Destruction of high voltage insulator due to action of moisture, electrical field and acidic environment. Copyright 2014. Reprint from [92]. 100

Figure 3 Stress-corrosion cracks after $336 \mathrm{~h}$ of acid exposure of E-glass/vinil ester without mechanical load. a,b,c) single fiber crack, and d) multiple fiber crack zone. Copyright 2014. Reprint from [96]. 101

Figure 4 A three zone model of thermo-oxidative aging. Copyright 2014. Reprint from [105]. 102 
Figure 5 Damage development in polymer after aging in nitrogen and air environment. Copyright 2014. Reprint from [123]. 103

Figure 6 Development of mechanical stress in polylactide samples for different hydrothermal aging temperatures. VPLA and RPLA- $i$ corresponds to virgin polymer and polymer after $i$ processing cycles, respectively. Copyright 2014. Reprint from [135]. 104

Figure 7 Schematic of self-healing using microcapsules. Copyright 2014. Reprint from [356]. 105

Figure 8 SEM image of the healed surface of composite fiber-reinforced polymer after $30 \mathrm{~min}$ healing time. Copyright 2014. Reprint from [17]. 106

Figure 9 Types of fracture mechanism that generally distinguished for initiation and propogation 107

Figure 11 Normalized Tensile strength (TS) of different polymer composites, all values are normalized to its pure state $\left(\mathrm{TS}_{\mathrm{PC}} / \mathrm{TS}_{\mathrm{Pure}}\right)$. Inset shows increasing trend from red circle to angular dark yellow triangle [256-260, 357-359]. 108

Figure 12 Toughness measurement of different polymers (Polyester, Ethylene oxid, PMMA, Emeraldine salt) correspond with different modifiers (PET, HNT, mica, Bentone (Ben),(MMT) concentration[269, 287-290]. 109 


\section{Introduction}

Polymer materials used in the automotive, aerospace and space industries are required to perform in conditions where they may undergo severe mechanical, thermal and chemical damage. Replacing or repairing damaged parts is often expensive and difficult.

Polymer structural damage can be classified into macro and microscopic levels. Microscopic scale damage such as microcracking occurs as a result of impact and internal stresses. Microcracking is the major cause of material failure due to its nature of being undetected and also because of the induced structure fragmentation which leads to the reduction of mechanical properties such as strength, stiffness and dimensional stability [1,2]. Table 1 shows the most common polymer composites and their advantageous of use, applications and main source of cracks and microcracks damage.

Macroscopic damage is traditionally detected visually and repaired manually. Damage inspection techniques such as ultrasonics and radiography are used to detect microscopic and internal damages. However, damages like microcracking are difficult to detect due to limitations in the resolutions of these techniques and hence it won't be repaired. Further, cracks, structural defects and delamination that form deep into the structure of polymer composites are extremely difficult to detect and repair $[1,3,4]$. These internal defects not only decrease the material performance but also serve as catalysts for further damage like macrocracks, moisture swelling and debonding. Microcracks are also responsible for the environmental degradation of the polymer and the 
consequence reduction in performance [5-7] as well as reducing adhesion which leads to debonding [8].

Most of the damage that occurs on the surface of polymer structures or laminating polymers causes chains and structure break-up. This causes a rapid deterioration of physical properties at the damage site which also can propagate locally or migrate to other sites. Repairing the damaged chains often result in restoring the original properties and prevents the damage from expanding.

Polymer chains are damaged when subjected to external stress such as aggressive chemicals, heat, light (including UV), mechanical impact, radiation and particles. The damage might manifest as a dent, crack, microcrack, rupture and fracture. Damage retardant and resistant additives are added to polymer and polymer composites for industrial application to provide protection. However, once damage stress overwhelms the protection barrier, these additives have no repairing mechanisms [9-12]. In thermosetting polymers, the final molecular structure depends on the curing reaction conditions during the manufacturing process. Therefore, monitoring the progress of the curing reactions enables more control over the final product specifications including formation of cracks and microcracks [13-15].

Polymer composites with the capability of self healing or self repair based on mimicking the biological process of wounds healing have been introduced recently [1, 3, 16-20]. The incorporation of microencapsulated dicyclopentadiene (DCPD) healing agent into epoxy composite can extends fatigue life by as much as $213 \%$ [16]. Up to $80 \%$ recovery has been reached by healing at $80{ }^{0} \mathrm{C}$ of the fiber-reinforced composite materials filed with 
dicyclopentadiene monomer stabilized with 100-200 ppm p-tert-butylcatechol in form of microcapsules with a mean diameter of $160 \mu \mathrm{m}[17,18]$. At present, self healing polymer composites face serious challenges of being expensive to manufacture and lack of fundamental process knowledge. These composites mostly work in preventing further damage rather than complete healing. They also have poor mechanical properties and they are difficult to mould into large structures. A new generation of self cross-linkable polymer resin composites (thixotropic and phenolic epoxies) with self healing properties has the potential to provide the essential understanding as well as the economic and the industrial solution. Significant research is needed to understand the self healing concept and the cross-linking reactions mechanism to successfully apply self healing material in the automotive, aerospace and space industries.

\section{Crack and microcrack: Formation; initiation and propagation}

Most polymer composites are subjected to mechanical loadings and environmental factors during fabrication, storage and service. As a consequence, microcracks may be formed in the composites during static, dynamic, fatigue cyclic loading of different types, such as tension, compression and shear.

Exposure to variable environmental conditions such as temperature, moisture, chemicals, and radiation also cause the formation and propagation of microcracks. Polymer composites subjected to synergistic effects of mechanical loading and environmental exposure usually are more susceptible to microcrack formation and propagation. Microcracking in the polymer composites immediately cause deterioration of the thermomechanical properties and it also serves as initiator to other forms of damage; induce delamination and fibre-matrix interfacial debonding and cause fiber fracture, provide pathways for entry of moisture, oxygen, and other 
corrosive liquid [21, 22]. Thus, microcracks can ultimately lead to overall material degradation and affect the long term durability of the polymer composites materials[23]. Table 2 presents examples of various causes of defects in composites and their detection methods.

Several models have been proposed for a polymer composite system in which a crack start travelling in the matrix approaching the reinforcing fibres. For a given fibre reinforced composite where the fibre is gripped by the polymer matrix, a matrix crack is halted by fibre. Upon increasing the load, crack starts to pass around the fibre without breaking the interfacial bond. Interfacial shearing and lateral contraction of the fibre result in debonding and a further increment of crack extension. After considerable debonding the fibres break at some weak points within the matrix and further crack extension occurs. The total failure of the composite happens when the broken fibre end is pulled out against the frictional grip of the matrix[24].

\subsection{Thermal stress induced microcracking}

Thermal stress could be generated in polymer composites either during manufacturing process or when the composites are exposed to service conditions. Thermal stresses mainly arise from the mismatch of thermal expansion coefficients between the reinforcement and the matrix, cure shrinkage in thermosetting matrices and melting/solidification volumetric changes in thermoplastics[23, 25]. Microcracks in carbon fiber/epoxy laminates were studied at the range of cured temperatures of $70-180{ }^{\circ} \mathrm{C}[25]$. The average final crack density $\left(\mathrm{cracks} / \mathrm{cm}^{2}\right)$ has been increased from 10 to 35 with increase of stress free temperature from 120 to $200{ }^{\circ} \mathrm{C}$. Thermal stress increases as the difference between the operating temperature and the stress-free temperature increases. Accumulation of thermal stresses in polymer composites could initiate microcracking and cracking even in the absence of applied mechanical loading [23, 26, 27]. 
The development of thermal stress induced microcracking in polymer composites depends on many factors, such as the matrix composition and structure[28], type of reinforcement[29], interfacial properties[30], stacking sequence of the laminates[31], fibre volume fraction and fibre distribution, the presence of moisture or any inhomogeneity (voids) within the composites structure. Timmerman et al [29] studied the influences of matrix and fibre on microcracking of carbon fibre/epoxy composites exposed to cryogenic thermal cycling. Their study revealed that microcracking occurred in the polymer matrix transverse to the fibers and increased backbone flexibility of the polymer matrix (lower glass transition temperature $T_{\mathrm{g}}$ ), higher tensile moduli and coefficient of thermal expansion of the fibres led to an increased microcrack density. An increase of microcracking from 8.5 to $72 \mathrm{cracks} / \mathrm{cm}^{2}$ has been observed with decrease of laminate glass transition temperature from 142 to $69^{\circ} \mathrm{C}$, respectively.

Polymer composites that are used in aerospace applications are often exposed to cyclic thermal loading. For example, service temperatures for aircraft components normally range from $-55^{\circ} \mathrm{C}$ to $80^{\circ} \mathrm{C}$. The temperatures in the low earth orbit (LEO) where most satellites and space shuttle orbit can vary from $-150{ }^{\circ} \mathrm{C}$ to $150{ }^{\circ} \mathrm{C}$. Awaja and co-workers [32] evaluated the epoxy resin composites reinforced with various reinforcing materials such as carbon fibre, carbon nanotube, nano-clay and 3D-glass fibres under the simulated LEO environmental conditions, including high vacuum, UV radiation, atomic oxygen (AO) and thermal cycles. Occurrence of chemical reactions such as chain scission and oxidation resulting from degradation in the LEO conditions were confirmed for all composites. The degree of the degradation reactions was found to be related to the type of the filler reinforcement. Among the five selected polymer composites, $\mathrm{CF}$ suffered least surface degradation with increase of $\mathrm{O}$ 1s percentage from $10.6 \%$ to $15.6 \%$ and a 
decline of C 1s percentage from $86.1 \%$ to $80.52 \%$ under typical LEO conditions based on XPS results. Resin mass loss and flaking occurred on the treated epoxy composites and microcracks were formed in the CF sample at the interface of the fibre/resin interface. Synergistic effects of simulated LEO environmental conditions accelerate polymer degradation through chain scission, oxidation and crosslinking. No surface microcracks were observed for composites reinforced with 3D glass woven fabric, which could be due to the high thermal cycling resistance of the 3D glass composite as well as the number of thermal cycling performed [33] .

A number of studies have been undertaken to investigate the effect of thermal cycling on microcrack initiation and growth in polymer composites [29, 34, 35]. Shimokawa et al.[34] have carried out thermal-cycling tests of up to 10,000 cycles on two kinds of carbonfiber/thermoplastic polyimide composite material: IM7/PIXA, IM7/K3B, and up to 1000 cycles on G40-800/5260 carbon fiber/bismaleimide composite material. A fairly large number of transverse microcracks were observed in carbon fibre reinforced composites by the end of thermal cycling tests but these microcracks were found not to contribute to the failure of out-ofplane delamination buckling due to their directions[34]. The type of fibers and the polymeric matrix used in the composites play a large role in propagation and distribution of microcracks in carbon fibre epoxy composites. Higher fiber tensile moduli resulted in increased microcrack density and larger cracks. Increased polymer backbone flexibility caused an increase in microcrack density and decreased the $T_{\mathrm{g}}$ of the studied laminates [29, 35]. With a $100{ }^{\circ} \mathrm{C}$ temperature change an unidirectional laminate stresses of $\pm 15 \mathrm{MPa}$ can be generated, with somewhat higher values for a typical 0/90 laminate resulting in mainly matrix cracking with change of flexural and transverse properties. 
Damages in the forms of transverse cracks resulting from thermal loading in extreme conditions such as space environment $\left(-157^{\circ} \mathrm{C}\right.$ to $\left.+120^{\circ} \mathrm{C}\right)$ have been studied in epoxy composites for potential applications in space stations. Microcracks and further surface erosion occurred when the composites were exposed to UV radiation, thermal cycling, simulated AO and vacuum [36].

Awaja et. al. [37] have studied the structural change of epoxy resin composites reinforced with hollow glass microspheres, microlight microspheres, 3D parabeam glass, and E-glass subjected to accelerated thermal degradation conditions by $\mathrm{X}$-ray microcomputed tomography $(\mathrm{X} \mu \mathrm{CT})$ and optical coherence tomography (OCT). The results showed that air bubbles originally trapped in the glass microsphere and microlight microsphere composites underwent expansion as a result of thermal treatment, which has been proved to be the main cause for crack initiation and propagation in the resin matrix. Cracks/voids found in the E-Glass and 3D-Glass composites subjected to elevated temperature result are mostly in the resin matrix and propagate into the fabric filler.

\subsection{Mechanical fatigue induced microcracking (mechanical cycling)}

Fatigue, in general, and of polymers in particular, is the major cause of component failure due to cyclic or random application of load [38]. Once under alternating loads, most polymers will fail at stress levels much lower than they can withstand under monotonic loading conditions. As a result of the periodic nature of the applied load, micro-cracks initiate and propagate at relatively low stress level and finally structure will fracture. Although investigation of the fatigue failure phenomenon in metals dates back to $18^{\text {th }}$ century [39], studies in polymer fatigue has been conducted since 1960's and several early articles and review papers cover both experimental and theoretical investigations of fatigue failure in polymers [40-46]. In most cases, principles initially 
developed to explain fatigue failure in metals can accurately describe polymer fatigue phenomenon [38].

Increased application of polymer based materials in various engineering components and advanced structures demands improved polymer fatigue properties. There are several parameters influencing the fatigue behaviour of polymers including stress amplitude, intensity and frequency; environmental factors such as temperature and humidity; surface coating as well as material variables e.g. polymer structure, its viscoelastic characteristics and molecular weight distribution [47].

One of the strategies for improving fatigue behaviour of brittle thermosetting polymers is to enhance fracture toughness. This could be achieved by introducing a second phase such as rigid fillers, rubbery particles/thermoplastic modifiers and microcapsules to polymer matrix $[16,48$ 57]. While the toughness mechanism in rubber modified polymer is due to shear bending and plastic void growth, a crack tip pinning or crack surface bridging mechanism is in play for solid filler modified polymers. Using both rubbery particles and solid fillers have been shown to result in synergistic toughening in epoxy polymer[48]. Addition of modifiers at 10 vol $10 \%$ into a ductile epoxy polymer led to improve of fatigue crack propagation resistivity of the polymer to more than $100 \%$ [49]. L. Becu et al. [50] have shown that the fracture toughness of the epoxy matrix expressed as constant of the Paris Law can be improved from $437 \times 10^{-3}$ for pure epoxy to $0.7 \times 10^{-3}$ by introducing core-shell particles at a volume fraction of up to $24 \%$. In [51] the Paris law constant for epoxy polymer was found to be strongly dependent on the liquid-filled ureaformaldehyde microcapsules concentration, varying from $8.2 \times 10^{-2}$ for neat epoxy to approximately $8.6 \times 10^{-4}$ above $10 \mathrm{wt} \%$ microcapsules, but was independent of microcapsule 
diameter. Similar result was observed for use of wax-protected, recrystallized Grubbs' catalyst leading to $10^{4}$ increase in the rate of polymerization of bulk dicyclopentadiene and extends the fatigue life of a polymer over 30 times longer [52]. Artificial crack closure and hydrodynamic pressure crack-tip shielding have also shown to reduce the fatigue crack growth. The mechanism involved in these methods is crack-tip shielding in which the intensity of crack tip is reduced using polymer infiltration and/or a viscous fluid [16, 58-66]. This therefore makes the concept of employing microcapsules very interesting as it utilises all the aforementioned mechanisms to enhance the fatigue performance of polymer $[16,52]$. Recently the interest in the hydrodynamics response of ships in rough seas has been increased significantly. The navigation of ships and other floating structures in seaways are frequently experiences wave slamming or pounding which give rise to elastic vibration throughout the hull. As a result of the slamming waves, the ship's structure is subjected to repeated impulse forces that cause high fatigue stresses and damage to the structure[67-69] made of carbon steel. Reinforced polymer offers a better alternative to carbon steel. It is about $30 \%$ to $70 \%$ lighter than carbon steel and provides stealth capability. More importantly, the fatigue accumulation of composite materials are reported to be $4-7$ orders of magnitude slower than in metals and that is why composite vessels has never shown fatigue problems [70-72]. However, composites have their own drawbacks, they are only suitable for smaller ships or boats because they lack the stiffness and the in-plane strength required for the large ship hulls.

Sandwich composite are finding an increasing number of applications in marine structures such as floating marina or the deck of an offshore platform. The high stiffness, light-weight and energy absorption gives the sandwich composites an advantage over the conventional materials 
[73]. Marine sandwich structures demonstrate particular failure modes as a consequence of complex in service cycling slamming loads. Slamming loads can cause core crushing, shear failure in the core, facesheet-core debonding and compressive or tensile failure of the laminates that overtime can reduce the load carrying capability of the marine composites and compromise the seaworthiness of the structure. Detection of extent of damage in marine sandwich structures under slamming impact are of high importance as it has been found that the face sheets in sandwich composite usually remain intact with no visible or apparent damage and therefore obscuring any failure events in the core and the interface where damage is likely to initiate and propagate [74-76].

\subsection{Surface breaking cracks}

Polymers and polymer composites are widely used in space technologies and space structures due to their strength, light weight, good thermal and electrical insulation properties. Most of the components in aerospace structures are subjected to cyclic loads and thermal stresses. As a result of cyclic loads; cyclic stresses are induced which can result in local crack initiation and growth. The cracks are mostly initiated at external surfaces. Initiation and propagation of small cracks deep within the structure where detection is difficult and repair is virtually impossible can cause catastrophic component failure. Prevention of fatigue failure depends on accurate life prediction and regular inspection. In addition, a self healing approach has been recently explored [77] to improve the fatigue life of polymers and preventing catastrophic failure of aerospace components. The dicyclopentadiene microcapsules $(50-200 \mu \mathrm{m})$ with a urea-formaldehyde shell were used for a self-healing composite production. A recovery of about $75 \%$ of the virgin fracture load has been achieved with an average healing efficiency of $60 \%$. 


\subsection{Thermo-mechanical stresses induced cracking}

Many engineering components or structures are often subjected to combined thermal and mechanical loads. These components are subjected to cyclic strains which are generated both thermally and mechanically. Example of such components and structures are the parts of aircraft engine hot section that operate in a high temperature environment along with mechanical loading, nuclear reactors that subjected to both high temperature and pressure and high pressure vessels and boilers[78-80].

Thermo mechanical cyclic loading may result in cracks initiation and the propagation of existing cracks. These thermo-mechanical stresses cause damage to the components and lead to a failure. Predicting the safe life period of components subjected to thermo-mechanical stresses is of great importance and challenge to the industry [81-83]. In [83] the combined thermal cycling (CTC) and mechanical loading (ML) tests were shown to be a time and cost efficient way to generate crack propagation data and so can be used to predict isothermal crack processes.

\subsection{Stress corrosion cracking}

Stress corrosion cracking (SCC) is a common problem for polymers and composites that serve under a combination of mechanical stress and chemically aggressive environment. For polyolefin pipe, it is commonly observed in the form of a microcrack colony within a surface layer of degraded polymer exposed to both mechanical stress and chemically aggressive environment [84, 85]. Four stages of SCC have been distinguished by Choi et al [85]: (1) multiple crack initiations due to localized material degradation, (2) individual crack growth, (3) cracks interaction and formation of crack clusters, and (4) crack/cluster instability or crack cluster growth resulting in ultimate failure. Figure 1 shows stress SCC formation in combined aggressive chemical 17 
environment and mechanical stress. Hogg et. al. [86] developed a model for SCC growth in fibre reinforced composites in acidic environment and concluded that the resin toughness plays a critical role in resisting the crack growth. The rate of crack growth under stress corrosion conditions was found to be controlled by the stress acting on the fibres as $\log d a / d t(m / s)=$ $0.0057 \sigma_{22}(\mathrm{MPa})-12.57$ (conditions: $\mathrm{T}$ is $20{ }^{\circ} \mathrm{C}, 0.65 \mathrm{M} \mathrm{HCl}$ ) where $\sigma_{22}$ is the stress acting in the fibre direction. The resin matrix modifies the stress acting on the fibres which leads to controlling the crack growth rate during stress corrosion.

Polymer composites can be used as high voltage insulators for overhead high voltage transmission lines with voltage ranging from $69 \mathrm{kV}$ to $735 \mathrm{kV}$. Composite insulators are susceptible to brittle fracture caused by SCC of the composite materials, see Figure 2, as a result of combined effect of moisture, and corona discharge which forms acid solutions in service [8793]. Several critical factors have been identified to influence the SCC in polymer composites insulators. These include resin and fibre type, acid type and concentrations, composite surface conditions and external stress. M.J. Owen et al. [92]analysed various states of electrical and mechanical damages of a group of ten $275 \mathrm{kV}$ polymeric insulators. The combined effect of electrical activity and moisture appears to be similar to acid stress corrosion and responsible for producing brittle fracture of the pultruded rods of insulators.

It has been demonstrated that in nitric acid environment and in the presence of mechanical bending load, the extent of stress corrosion damage on the surface of high voltage composite insulators is strongly dependent on the type of polymer resin used. Vinyl ester, epoxy and polyester are the three most common used resins for composite insulators. Studies showed that the resistance to the initiation of SCC in nitric acid of the E-glass/vinyl ester composite is 18 
approximately 10 times greater than the E-glass/epoxy composite. Furthermore, the Eglass/epoxy system exhibits approximately 5 times higher resistance to the initiation of SCC than the E-glass/modifed polyester system [94]. SCC growth on composites can occur far below the fracture strength since fibres under stress are very sensitive to acid environment. Under the stress corrosion, acid environments drastically affects the life of composites[95].

The initiation of SCC has also been evaluated in acid environment and in the absence of mechanical loads. Kumosa et. Al. [96] demonstrated that E-glass/epoxy composite used in composite high voltage insulators with the line voltage from 60 to $735 \mathrm{kV}$ are the most susceptible to the stress corrosion damage in nitric acid environment when no mechanical stress is applied. It has been speculated that this is mainly due to the different amount of fibres exposed on the surface of polymer composites $35.5 \%$ and $11.7 \%$ for the epoxy and modified polyester composite, respectively) as a result of different manufacturing process and physical properties of resins used. The externally applied stresses are not necessary for the initiation of SCC on the surfaces of fibre reinforced polymer composite insulators. The SCC can develop in the fibres embedded in a polymer resin due to presence of residual stresses in the composites, Figure 3. However their initiation rates will decrease with time to zero if external mechanical loads are not applied.

Surface condition of polymer composite used in high voltage insulators plays a key role in SCC. In order to provide a better adhesion between composite rods and other components used in insulators which ultimately leads to preventing moisture coming to contact with composite rods, sandblasting is applied on the composite surface. Sandblasted polymer composite insulators have shown no negative effect on the SCC initiation and propagation. Low and medium level of sand 19 
blasting exhibited slight improvement in composite resistance which was estimated as acoustic emission signal (AE) to stress corrosion cracking. The improvement of resistance of Eglass/vinyl ester from 34.2 to 17 and $7.5 \mathrm{AE}$ events for as-supplied, low sandblasted, and medium sandblasted samples was attributed to release of residual extrusion stresses in the fibres [97].

Chemical composition of fibres used in fibre reinforced composite insulators has an influence on SCC resistance of composites. Boron free E-glass fibre reinforced polymer composites exhibit a significant enhancement in SCC resistance in nitric acid environment of $\mathrm{pH} 1.2$ from $43699 \mathrm{AE}$ events for E-glass/modified polyester to $327 \mathrm{AE}$ events. This effect is despite the fact that boronfree E-glass composites has a high level of surface fibre exposure[98].

Polymer matrix composites are increasingly being used in advanced structures such as aerospace components that experience high temperatures (more than $100{ }^{\circ} \mathrm{C}$ ) and oxidative environments. While reinforcing fibres used in these structural parts may tolerate such a severe condition, it is the matrix and fibre/matrix interphase that can be readily degraded causing the structural failure [99, 100]. Two epoxy/carbon model composite systems, R922- 1 /C- 12K and R6376/C-12K, were investigated for aging at $177^{\circ} \mathrm{C}$ up to $10000 \mathrm{~h}$. In the absence of oxygen, the weight loss rate difference between the two material systems at $177^{\circ} \mathrm{C}$ was not significant $\left(0.010 \% \mathrm{~h}^{-1}\right)$, but the weight loss rate difference in air was dramatic $\left(0.126 \% \mathrm{~h}^{-1}\right)$ [99]. In [100] 977-2 epoxy/amine resin plates have been aged at $150{ }^{\circ} \mathrm{C}$ under vacuum and ambient air. The thermal ageing under vacuum, even after $1000 \mathrm{~h}$, does not lead to any noticeable variation of the elastic modulus. In contrast, $1000 \mathrm{~h}$ of isothermal ageing in air leads to an increase of the elastic modulus up to $35 \%$ : $5500 \mathrm{MPa}$ compared to the initial value of $4070 \mathrm{MPa}$. 
Studies on oxidation of matrix revealed that resin oxidation occurs at the matrix surface controlled by oxygen diffusion that creates cracks even without any external loading. The matrix cracks then become a pathway for oxygen penetration through oxidised layer increasing in an amine epoxy by $19 \%$ with increase of ageing temperature from $180{ }^{\circ} \mathrm{C}$ to $220{ }^{\circ} \mathrm{C}$ causing more damage to the structure which ultimately leads to failure [101, 102].

\subsection{Thermo-oxidation-induced crack}

Thermo-oxidative behaviour of fibre reinforced composites is highly influenced by the type of fibres used to reinforce the resin matrix[103]. Carbon fibre has a stabilising effect on matrix oxidation due to the radical scavenging property of carbon [104]. The stabilizing effect appears to have little dependence on the polymer nature or the carbon fibre nature as it was found to be about $35 \%$ for $\mathrm{T} 800 \mathrm{H} / \mathrm{BMI}$ and $44 \%$ for IM7/ACE composites where fibre volume fraction ws estimated to be 60 and $65 \%$, respectivly. While thermo-oxidative degradation in neat resin is mainly diffusion controlled, thermo-oxidation in fibre reinforced polymer composites is only diffusion controlled until damage process is activated [105].

Thermo-oxidation consists of a coupled oxygen diffusion-reaction phenomenon which initially is confined to a thin surface layer. Thermo-oxidation environment induces matrix shrinkage strains due to the departure of volatile chemical species, and changes local mechanical properties as a result of chain scission and internal antiplasticisation of resin network following 3 steps process (Figure 4). Experimental and numerical analysis have demonstrated that matrix shrinkage generates tensile stress that leads to microcracks. Marco Gigliotti et al. [106] investigated local shrinkage and stress induced in composite IM7/977-2 in thermo-oxidative (5 bars O2, 48 h,150 1C) and neutral environments (5barsN2, 48h,150 1C). During the oxidation phase, the thermo21 
oxidation shrinkage strains and displacements develop only in samples in thermo- oxidative environments, with a relative increase of around $48 \%$ leading to microcracks. Development of microcracks then gives rise to fibre matrix debonding since the matrix microcracking progressed along the fibre matrix interface [106-109]. Cracks are generally initiated around fibre tips and propagate in the fibre axial direction particularly along the fibre-matrix interface where there is no obstacle[110, 111]. Therefore, the interface is considered as an important element in determining the extent of surface damage in composites exposed to thermo-oxidative conditions. The critical nature of interface signifies the importance of improved fibre matrix interfacial adhesion. The composites reinforced with surface treated fibres exhibit lower amount of matrix microcracking in the surface layer[112].

Thermal cycling of composites laminates subjected to oxidative environment demonstrate an acceleration of matrix cracking and matrix shrinkage due to coupling between oxidation and thermo-mechanical cyclic stresses. Qualitative analysis showed that damage induced by thermooxidative environment is highly influenced by different orientation of plies, laminates stacking sequence and the neighbouring ply effect [99, 113-115]. Thermal cycling of carbon/epoxy laminates in [113] revealed that cracked surface area of $\left[0_{3} / 90_{3}\right] \mathrm{s}$ in nitrogen is about $28 \mathrm{~mm}^{2}$ and $500 \mathrm{~mm}^{2}$ in air whereas for $\left[-45_{3} / 45_{3}\right] \mathrm{s}$ orientation it was 0 in $\mathrm{N}_{2}$ and only $225 \mathrm{~mm}_{2}$ in air. Similar results were obtained in [114] where the cracking damage induced by 500 thermal cycles was found dependent on the lay-up: the cracked surface area measured in the $\left[0_{3} / 90_{3}\right]_{\mathrm{S}}$ laminate (e.g. in oxygen: $\left.580 \mathrm{~mm}^{2}\right)$ is twice higher than in the $\left[45_{3} / 45_{3}\right]_{\mathrm{s}}$ laminate $\left(210 \mathrm{~mm}^{2}\right)$ and much higher than in the QI sample $\left(6.5 \mathrm{~mm}^{2}\right)$. A significant increase in matrix cracking of cross-ply laminates aged in thermo-oxidative conditions is mainly due to a decrease in resin toughness close to the exposed surfaces. This has a direct effect on onset of damage and causes fast 22 
propagation of the matrix micro-cracking [116]. Table 3 shows examples of polymer structures with measured shrinkage due to thermal and oxidative damage.

\subsection{Microcracking due to UV exposure}

Polymeric materials exposed to ultraviolet (UV) light radiation generally lose their physical and mechanical properties with time. X. Gu et al. [117] have shown with micro-FTIR images of the outdoor exposed epoxy/polyurethane samples, substantial amounts of oxidation products in the $60 \mu \mathrm{m}$ deep region from the surface to the epoxy bulk which was confirmed by significant increase of the elastic modulus in the first $60 \mu \mathrm{m}$ region after UV degradation by nanoindentation. Upon UV exposure, UV photons are absorbed by polymers and these give rise to photo-oxidative reactions which causes molecular chain scission and/or chain crosslinking [6, 118]. Molecular chain scission process generates polymer radicals and lowers the molecular weight of polymers. Chain crosslinking results in excessive embrittlement as a result of reduced molecular mobility and is mainly responsible for the formation of microcracks [119]. For some polymers such as polyethylene, both crosslinking and chain scission may take place concurrently as a result of UV exposure.

UV degradation is not limited to the polymer bulk, it usually starts at the surface and penetrates gradually to the bulk. In a set of experiments with high-performance polymers (Kapton, Mylar,

Lexan, PEEK) effect of UV treatment/atomic oxygen (fluence $1.7 \times 10^{20} \mathrm{~cm}^{-2}$ ) for 5-8 hours has been studied in [120] and top layer of 0.1-0.2 $\mu \mathrm{m}$ was effected by UV degradation [120]. Surface oxidation occurs upon UV radiation which accumulates thermomechanical stress on the surface leading to mechanical pressure that spreads into the bulk and forms cracks. 
Thermal history of polymers has been found to influence their UV stability. PVC that has been processed for long periods and/or high temperature demonstrates less resistance to UV damage [10].This may be due to the increase in the degree of degradation of macromolecular compounds as a result of processing temperature and time. Thermodynamic analysis for PVC has shown that the generation and growth of microvoids ( both in number and length) which is followed by formation of cracks is a result of relaxation of residual energy, creation of polar groups and the adjustment of conformation of macromolecular chains [121]. UV radiation has enough energy to break the carbon and oxygen bonds in polymers and to build volatile fragments. Surface outgassing of volatiles leads to shrinkage of the skin layer which generates further mechanical stresses that can propagate into the bulk of the composites [107, 122, 123]. In [122] oxidative induced shrinkage of the polymer made of a mixture of aromatic epoxy (triglycidyl amino phenol-diglycidyl ether of bisphenol F) crosslinked by an aromatic diamine, has been studied after thermal ageing. At the surface of a $1.5 \mathrm{~mm}$ sample exposed $900 \mathrm{~h}$ at $150{ }^{\circ} \mathrm{C}$, the shrinkage was equal to $2.5 \%$ and tensile stress of $85 \mathrm{MP}$ with corresponding compressive stress in the sample core of $10 \mathrm{MPa}$. The environmental degradation behaviour of epoxy-organoclay nanocomposites due to accelerated UV is studied by Woo et. al. [6]. SEM results showed that microcracks started to appear on both the neat epoxy and nanocomposite surface after about 300 $\mathrm{h}$ of UV exposure. Upon further exposure, the microcracks propagated deeper into the matrix and become broadened in the neat epoxy. Compared to neat epoxy, cracks on the nanocomposite surface appeared to be wider and shallower due to the present of organoclay in the nanocomposites. Similarly, after exposure to $500 \mathrm{~h}$ of UV radiation, formation of microcracks has also been found in the epoxy matrix in carbon fiber reinforced epoxy composites[118]. These microcracking phenomenon are caused by excessive embrittleness of the polymer matrix 24 
resulting from increased crosslinked molecules generated through photo-oxidation reactions induced by UV radiation. Matrix cracking and extensive debonding of the glass fibre-epoxy matrix interface after 100 hours exposure to UV has also been reported [124].

Solar UV radiation in the presence of oxygen generates a strong thermal and oxidative degradation force for polymer composites. Oxidative thermal degradation at the surface of epoxy resin composites leads to structural damage as a result of thermal-mechanical stress and oxidation effects (Figure 5). Thermal stress generates mechanical pressure at the surface and in the bulk resulting in crack initiation and propagation. It has been shown that fibre reinforced epoxy composites suffer significant surface oxidation as a result of UV radiation and that the nature of the reinforcement affects the epoxy resin composite response to UV degradation. Surface analysis revealed the occurrence of the chemical phenomena of chain scission, crosslinking, condensation and oxidation as a result of the accelerated degradation which may cause micro-cracks in structure[125].

\subsection{Microcracking due to hygrothermal ageing}

Water is always present as one of the environmental conditions due to the humidity of the atmosphere. Polymer matrix composites used in many structural applications such as aerospace, marine and civil engineering are often exposed to a hygrothermal environments defined as an environment with combined moisture and temperature. Many polymer matrices tend to absorb significant amounts of water when exposed to high humidity. The absorbed moisture combined with an elevated temperature causes detrimental physical and mechanical effects to the composites [126-128]. Hygrothermal aging in polymer composites is illustrated in Figure 6. 
Three mechanisms are responsible for moisture transport in composites: diffusion through microgaps between polymer chains, capillary processes via gaps and flaws at fibre-polymer interface and transport by micro-cracks formed in the matrix during the compounding process[129]. Diffusivity of water along the fibre-matrix interface is much more rapid than that in the direction perpendicular to the fibres or in polymer with no fibre reinforcement, representing the major transport mechanism. The moisture diffusion rate in Kevlar reinforced epoxy composites has been found two orders of magnitudes higher than that of epoxy matrix[130] Similar behaviour has been reported for sugar palm reinforced epoxy composites [131] . Moisture can also diffuse into the composites through microcracks (that accompanies curing) and voids. Transport of moisture by microcracks and voids gives rise to swelling and the formation of a range of inter- and intra- stresses which can lead to stress cracking. In fibre reinforced polymer composites, moisture absorption disrupts the fibre-matrix interfacial bonding leading to premature failure. Thus in [132]a reduction of about 34-39\% in delamination damage threshold has been observed for the composite laminates of woven carbon and woven glass/SC-15 Epoxy resin after 32 weeks of hydrothermal exposure. The absorbed moisture can also act as a plasticizer in the polymer matrix and give rise to plastic deformation as well as reduction in $T_{\mathrm{g}}$ [132-134]. The absorbed moisture could interact with the polymeric matrix chemically and cause hydrolysis. In [135] water absorption has been studied in polyactide 2002D polymer. FTIR analysis of the samples tested by hygrothermal ageing in water at $70^{\circ} \mathrm{C}$ during $8-100$ hours have revealed chemical changes in the bulk of the polymer confirmed by the relative variation of the peaks located at wave numbers $921 \mathrm{~cm}^{-1}$ and $955 \mathrm{~cm}^{-1}$ corresponding to the coupling of the $\mathrm{C}-\mathrm{C}$ backbone stretching with the $\mathrm{C}-\mathrm{H}_{3}$ rocking modes, which are related to the presence of acrystalline and amorphous regions. The hydrolysis process is generally accelerated by high 26 
moisture content and temperature that results in premature failure of matrix. Hydrolysis can also contribute to a decrease in $\operatorname{Tg}$ due to chain scission within the matrix structure [136, 137].

Moisture absorption and diffusion process for polymer composite materials have been the subject of many investigations. Most studies rely on Fick's law of diffusion in which a rapid increase of the absorbed humidity occurs before a maximum is reached after a long immersion time. However, due to complexity of interaction between polymer molecules and water, discrepancies from the Fickian behaviour are very common. Over the years, various diffusion models have been developed and employed to fit the experimental data for hygrothermal effects in polymer matrix composites [111, 126, 135, 138-142].

There is a vast body of literature detailing the long term durability of polymer composite for application in marine environment [143-146]. To simulate the marine environment, many researchers have employed distilled water as an ageing medium to conduct marine composite research. Researchers comparing the effect of distilled and sea water on the properties of polymer composites highlighted the significant differences between sea water and distilled water aging particularly in weight gain of composites[147]. It's been speculated that due to the presence of salt crystals blocking water diffusion passages, sea water is absorbed in a lesser extent compared to distilled water[148]. There is information in the literature indicating that the structural differences in the networks of resins influences the unequal gain in sea water molecules and ultimately their mechanical behaviours. Kawagoe et al. found that interfacial fracture occurred at the polyester resin-fibre glass interface due to hydrolysis reaction caused by seawater molecules[149]. However, the vinyl ester resin composites showed higher hydrolytic resistance when immersed in sea water. Microscopy analysis revealed that polyester resin has 27 
developed considerably more microcracks compared to vinyl ester counterpart [146]. Table 4 present details regarding the ageing in polymer composites due to hydrolysis reactions.

\section{Crack and microcrack detection: non-destructive evaluation}

Polymeric materials have wide range of applications such as plastic bags, packaging, coating, textiles, fuel storage tanks, containers, electrical insulation, biomedical uses, and large number of engineering structures. The extensive use of polymers makes damage detection and monitoring vital during the service period. Microcracks formation and propagation are the primary damage mechanisms of structural components, it cause a significant degradation in the mechanical, thermal and electrical properties of the materials.

Cracks detecting techniques in polymeric materials include non-destructive testing (NDT) methods such as visual testing, strain measurements[150-154], CT scanning, ultrasonic testing, acoustic emission (AE) [155], vibration-based damage detection techniques[154, 156], electric impedance and thermography [150-157]. These techniques are mainly used to detect local damages in structures. The implementation of NDT are limited in use for remote measurements[151], they also depend on accessibility nature of the discontinuity, the thickness of the material, the depth and type of defect. Furthermore, the signal measuring techniques require a highly trained operator to acquire and interpret the data, the signals are also corrupted by the structural and electrical noise in addition to attenuation and scattering.

The uses of high resolution inspection techniques such as electron microscopy and electron probing are suitable only for certain specimen type and size and they are in general expensive to 
use. Another class of cracks monitoring techniques are based on employing fiber optic probe or fluorescent probe $[4,151,158]$.

Optical fiber sensors were developed to detect and monitor cracks in polymers. They are embedded into the monitored matrix and hence any cracking in the matrix results in cracking in the fiber itself causing its transmission properties to be affected. The optical fiber sensors are brittle, consequently they must be embedded into other materials, and they are very expensive to manufacture and maintain.

The molecular fluorescent probes are originally used in molecular biology, the pre -dispersed probes in the matrix are subjected to changes in the fluorescent intensity as a result of any topological changes in the matrix, it has been suggested that it can detect nanoscale cracks in polymers[158]. The major limitations of this technique are that it requires a uniform pre dispersion of the die and transparent polymer specimen in addition to geometry limitation of the specimen due to use of the fluorescent microscope. In Table 5, a comparison between different NDT methods is presented.

\subsection{Optical}

Optical test methods which utilize visible part of electro-magnetic spectrum (wavelength roughly between 400 and $700 \mathrm{~nm}$ ) are primarily used to detect surface and near-surface defects of many polymers and PMC. Visual inspection (eye, photography, dye penetrants) Optical microscopy is commonly employed to observe surface microcracking in the polymer composites. Photomicrographs of the sample surfaces are taken and the number of microcracks on the surface is counted. Quantification determination of microcracking density in polymer composites can be 
done by dividing the total number of microcracks on the sample face by the face area. Microscopy is also used to study the propagation of microcracks by recording the location of microcracks before applying thermal or fatigue cycling. Bright filed and polarized light microscopy are generaly used to identify micro-cracks in composites however in composite materials with low contrast such as carbon fibre reinforced composites a contrast dye and dark filed illumination or a lazer dye and epi-flurosence are employed to enhance the contrast helping to detect microcracks. Dyes are employed along with dark field or polarized light to analyse micro-cracks in polymer composites containing translucent fibres such as Kevlar, glass, nylon and polyester. Colored dyes are impregnated into fine micro-cracks through capillary action that otherwise cannot be detected. In order to examine micro-cracks in thermoplastic polymers fluorescence penetrants are used and florescence microscopy is employed to observe microcracks[159, 160].

\subsection{Optical Coherence Tomography (OCT)}

OCT is a non-destructive and contact-free optical imaging technique which allows extremely high-resolution, depth-resolved, three-dimensional imaging of microstructure within scattering media [161]. It is originally developed for biomedical applications of biological tissue evaluation and it is based on the interference phenomena of white or low-coherence light to determine distances and displacement. The principle of OCT is similar to B-mode ultrasound imaging, except that OCT typically employs near-infrared light rather than sound. OCT imaging has also found application in non-destructive evaluation for non biological materials including polymers which have transparent or translucent appearance. Besides polymers, OCT is also well suited to retrieve relevant information on the internal defects and structure of polymer composites, such as 
GFRP. However, some polymer composites comprising of certain filler materials like carbon particles, carbon fibres and nanotubes could render the polymer matrix opaque resulting in incompatibility with OCT imaging [162]. With the advancement of OCT technique, several other OCT techniques have been developed in addition to classic OCT, such as ultrahigh-resolution OCT (UHR-OCT) and polarisation-sensitive OCT (PS-OCT). UHR-PS-OCT imaging of the matrix fracture, cracks and internal stress in GFRP materials has demonstrated its promising potential in detecting defect in the early stage [163].

\subsection{Microscopy (optical microscopy, SEM)}

Microscopy is a useful tool to determine the cause of failure, as well as establishing the area of crack initiation. Optical microscopy sample preparation is generally involved sectioning, mounting and polishing the area under examination. Not all cracks can be detected using optical microscopy, for some materials introducing fluorescent dyes are required to identify the matrix cracking[164]. Scanning electron microscopy on the other hand provides more information on the process of crack initiation and propagation, however, the samples need to be coated using a thin layer of gold in order to avoid electron charges building up on sample. Scanning electron microscopy has been extensively used to study the failure mechanism of polymer composites and to identify the directions of crack propagation and to determine the origins of fracture in fibre reinforced composites[164, 165].

\subsection{Sonic testing}

Sonic and ultrasonic test methods are based on elastic waves propagation in solid or fluid media. They can be grouped into two categories: active and passive methods. Active methods require 
emission of acoustic waves into materials and the reception of waves reflected or transmitted from the materials. Passive methods only involve the reception of the waves emitted by the material itself.

\subsection{Tap testing}

Tap testing requires an operator to tap the structure to be inspected by hand or by a suitable instrument such as a hammer or some other light weight object and detect the defects by listening to the resulting sound. It is an inexpensive, fast and easy method to roughly evaluate and locate the defects of PMC materials[166].

\subsection{Acoustic emission}

Acoustic emission (AE) refers to the phenomenon of transient elastic wave generation resulting from a rapid release of strain energy due to microstructural changes in the material when subjected to mechanical or thermal stresses. It is an example of passive methods which analyse the ultrasound pulses emitted by the defects in real time. AE sensors (transducers) which can sense the stress waves propagating through a structure are required to detect AE activity. It is an effective non-destructive technique to monitor damage growth in different structural materials. When a failure mechanism is activated, strain-energy release propagates as a stress-wave from the failure source through the medium and is detected at the surface. AE technique can be applied to determine both the location of the source and the nature of the damage. For polymer composites, many failure mechanisms have been identified as AE sources, including matrix cracking, fibre-matrix interface debonding, fibre fracture and delamination [167]. 


\subsection{Ultrasonic testing}

Ultrasonic testing of polymer composites is based on the detection and the interpretation of the ultrasonic waves reflected by defects such as cracks or voids. The term ultrasonics refers to acoustic waves with a frequency above the limit of human hearing, approximately $20 \mathrm{kHz}$. In contrast to electromagnetic waves, ultrasonics waves are a form of mechanical energy that consists of oscillations or vibrations of the atoms or molecules of a material. Based on the oscillation pattern of the atoms/molecules, Ultrasonic waves can propagate in four principle modes, including longitudinal waves, transverse/shear waves, surface/Raleigh waves, and Lamb or plate waves. In ultrasonic testing, generation and detection of ultrasonic waves requires the use of ultrasonic transducers which convert electrical energy into acoustical (mechanical) energy and also a couplant with high ultrasonic signal transmission strength being placed between the transducer and the sample. The signal can be detected in either reflection or transmission mode.

Kinra et. Al. [168] developed an ultrasonic backscattering technique for the detection of matrix cracks in laminated composites. The extensive damage of matrix cracking in this composite was produced during liquid hydrogen (LH2) permeability test where the composite was subjected to thermo-mechanical loading at cryogenic temperature. The incident wave is reflected away from the transducer which is also acted as a receiver when there is no interaction between the incident wave and the matrix crack, and this indicates the received signal is zero. With the presence of matrix cracks, the incident wave is partly reflected back to the transducer and the received signal become finite. This technique has shown the ability to detect matrix cracks in each ply of the composite laminate in the present of extensive damage in all the plies. 
The ability of pulse-echo ultrasonics to detect fatigue induced damage generated by cyclic flexural loading in thick glass fibre reinforced polymer (GRP) composites has been assessed [169]. The results indicated that low fatigue stress induced cracks were difficult to detect by ultrasonics because cracks grew in the through-thickness direction which is parallel to the transmission direction of the ultrasound waves. While at high fatigue stress, damages are more easily detected.

Shear wave through-transmission ultrasonic C-scan imaging was shown to be a useful technique for detection of the partial and internal transverse cracks in a cross-ply graphite/bismaleimide laminate[170]. With shear wave through-transmission ultrasonic technique, inclined transducers were placed in a confocal configuration with the sample occupying focal plane. When a crack is present across the focal area of the transducers, ultrasound beam is partially reflected by the crack which causing the change of the transmitted signal amplitude.

\subsection{Penetrating radiation}

\subsubsection{Conventional X-ray radiography}

Radiation methods used for non-destructive testing of materials are based on recording and analysing of penetrating ionising radiation after interaction with the object being inspected. In conventional radiography X-ray beam is used to bombard the target. The unabsorbed radiation hits a radiation sensitive film and a 2-D image is formed upon development of film. Microfocal X-radiography produces sharper images compared to conventional X-ray methods as it utilises a significantly smaller X-ray beam. X-ray images with sufficient contrast are usually hard to obtain 
in fibre reinforced composites due to low atomic weight of composite molecular components. To improve images contrast medium such as sulphur and silver iodide is used[171].

\subsubsection{X-ray computed microtomography}

$\mathrm{X}$-ray microcomputed tomography $(\mathrm{X} \mu \mathrm{CT})$ is a non-destructive radiographic imaging technique that can be used to reconstruct interior structural details at a spatial resolution better that $1 \mu \mathrm{m}$. The term tomography refers to the reconstruction of an object from its projections. In this technique, 3D image revealing the internal structure of the sample is reconstructed from a series of 2D X-ray absorption images taken at different rotational angles. X-ray tomography allows visualization of the 3-D internal microstructure of a material. Quantitative measurements can be made from 3D image data, including the spatial distribution and volume fraction of phases. Furthermore, structural visualization is possible and $\mathrm{X} \mu \mathrm{CT}$ was used previously in inspecting mechanically and thermally induced polymer composite damages. One of the drawbacks for this technique is the fact that the sample needs to be cut in order to obtain high resolution.

Several studies have been undertaken to assess the capabilities and limitations of Micro-CT for the characterization of damage and internal flaws including delamination and microcracking in the polymer composite materials. High-resolution X-ray computed tomography, or microtomography (micro-CT), Gain popularity as a technique for Non-destructive testing (NDT) of materials and components.

Schilling et al [172] have carried out a study to evaluate the capabilities and limitations of micro$\mathrm{CT}$ to characterize damage and internal flaws in fibre-reinforced polymer-matrix composites materials and special attention is given to microcracking detection by performing tests to detect 
microcracking in graphite epoxy laminates with and without the use of a dye. Their results showed micro-CT can facilitate characterization of the internal flaws in the composites. The magnification is a critical experimental parameter for detecting microcracks in the composites by micro-CT without using the dye penetrant, as a result of which, limiting the sample size. Excellent characterization of the three-dimensional crack geometry can be obtained using the dye penetrant, given sufficient connectivity of the cracks and penetration of the dye.

In the field of polymer composites, $\mathrm{X} \mu \mathrm{CT}$ has been successfully applied as a NDT technique to identify and characterize damage and internal flaws including voids, delamination and microcracking [37, 172-178]. For example, Sket et al[177] utilised $\mathrm{X} \mu \mathrm{CT}$ to monitor initiation and evolution of damage in a notched glass fiber/epoxy cross-ply laminate subjected to threepoint bending. Beier et al. [173] reported that resin rich and fibre defects were observed in a noncrimp fabric (NCF) carbon fibre-reinforced epoxy composite from the cross-sectional $\mu \mathrm{CT}$ images. Awaja and Arhatari [174] evaluated the internal damage of syntactic foam materials caused by thermal cycling. They reported different types of filler damage and the role of void expansion in the generation of cracks. Another study carried out by Schilling et al has shown that $\mathrm{X} \mu \mathrm{CT}$ is useful in characterizing damage and internal flaws in fibre-reinforced polymer-matrix composites materials[172]. Excellent characterization of the three-dementional crack geometry can be obtained using the dye penetrant, given sufficient connectivity of the cracks and penetration of the dye. Tan et al.[178] employed X $\mu \mathrm{CT}$ to characterize damage distribution and mechanisms (including matrix cracking and delamination) in stitched polymer composites subjected to impact loading. Liotier et al[175] employed $\mathrm{X} \mu \mathrm{CT}$ to detect hygrothermal fatigue induced microcrack network in polymer composites reinforced by multi-axial multi-ply stitched 
carbon performs. Table 6 lists recent literature demonstrating quantitative measurements of defects in composites using tomography technique.

\subsubsection{Compton backscattering diffraction}

The idea of producing X-ray images based on Compton scattering employed in non-destructive testing of materials is relatively old. Compton X-ray backscatter images are formed by scanning a pencil-shaped beam of $\mathrm{x}$-rays over the inspected object and back-scattered $\mathrm{x}$-rays are scattered by interactions with atoms in the object being inspected and the intensity distribution of scattered $\mathrm{X}$-rays is measured. Compton backscattering technique is used to on-site crack detection of composite structures and can be used where one sided inspection of composite is required. This is due to the fact that the x-ray source and detector can be positioned on the same side of the target object, enabling testing of large structure such as glass reinforced polymer composite sheep skins. Studies showed that Compton back scattering technique has the potential of detecting cracks in structures below deposit without removing the deposit or performing other surface preparations [179-183]. Table 6 details the usage of X-ray tomography by researchers in detecting structural damage in polymer composites at different resolutions.

\subsection{Thermal/Infrared Techniques}

Thermographic techniques are based on the use of thermal energy and its absorption and dissipation in a specimen under inspection. There are two types of techniques namely passive and active thermography. While in active thermography an external source of thermal energy is required, in passive method heat generates internally as a result of actions such as friction of 
fracture surfaces. Thermography can be used to inspect large composite structures such as aerospace components.

Infrared thermography is a non-contact, passive thermography and non intrusive optical imaging technique for detecting invisible infrared radiation. The distribution of infrared radiation emitted by objects can be measured and then transformed into a visible image in temperature scale. Infrared thermography has been applied widely in various industries due to the availability of wide range of excitation and inspection methods developed for different purposes, such as pulse thermography, lock-in thermography and step thermography. Flaw detection such as detection of cracks and microcracks by infrared thermography is one of the NDT techniques. Thermal imaging which provides temperature distribution profile images clearly indicates the shape and location of the defect area. Low amplitude vibration is often used in vibrothermography technique where localised heating is induced in specimen. Heat flow is then monitored and thermograph is obtained using infra-red sensitive cameras. Thermographs of defected composites clearly demonstrate the anisotropy of heat flow. Carbon fibre reinforced composites has been evaluated for structural defects using this technique[183, 184]. Table 7 details a comparison between the above mentioned methods for cracks and microcracks detection of polymer structures using attributes such as resolution, accuracy, ease of use and the type of defects that could be detected.

\section{Self Healing: Autonomic Repair and Manufacturing techniques}

Self healing polymeric composites capable of autonomically healing themselves and restoring the materials performance in the event of damage possess great potential to solve some of the most limiting problems of polymeric structural materials including microcracking and hidden 
damage. The concept of self healing is based on mimicking the biological process of wounds healing. Self healing in polymer composites as a concept mimics the physiological process of Hemostasis. Hemostasis is a process in which bleeding is stopped following a series of steps. Initially, the ruptured blood vessels are constricted, hence minimizing its diameter to reduce blood flow. Then an element of the blood called platelets bind to collagen in the ruptured blood vessels walls to form a plug. Then the coagulation step follows, a blood protein (fibrinogen) is transformed into polymerized fibrin which generate a clot. The clot makes the basic platform for the growth of fibroblasts and smooth muscle cells within the vessel wall. The repair process that follows results the dissolution of the clot.

The successful self healing process is reported to consist of several key elements [1, 3, 19]; (1) A repairing chemical, often called healing agent, which is either a monomer or a polymer (2) A fibre to encapsulate the healing agent within the polymer matrix (3) A procedure of hardening the healing agent in the polymer matrix. The key element of self healing is that no external component is required to repair the damage such as tools or external materials. Self healing agents must satisfy the properties of fast reaction during cure $[1,19]$.

The self repair materials have a healing agent contained within the structure that is activated to seal the damage when it occurs. The cross linking agent (hardener) which is embedded in the polymer matrix should works on sealing the damage and providing permanent repair and also must be feasible and readily available. Furthermore, self cross-linkable resin could be used as a laminating substance to coat other materials and structures, such as solar cells, providing long lasting protection against chemical and physical damage. This self healing material and technique has the potential to have a revolutionary impact on the use of polymer materials in 39 
harsh environment applications. Table 8 specifics different healing agents that are used in cracks and microcracks self-repair operations and describe their healing efficiency.

Earlier self repair attempts were focused on sealing cracks, regaining strength and cracks retardation as a result of mechanical impact [3]. Dry [3] used a system that involves a polymer composite with repairing agent contained in hollow fibre. The repairing process is triggered by the breakage of the hollow fibres as a result of cracks and the release of the repairing agent to seal of the cracks. Another process was needed to harden the repairing agent in the case of crosslinking resin. Kessler and White [18] investigated a self repairing system of delamination damage of E-glass/ epoxy composites. The healing agents were introduced in two different processes. They injected a catalysed healing agent directly to the composite. They also injected a healing agent to delaminated composite with catalysts embedded in the matrix. The first process showed $67 \%$ while the second process showed $19 \%$ recovered fracture toughness in comparison with the virgin polymer matrix. Cho et al [185] introduced a self healing system in which the din-butyltin dilaurate (DBTL) catalyst is encapsulated in polyurethane microcapsules while the siloxane based healing agent was phase separated in a vinyl ester matrix. The authors claim that this method would provide the advantageous of stable healing mechanism in wet conditions and elevated temperature up to $100{ }^{\circ} \mathrm{C}$.

Previous work on self healings of polymer composites aimed at creating a polymer matrix that contain a healing agent(s) with the ability to seal mechanical cracks damage, restoration of strength and retard crack propagation [3]. Techniques such as micro-encapsulation of healing agent to repair fatigue cracks have been used recently by researchers $[1,16]$. These attempts faced the problems of the side reactions with the polymer and air [185]. Different types of 40 
healing agents were introduced then to tackle these shortcomings such as diene monomers and polydimethylsiloxane-based material $[19,185]$. However an added catalyst foreign to the resin matrix was needed for the healing process [19].

Other successful self healing processes were reported by different researchers $[1,20,186]$. The crack retardation as a result of polymer healing was discussed by Maiti and Geubelle [186]. They showed through simulations that by providing wedging materials in the path of the crack result in fatigue retardation. Pong and Bond $[1,20]$ used the encapsulation methods to release a UV fluorescent dye into damaged sites within the internal structure of the composites. The affects of these materials on the polymer matrix homogeneity is yet to be investigated. They also reported on significant restoration of mechanical properties of damaged sites using a healing agent stored in a hollow fibre within the composite. They explained that the proposed self-repairing mechanism is temporary and mainly used to inhibit further damage propagation.

Design of self healing materials system which is capable of reversing damage and recovering load bearing capacity can mitigate the effect of microcrack growth is highly desired. Thixotropic and phenolic epoxy resin has superior molecular qualities which make them very attractive for use in self healing process. Thixotropic resin has a specific molecular arrangement in which the material reduces in viscosity when subjected to mechanical stress. This means that the materials provide a faster migration rate of cross-linking agent when mixed together allowing the faster repair of damaged links. The phenolic epoxy resin has $50 \%$ more functional epoxide groups than the conventional epoxy resin which facilitate higher cross-linking connections. This would increase the cross-linking reaction rate and provide denser network which strengthen the repaired structure when applied to. 
Several different self healing strategies which incorporate self healing functionality to polymeric materials have been studied over the past decades. Up until now, the microencapsulation approach has been the most studied. In this approach, a microencapsulated healing agent and a dispersed catalyst chemical have been embedded within the polymer matrix. When damageinduced cracking ruptures the microcapsules, it causes the release of the healing agent into the crack by capillary action, followed by subsequent polymerization through chemical reaction between the healing agent and the catalyst which repairs the polymers. .

\subsection{Microencapsulations}

Microencapsulation is a process in which a micro-scale particles or droplets of a desired substance is engulfed inside a coating material producing capsules with many useful properties. Microcapsules are used mainly in the drugs industries for the control release of medicine. They have also been used in the polymer composite industries for the delivery of damage-induced healing agent in the self repair polymer systems. So far, all the produced microcapsules for polymer self repair systems use healing agents and coating material alien to the polymer matrix that is dispensed into resulting often into incompatible ingredients. Thermoplastic coated curing accelerators and epoxy resins are introduced recently and have the potential to be used in self healing polymer systems. However, incompatibility concerns about these microcapsules with the resin polymer matrix reduce its potential to be used in industrial applications. Microcapsules containing a cross linking agent of the same material that the polymer composites are made of will present the solution for the compatibility issue and will provide more reliable self healing polymer composites for the automotive and aerospace industries. Figure 7 shows a schematic of self healing process using microcapsules. 
Many parameters should be considered when generating microcapsules type self healing composites. Microcapsules wall thickness, stiffness and interfaces with the polymer matrix should be carefully designed [77]. Too thick walled microcapsules might not break during the polymer structural damage while too thin walls might lead to breakage during processing [77].

The autonomic healing system that was introduced by White et al. [77] consists of microencapsulated healing agent that is embedded within the polymer composites. The proposed polymer composite contains a catalyst that reacts with the healing agent. When cracks occur in the polymer composite at any position, it ruptures the microcapsules releasing the healing agent. The healing agent then seeps through the cracks through capillary action. A reaction then formulates between the catalyst and the healing agent creating a polymerised material that bond the crack faces leading to closure (Figure 8). White et al. [77] reported a $75 \%$ recovery in toughness after damage. The polymerisation catalyst used in this technique has unterminated chain ends, hence it would allow for multiple repair. However, it is obvious to notice that multiple repairs in same position could not be possible if the healing agents contained in the microcapsules is consumed or reduced to insufficient quantities for repair.

Crack tip shielding mechanism was introduced by Brown et al. [187] in their effort to design a crack healing methodology for cycling loading. They injected a precatalyzed monomer into the crack plane which created a wedge at the crack tip that led to shielding with an extended fatigue life by 20 times. They also used injected mineral oil for same purpose taking advantage of hydrodynamic pressure and viscous damping mechanisms. They reported at a later work [16] a successful fatigue crack retardation and arrest in a self healing matrix using microencapsulated dicyclopentadiene (DCPD) healing agent and Grubbs' first generation Ru catalyst. They reported 43 
an extended fatigue life of $118 \%$ in a rapidly growing crack damage and $213 \%$ in a moderate crack growth. At low crack growth, the self healing system they introduce is reported to yield complete arrest of fatigue crack with infinite fatigue life-extension.

The microcapsultation using the urea-formaldehyde (UF) process is developed further. Blaiszik et al. [188] reported the processing technique for producing nanocapsules for self healing material using UF capsules filled with dicyclopentadiene (DCPD) as healing agent. Capsules size of $220 \mathrm{~nm}$ was achieved using sonication technique and successfully dispersed in an epoxy system. As a result of this technique, active crack pinning and crack deflection mechanisms were described which also led to higher fracture toughness.

\subsection{Hollow short Glass fibres}

Unlike intrinsic self-healing approach where the polymer matrix is healable, in what is called extrinsic self-healing, healing agent has to be encapsulated and embedded into the materials. In this approach no external stimulant such as heating is necessary to activate healing process[11].

Hollow glass fibres and tubes have been employed for loading healing agent pre-embedded in polymer matrix. Like some other self-healing approaches this system is inspired by nature as it mimics the bleeding in arteries[189]. Potential application of hollow glass fibres to repair polymer damage was first reported by Dry[3]. Filling of fibre/tubes with healing medium is achieved using vacuum assisted capillary action filling technique. When choosing glass fibres, one should take into account the suitable fibre diameter; large fibre diameters (millimetre scales) can initiate composite failure. It has been reported that fibre with smaller diameters reduce the detrimental effect associated with large diameter fibres[190]. Compared to embedded 
microcapsules, glass fibre has the advantage of reinforcing composite while providing self repair. There are three approaches for self-healing using hollow fibres; fibres containing a one-part resin system, a two-part resin and hardener system or a resin system with an encapsulated hardener in matrix.

Hollow glass fibres with external diameter of $60 \mu \mathrm{m}$ and an internal diameter of $40 \mu \mathrm{m}$ and hollowness of about 50\% containing a two-part epoxy healing resin was prepared and incorporated within both glass fibre/epoxy and carbon fibre/epoxy composite laminates. This study revealed that the inclusion of self-healing plies or individual fibres repair internal matrix cracking and delamination throughout the thickness of a laminate. As claimed by authors, one of the advantages of this self-healing technique is that it can be readily applied to the existing composite manufacturing techniques such as autoclave process[191].

UV active hollow glass fibres filled with epoxy resin and a fluorescent dye has been examined as a self-healing composite system that allows the easy detection of damage location as well as the extent of damage. Bleeding action of the fluorescent dye was used to visualise the area of damage. This approach was employed for non-destructive evaluation of damage in composite.

\subsection{Intrinsic self-healing}

Intrinsic self-healing approach relies on the chemical and physical interaction of polymers themselves. In intrinsic self-healing materials, there is often a mendable polymer phase which repair damage under an external stimulus (mostly heating). This group of self-healing materials are easier to implement than that of capsule or hollow fibre based self-healing materials as the challenges associated with integration and compatibility of healing agent no longer exist. 
Nevertheless, these systems are limited to small-scale damages and the interfering mechanism to trigger healing remains a limiting factor for application such as aerospace[1, 20].

Intrinsic self-healing strategies such as employing thermoplastic/thermoset blends, resins containing reversible Diels-Alder cross links, hydrogen bonded polymers, molecular diffusion or ionomeric coupling have been investigated in an attempt to find a reliable, simple and low cost solution to repair damage in composites. Readers are referred to the recent reviews on intrinsic self-healing which covers various polymer systems synthesis and developments[192, 193].

Chen et al.[194] announced the discovery of novel organic molecule with the ability to cross-link and dis-connect at certain specific temperature. These molecules were thought to have the ability to rejoin and restore fractured locations multiple times. This technique is significant in many aspects. It introduces the quality of multiple repairs and provides one substance healing. Nevertheless, this technique requires the addition of energy from external energy source which might be inconvenient for application which external healing force is not feasible or practical.

Chen et al[194, 195] have developed a transparent and highly cross linked polymeric materials based on synthesised furan-maleimide via Diels-Alder reaction that was thermally active. Broken bonds reformed upon heating above $120^{\circ} \mathrm{C}$ and an infinite number of crack healing could be achieved. Using maleimide -furan compounds other researchers modified this approach and developed thermally reversible cross-linked polymers such as polyamides and epoxy. Despite the popularity of furan-maleimide Diels-Alder reaction, other polymers based on Diels-Alder reaction have been reported. 
Inclusion of thermoplastic additives to thermoset polymers has shown to reduce the delamination area and eliminating matrix cracking, allowing for multiple healing cycles. Upon heating, dispersed thermoplastic polymer melts and undergoes a volumetric thermal expansion to fill the damage area [196-198].

Ionomeric copolymers have also demonstrated self-healing capability through forming reversible cross-links that can be activated by external stimuli such as heat or UV[199-202]. This method is claimed to be robust and multiple repairs and recoveries can be achieved. Utilising technologies such as high frequency ultrasonic pulses as heating mechanism allows rapid in-filed repair of composite structures[203]. Interlayer woven and non-woven ionomeric copolymers as selfhealing agents have also been explored[204, 205].

\section{Active protection}

Active protection concept is introduced and it basically means unlimited repairs [206]. Polyphenylene-ether was introduced as active protector material that uses oxygen as an energy source and copper complexes as a carrier to repair chain scission as a result of damage [206].

Many factors need to be present to achieve active protection. Those factors are selectivity of repairing agent and memory of the original structure [206]. Repairing agents need to target the scission functional end of the chain only and not the natural end group of the chain. Without selectivity, the repairing agent would result in linking the entire chains end leading to an undesired increase of molecular weight of original chains at the site of damage. This results in different molecular structure than the original material [206]. Repairing agents have to be able to restore the damage to its original state regardless of the cause of the damage, ie. Heat, light etc. 
This is one of the most challenging tasks in active protection [206]. Different damage factors produce different molecular changes and in all cases the repairing agent needs to remember the original structure regardless of the nature of the molecular change.

Aramaki [207] introduced a self healing polymer film consisting of 1,2-bis(triethoxysilyl)ethane (BTESE) polymer containing sodium silicate and cerium(III) nitrate to protect zinc electrode that was treated with cerium(III) nitrate at $30{ }^{\circ} \mathrm{C}$ for $30 \mathrm{~min}$. The assessment technique for self healing ability was based on polarization measurements of knife-scratched electrode. The authors reported no occurrence of pitting corrosion at the scratch sites after $72 \mathrm{~h}$ emersion in solution.

\section{Fracture mechanics for polymer composites.}

The term "fracture" in science and technology is deduced as total or partial separation of an originally intact body or a structure. Often, these separations occur by propagation of one crack or several cracks through the material. Fracture analysis, in its most general interpretation, comprises all modes of failure, including buckling, large deformation and rupture (ductile fracture), failure due to a distributed damage growth, as well as a brittle fracture[208]. Figure 9, shows an example of different fracture mechanisms that can be classified according to their starting point and progression.

Fracture analysis of polymer commonly addresses two perspective: a statistical, micromechanical (e.g., using Bell theory or atomic potential) or a continuum mechanical (e.g., using phase field theory or linear/nonlinear fracture mechanics based on Griffith's work[209]. With consideration of later approach, linear elastic fracture mechanics (LEFM) reveals fracture processes, where a cracked body is regarded as linear elastic in whole region[210]. This 
description is mostly applicable for brittle structure, therefore, it understood as "brittle fracture mechanics". Certain shortcomings have been reported during LEFM analysis as it is restricted to sharp cracks only, predicting infinite defect free strength of material only[211], lack of correlation between strength of a material and hole size, and no such treatment for or attending towards cracks [212]. Investigation through theoretical approach incorporates LEFM and its extension as quantized fracture mechanics (QFM) relevant to the structural materials especially fracture of relatively small structures $[213,214]$. Non-linear fracture mechanics deal with challenge like ductile-brittle transition, failure under substantial plasticity, crack tip process under fatigue loading condition[215]. Typical viscoelastic effects (like creep and relaxation) appears in case of polymers or composites[216].

Generalization of fracture analysis to composites can routinely be made using crack stress analysis in anisotropic solids, but failure process for polymer composites is not trivial to define due to structural irregularity of composite system that comprises random arrangement of atoms and molecules and presence of fiber/matrix interface. The individual event of failure development and final fracture can be too complicated to describe if there were two or more physically distinct and mechanically separable material, particularly with complex microstructure. Fracture of the individual phases in the composite, between them and between well-defined arrays, can take place separately, sequentially or simultaneously, depending on type of loading, the external testing condition, the particular microstructure of the composite and other factors [217]. There are several fracture modes in polymer composites namely delamination or interlaminar fracture, matrix cracking or intralaminar fracture, matrix-fiber debonding, fiber breaking, fiber pullout [218].Typically, failure process in polymer composites is 
time dependent, reflecting at least in part the viscoelastic nature of polymer mechanical response, and can be accompanied at high stress permanent deformation, crazing, voids and shear force localization.

\subsection{Micromechanical deformation "crazing"}

Composites comprises defects of different sizes from its initial stage, the defects are essentially given by foreign particles and microvoids. Under external tensile loading, the microscopic deformation initially takes place at heterogeneities of the molecular network and at the foreign particles (like deboding and shear yielding [219]). With further increase of damage, void formation localizes in thin zones perpendicular to the macroscopic loading direction. These regions comprise polymer material between voids and are stretched in to fibrils. This damage

mechanism on the mesoscale is called crazing. Typical dimensions for craze vary from $0.5 \mu \mathrm{m}$ to $200 \mu \mathrm{m}$ long [220]. The phenomenon is more prominent in polymers that allows to find their way into applications where they are replacing metals. Recently, it has been shown that low surface energy polymer (lower wettabillity) like polypropylene facilitate dyeing after introducing regular spaced crazes[221]. The dye incorporated in craze section and get fixated, rest part of fabric was unaffected and hence did not produce any color. The authors further emphasized this method by applying controlled and periodic crazing with polymer and by its composite structure to produce anisotropic transparent polymer[222].

A simple linear craze model for crack tip region for brittle polymer is

$$
K_{c}=u \sigma_{y} E
$$


Whereas; $\mathrm{K}_{\mathrm{c}}, \mathrm{u}, \sigma_{\mathrm{y}}$ and $\mathrm{E}$ are fracture toughness, displacement of crack tip, yield stress, Young's modulus respectively. Since $\sigma_{\mathrm{y}}$ and $\mathrm{E}$ increase with crack speed, so does $\mathrm{K}_{\mathrm{c}}$, that produces astable situation[223]. Therefore, physical characteristic of craze is dissimilar from cracks. Using LEFM, Bucknall proposed criteria, where craze initiation is treated as a frustrated fracture process rather than a yield mechanism[224]. Usually, craze stress is less than yield stress by relation $\left(\sim \sigma_{y} / 3\right)$, improbably high stress concentration would be require to form pores. Mills[225] also suggested to include surface scratches or grooves to define realistic model for craze initiation. Nevertheless, any purely elastic analysis is not adequate to predict craze growth kinetics and hence its preferred to introduce creep process to describe extension of craze. The empirical viscoelastic model used to describe the creep process in the craze and to predict the variation of craze length with time " $\mathrm{t}$ " is found as $\mathrm{c}_{\mathrm{z}}=A \ln \left(\mathrm{t} / \mathrm{t}^{*}\right)$, where $\mathrm{c}_{\mathrm{z}}$ is craze length and $A, t^{*}$ are constants[225]. The prediction of equilibrium length of crazes by minimizing the potential energy of the surrounding elastic material of given craze has been suggested. By taking into account the stress transfers (i) between main fibrils and matrix, and (ii) between main and cross-tie fibrils, a micro-mechanics model has been discussed by Sha et al[226].

Although crazing (craze initiation, growth and break down) is a consequence of mesoscale phenomena but deformation and failure of polymers are cross-scale process. It start at microscale level like rearrangement, slippage, orientation, disentanglement and scission of entangled chain segment[227]. Numerous factors, some are known as stress, temperature, humidity, and molecular orientation influences crazing process. Sha et al. [228], Hui et al. [229] and Hui and Kramer [230]attempted to correlate the molecular weight, the areal chain density of entanglements and the force required to break a carbon-carbon bond with the macroscopic 
fracture toughness of the material fractured through crazing as its dominant mechanism. In contrast, several reports suggest that molecular weight does not have any significant effects on the critical stress for craze initiation especially for polystyrene and styrene-acrylonitrile copolymer[231, 232]. Other reports explained that molecular weight has incremental influence through increasing network density of polymer like PS blended with poly(2,6-dimethyl-1,4phenylene- oxide) (PPO)[233]. The addition of acrylonitrile [231], Polybutadiene (PB) [234] to PS lowers its plasticization characteristics lead to increase in critical stress for the initiation of chain flow such as crazing. The presence of rubber like dispersion markedly lowers the $\sigma_{\mathrm{y}}$ but essentially no effect on fracture stress[235]. Craze initiation stress has a good correlation with the solubility parameter difference between the polymer and crazing agent i.e. the critical stress decreases as the solubility parameter of the crazing agent approaches that of the polymer. Environmental stress cracking (ESC) agents like Freon vapor for styrene-acrylonitrile copolymer [231] and benzene vapors for PVC and PVC-CPE[236] causes reduction in mechanical properties (followed through swelling) and reduces craze initiation stress. Craze influences from the deformation speed, with higher speed of deformation leads to small craze size before failure which makes them undetectable and vice versa[220]. Thus any reproducibility obtained in crazing test on well prepared un-notched specimens appears to depend upon numerous factors like the presence of a characteristics population of microscopic surface flaws, embedded foreign particles and testing conditions (applied stress and temperature)[237].

Table 9 shows absolute values for craze initiation stress (MPa) carried out under different test conditions of different polymers and composites. These values are helpful to manifest stress fields of crazes to be able to make predictions of the growth in size and change of shape of 
crazes prior to crack initiation. Information for critical stress for crazing supports to establish bridge linking of material microstructural parameters and macroscopic mechanical properties. Multiple crazing is found to be most prominent toughening mechanism for HIPS (High intensity polystyrene), ABS (Acrylonitrile butadiene styrene), and RTPMMA (Rubber toughened polymethyl methacrylate). [238]. Similar to the rubber particles in styrene, Shang et al. [239] found yeast acts as craze initiators in the polyurethane (PU) matrix. Where it acts as a plastic energy absorption source and improves the strength of composite. Crosslink between the yeast and the APTS (3-Triethoxysilyl Propylamine) modified PU further improve the strength by providing a strong interfacial adhesion that avoids the premature craze breakdown.

\subsection{Macroscopic stiffness of composites}

Macroscopic stiffness can be considered as the material strength that dictates the loading state at which a material begins to fail in an unstable manner and cannot withstand further loading. It is often characterized by either the yield stress or the ultimate stress at fracture. The associated material parameters are the yield strength and the ultimate tensile strength [216].

Numbers of theories are applicable to predict damage and failure analysis from macro to nanoscale or even at atomic scale. Koyanagi et al.[240] presented an elasto-viscoplastic constitutive equation for the matrix, which involves continuum damage mechanics regarding yielding and failure. It is revealed that the matrix strength varies more drastically with the strain rate than the interface strength. Sun et al. [241] developed a unified macro- and micro-mechanics failure analysis method to study micro structure effects on macroscopic failure. Though, in their analysis thermal residual stress was not considered, that has been addressed by Ye et al. [242] especially for biaxial loading of laminates. For unidirectional lamina their results revealed that 53 
thermal residual stresses influence on failure strength is closely dependent on fiber off-axis angles. They described failure theories of fiber and matrix constituents through maximum stress, criterion, maximum strain criterion and tsai-Hill criterion but their work is restricted to study inplane failure in composite laminates. Recently Lee and Roh[243] has developed a 2-D strainbased interactive failure theory to predict the final failure of composite laminates subjected to multi-axial in-plane loading. The theoretical results of the failure model developed are compared with the experimental data provided by the World-Wide Failure Exercise. The results of theory show reasonable accuracy for the final failure of multidirectional laminates as well as unidirectional ones.

Using concept of energy balance, D. Taylor et al[211] introduced FFM (finite fracture mechanics) to predict strength of bodies containing short cracks and notches in micro or submicron range. Their predictions are of good accuracy for a wide range of materials, including metals, polymers and ceramics. Novozhilov [244] proposed propagation of crack occurs in discrete quanta unlike smooth occurring. The quantum of advance take place in an individual atomic bond. Later, static limit case has been proposed corresponds to quantized fracture mechanics that allows prediction of the strength of nanostructures and structural elements containing re-entrant corners [245]. It is a novel concept applicable for model for tiny structures even at atomic range that substitutes differentials in Griffith criterion with corresponding finite differences [214]. For finite size thin sheet, fracture strength for width (w), crack length (2l) and crack tip radius (r) can be written as; 


$$
\sigma_{f}(2 l)=\sigma_{p} \sqrt{\frac{1+\frac{r}{2 \Delta l}}{1+\frac{2 l}{\Delta l}}}\left[\frac{2 w}{\pi l} \tan \left(\frac{\pi l}{2 w}\right)\right]^{1 / 2}
$$

Where, $\sigma_{\mathrm{p}}$ is the failure stress of a pristine structure, $(\Delta \mathrm{l})$ is the fracture quantum, which is the extension of a crack by breaking one interatomic bond along the crack direction. Recently, it is demonstrated that prediction through QFM is more accurate than to Griffith energy balance criterion for fracture strength of material of atomic dimension like graphene[246]. While under dynamic loading as well as the crack tip evolution, dynamic quantized fracture mechanics (DQFM) has been predicted for strength (or time to failure) [247]. Recently these theories have been demonstrated to estimate the bonding strength of trabecular-like coatings, i.e. glass-ceramic scaffolds mimicking the architecture of cancellous bone, to ceramic substrates[248].

Experimental observations carried out at different scales, the strength calculated as tensile strength of scaled specimens increased with increasing specimen size like carbon fiber/epoxy laminates. It is attributed to the smallest specimens being more susceptible to free edge delamination[249]. Under unidirectional test, sub laminates specimens increased in strength by $10 \%$ over a factor of 4 increases in size. While, Ply level scaled specimens showed a $62 \%$ drop in strength over the factor of 8 size. But this phenomenon is not universal and is not valid for all specimens. The carbon-PEEK composite, under similar test condition, shows tougher matrix less prone to delamination and little scaling effect. Therefore, it is ambiguous to correlate laminate scaling to the scaling of material strength[250]. For non-laminate composite like epoxy resin with carbon and glass, Miwa and Horiba [251] estimated tensile strength of different fiber length. The estimation was based on strain rate and temperature dependence of both the yield shear strength at the fiber-matrix interphase and the mean critical fiber length. Strain rate strongly 55 
affects the ultimate tensile strength and but modulus of elasticity is almost insensitive to it while temperature only influences the modulus[252].

Apart from scaling, there are several factors affect the strength of composites, such as, strengths of fibers and matrix, fiber content and the interfacial bonding between fibers and matrix. Fibers work as carriers of load in the matrix; poor fiber/matrix interfacial bonding may leads to drop in tensile strength. It has been shown that macroscopic mechanical response of polymer composite can be alter by addition of fillers such as $\mathrm{CaCO}_{3}$, cuttlebone, carbon nano-tube and nano-clay to improve the stiffness of the polymer composite, though this is often accompanied by the decrease in tensile strength and elongation at break[253-257]. Figure 11, shows normalized tensile strength of polymer composites namely Epoxy, polyketone and polyurethane through incorporation of different fibers and fillers. Normalization has carried out as ratio between tensile strength of polymer composite $\left(\mathrm{TS}_{\mathrm{PC}}\right)$ to its relatively pure state of polymer $\mathrm{TS}_{\mathrm{pure}}$.

Tuning of tensile strength is possible with increasing the dispersion of fillers using modifier like Oleic acid [256], acrylic resins[258] before incorporation to polymer matrix. Appropriate dispersion of $\mathrm{CaCO}_{3}$ nanoparticles significantly improves tensile property of waterborne polyurethane (WPU) composite [256] and with MWNTs (10 wt.\%.) in PU [257]. Here, tensile strength of MWNTs/PU composite is increased by $18.7 \%$ from $16 \mathrm{MPa}$ to $19 \mathrm{MPa}$. Unlike, for Poly vinyl alcohol (PVA)/WPU blends that result in decrease of the tensile strength due to destruction of the intra-molecular and inter-molecular hydrogen bonding with PVA. The amount of fiber or fillers is needed to be optimized for interaction between different phases to avoid reverse effect. As lignin improves the PU properties only when is incorporated in limited extent (4.2\%), higher concentration of lignin (> 5\%) in PU causes lacking in lignin distribution and 56 
tends to agglomerate instead physically interact with the polyurethane chains cause decrease in strength of composite [259]. For polyurethane/nanosilica composites, Chen et al [258] observed compatibility between two different phases is the better parameter other than dispersion of nanosilica particles for static mechanical properties. Therefore, adhesion between matrix and fillers or fiber for adequate compatibility and good filler dispersion are necessary to enhance the tensile strength that may lead to achieve uniform stress distribution in composite [239]. By the rule of mixture adding fibers with a very high strength to the matrix with low tensile strength should result in increasing tensile strength of the composite, if interfacial bonding is good[260]. Using CLT (classic lamination theory) it was observed that tensile strength of the hybrid composite could be estimated by the additive rule of hybrid mixtures, using the tensile strengths of both composites[251].

In applications with limited aggression in damage development, composite strength is moderately well characterized because the problem is enormously complex. One of the major causes for the composites is that, it is hard to determine accurately. The high fiber strength makes it extremely difficult to introduce the load without stress concentrations which tend to lead premature failure especially at the grips[250].

\subsection{Resistance to crack}

The generic term usually applied to measures material resistance for crack extension is fracture toughness $\left(\mathrm{K}_{I c}\right)$. The important parameters include are stress intensity factor $\left(\mathrm{K}_{I}\right)$, the J-integral, the crack-tip opening displacement (CTOD), and the crack-tip opening angle (CTOA) [261]. Crack propagation rate is commonly expressed as a function of $\mathrm{K}_{I}$ or it equivalent partner energy release rate $(\mathrm{G})[208]$. It is revealed that different crack behavior can be predicted under variable 57 
loading conditions that include "crack driving force" (e.g., $\mathrm{K}_{l}, \mathrm{G}$, or J) and crack stability[262, 263]. The correlation between $K_{I}$ and $G$ (the elastic energy release rate) are connected as:

$$
\left.\left.\left.\mathbf{G}=\left(\mathbf{K}_{I(\text { model })}\right)^{2} / \mathbf{E}^{\prime}\right)+\left(\mathbf{K}_{I(\text { modeII })}\right)^{2} \mathbf{E}^{\prime}\right)+\mathbf{K}_{I(\text { modeIII })^{2}} / \mathbf{E}\right)
$$

Where, elastic constants of material $\left(E^{\prime}=E\right)$ for plain stress or $E^{\prime}=E /\left(1-v^{2}\right)$ for plain $\operatorname{strain}[247]$. $\mathrm{K}_{I}$ for crack propogation-mode I(opening), mode II(sliding), or mode III(tearing), is only function of geometry and applied load, multi-mode loading are described in literature for further discussion [220]. The improved $\mathrm{K}_{\text {Ic }}$ of polymer composite particular for reinforced one is achieved by reducing $\mathrm{K}_{I}$ at the crack tip[264]. Brighenti et al.[265] examined and calculated wide database of $\mathrm{K}_{I}$ for Fibre-reinforced composites to determine the applied stress value responsible for the appearance and propagation of the debonding-based crack along the fibre. They argued that knowledge of $K_{I}$ and the fibre-matrix critical interface energy allow to control detrimental effect and to properly tailor the degree of debonding under a defined stress level.

Though, $\mathrm{K}_{I}$ can be used to compare fracture toughness of composite material, but is limited to sharp cracks only that might not be applicable for notches and blunt cracked specimens[266]. Salazar et al. [267] suggested for blunt crack to consider an apparent fracture toughness $\left(\mathrm{K}_{B}\right)$ equivalent to sharp crack specimen with a stress distribution at the instant of fracture identical to that of a specimen with a blunt crack. Their investigation for epoxy resin found fracture toughness increased rapidly with crack tip radius and the microscopic analysis of the fracture surface indicated that blunting was the reason of the steady increase. Krishanan et al.[268] investigated bi-material (polymer/aluminum) specimens with notches at different angle $30^{\circ}, 90^{\circ}$ and $120^{\circ}$. They observed for weakly bonded polymer/metal specimens, crack initiation load 
increases with the increase of the notch angle. However, for strongly bonded polymer/metal specimens, the notch with a notch angle of $90^{\circ}$ has lower crack initiation load compared to other two notch angles $\left(30^{\circ}\right.$ and $\left.120^{\circ}\right)$ due to the complicated relationship between the crack driving force and material resistance at the crack initiation from a notch.

$\mathrm{K}_{I C}$ for polymer composite is depend on its inherent polymer matrix toughness, a linear relation has been observed for glass-polymer composite with improved toughness while increasing toughness of its neat polymer [269]. The capability of intrinsic plasticity of macromolecule network governs the inherent matrix toughness that relate to density of cross-links. If cross-links density increases, the 'deformability' of the network will decrease that has been observed in case of epoxy resin[270]. Therefore, with increasing molecular weight of polymer like epoxy carried out in order to decrease cross linking density and for enhancing toughness. Nevertheless, simply using highly cross linked epoxy matrices is not the ultimate solution for improving $\mathrm{K}_{I C}$. Polymer often behave undesirably brittle because plastic deformation is constrained[271]. Moreover, it alters other important characteristics such as thermo-mechanical properties, stiffness, strength and modulus that are desired and required in various applications.

The relation between local stress growth criterion in terms of $\mathrm{K}_{\mathrm{Ic}}, \mathrm{G}_{\mathrm{c}}$ (critical strain energy release rate) and crack tip stresses $(\sigma)$ is write as:

$$
\sigma=\sqrt{\frac{E G_{c}}{\pi a}}=\frac{K_{I C}}{\sqrt{\pi a}}
$$

The influence of $\mathrm{K}_{I C}$ and $\mathrm{G}_{\mathrm{C}}$ for different loading rate is observed by Kanchanomai et al. [263] where they observed decrease in $K_{I C}$ and $G_{C}$ with increasing loading rate for epoxy- 
polyamine composite.With assumption of quanta energy dissipation, N. Pugno et al.[214] formulated general relation for $\mathrm{K}_{I c}$ as quantized fracture mechanics (QFM), where crack propagation based on discrete extension rather continuous (Griffith approach). From energy balance, relation between $\mathrm{K}_{I c}$ of material and condition for propagation of cracks/defects obtain as:

$$
\mathrm{K}_{I \mathrm{C}}=\mathrm{K}^{*}=\sqrt{\left\langle K_{I}^{2}\right\rangle_{l}^{l+\Delta l}} ; \text { for Mode I,II,III, }
$$

Where $\mathrm{K}^{*}$ is the square root of the "mean" value of the $\mathrm{K}_{I}^{2}$ along fracture quantum length $(\Delta \mathrm{l})$ and for crack length "l". The hypothesis of QFM is based on quantized propagation in a linear elastic continuum medium. It is well suited to first-order with linear elastic fracture mechanics (LEFM) and to second-order for non-linear fracture mechanics. The advantage of QFM over classical LEFM is that prior one has no restriction for treating defects and cracks of multiple size and shape. The theoretical value obtained from QFM for variable micro size circular holes resembled well with experimental results carried out for polysilicon thin film[272]. Analogously, for dynamic loads, DQFM (Dynamic quantized fracture mechanics) has been presented and used to study the toughness, strength and time to failure of solids, as well as the time evolution of the crack tip[247]. The "mean" value of $\mathrm{K}_{I}$ is considered during quantum interval of time $(\Delta t)$ where discretization is assumed in both space and time during propogation of crack that follows given relation.

$$
\mathrm{K}_{I \mathrm{C}}=\sqrt{\left\langle\left\langle K_{I}^{2}\right\rangle_{l}^{l+\Delta l}\right\rangle_{t-\Delta t}^{t}} ; \text { for Mode I,II,III, }
$$


For viscoelastic material and under certain loading conditions $G_{c}$ is considered as the characterising parameter for crack extension rather than the fracture toughness $\left(\mathrm{K}_{I c}\right)$ [273]. It is also experimentally demonstrated for carbon-fiber/epoxy materials where $G_{c}$ found independent of debond length that supporting the idea that $\mathrm{G}_{\mathrm{c}}$ is a valid fracture criterion [274].

An analogous nonlinear elastic fracture mechanics approach may be used that based on J-integral $\left(\mathrm{J}_{I C}\right)[275,276]$, it is nonlinear elastic release rate and hence equivalent to $\mathrm{G}$ under linear elastic condition[262]. It represents the energy per unit area necessary to initiate a crack and it is obtained by extrapolation to zero crack advancement of the J-R curve, which describes the energy per unit area necessary for the advancement of a propagating crack. Recently, it is been determined from cracks propagating across a fully yielded ligament; where it represented energy required to initiate a crack in an already yielded material [277]. Salazar and co-worker demonstrated used J-R curves to determine the influence of the sharpening methodology on the stable crack growth resistance for ethylene-propylene block copolymers [278]. At fracture, $\mathrm{J}_{I \mathrm{C}}$ can be related to the crack tip opening displacement, CTOP $(\delta)$, and the yield stress $\left(\sigma_{\mathrm{y}}\right)$ by relation $\mathrm{J}_{\mathrm{IC}}=\sigma_{\mathrm{y}} \delta$. One important feature of the $\mathrm{J}$-integral is that, is path independent, so any convenient path can be chosen where stress and displacement are known. This approach works well for polymers provided they are not too ductile. To deal with highly ductile polymers, EWF (essential work of fracture) approach has been applied to determine the toughness response. The greater advantage of EWF over the J-integral is to provide clear distinction between surface (essential part: the work spent in the inner fracture process zone) and volume-related (nonessential part: the work spent in the plastic deformation zone) [279]. 
Certain modifiers has been suggested for tuning $\mathrm{K}_{I C}$ of polymer, the classification of modifiers has been describe depending on its rigidity relative to polymer matrix. Modifiers less rigid than the polymer matrix may serve as tougheners in matrices which show ductility to some degree. Generally, they serve toughening mechanism through formation of microvoids (eg. like rubber particles) and promoting delocalized micro-crack and crack bridging effect (for thermoplastic particles). In order to gain improvements of multiple properties, the fillers should possess (1) a higher rigidity than the polymer to increase its stiffness, (2) a high specific surface, (3) a sufficient filler-matrix bonding to improve strength and to allow a controlled stress transfer from the matrix to the fillers, and (4) preferably small dimensions to reduce local stress concentrations and to generate high toughness and impact resistance. Table 9 shows list of Epoxy polymer composites with different modifiers performed under toughness characterization.

In the presence of rigid filler of nearly micro dimension, the toughening mechanism may comprise crack deflection, plastic deformation and crack front pinning. The reduction of the filler dimensions in brittle polymer composites is one of promising pathway to improve the toughness, since the microstructural perfection of composites increases by minimizing the size of potential defects (e.g. inclusions, agglomerates)[280]. There were also reports on nano-void formation and presence of a dilatation zone when the interface is strong [281]. For composites, where the dispersed particles are in the nano-scale, several toughening mechanisms come to play depending on the filler type. For example, nano-sized silica particles increase the toughness of the epoxy matrix through de-bonding of particles which is followed by plastic void growth [282]. Whereas, for carbon nano-tubes reinforced epoxy system, pull-out of nano-tubes and de-bonding seems to contribute to the increase in fracture energy and the contribution from plastic void 
growth is minimal[283]. When it comes to fillers with layered structures such as nano-clay or silicates (layered), crack-deflection, micro-cracking and plastic void growth is the major toughening mechanisms [284, 285] and with graphene addition, crack deflection and crack pinning has been reported[286].

Incorporation of controlled and optimized amount of modifiers tunes mechanical characteristics of composite, figure 12. Concentration over critical value, modifiers like halloysite (HNT)[287], glass bead[270], Polyethylene terephthalate (PET)[288] lead to aggregates in the microstructure, causes poor interfacial adhesion and low stress transfer between the reinforcements and the matrix. For brittle polymer like Poly(methyl methacrylate) (PMMA), toughening as a function of modifiers like mica content merges into a plateau i.e significant enhancement of toughness upto $66 \%$ for critical value (mica $0.8 \mathrm{vol} \%$ ) without compromising its tensile strength. With further increasing filler volume, plastic deformation of PMMA matrix gets restricted by following reduction in the elongation at break[289]. For MMT-PANI (Montmorillonite-polyaniline) nanocomposite, the improvement of the toughness is attributed to the breakage of the clay aggregates. The clay layers (MMT or Bentonite) believed to be acted as stress concentrators and to promote large number of micro-cracks of fracture surface by crack deflection. Up to 23 wt. $\%$ of MMT clay in the nanocomposite of PANI (polyaniline as the emeraldine salt (EMS)) significantly improves fracture toughness, hardness and impact energy of polyaniline. At higher content clay aggregates present within the intercalated nanocomposites believed to reduce their resistance to crack propagation[290]. Another factor that describes the influences of fracture behavior of MMT-PANI nanocomposite is crystalline morphology, especially the size and the form of crystals, of semi-crystalline polymer PANI. In contrast for PEEK polymer, crystalline 
arrangement lead to drop in toughness[291], with incorporation of carbon fiber (APC-2), the fracture toughness of the laminates observed to be depend on interfacial interaction but not merely on matrix crystallinity.

\section{Recommendations for future work}

Detection and quantitative evaluation of cracks and microcracks is vital for the prevention and repair measures in polymer composites. While newly developed non-destructive instrumentation with improved image processing capability, for example X-ray microcomputed tomography $(\mathrm{X} \mu \mathrm{CT})$ has shown great potential in detection and quantifications of structural defects in composites, there is a great need in developing reliable and efficient techniques which produces consistent and precise measurements of variables such as voids volume and delamination lengths.

The introduction of nanoscale fillers into the polymer matrices such as clay minerals and carbon nanotubes (CNTs) has shown to enhance the physical and chemical integrity of polymers with very small filler loading. Further studies are needed to understand their role in improving the polymer composites resistance to many environmental factors, such as atomic oxygen, vacuum, UV radiation and thermal cycling.

Polymer degradation due to different environmental factors such as heat, UV, moisture and mechanical loading often leads to reduced performance and long-term exposure can result in material failure; a serious and undesirable event in many applications. There is still a lack of knowledge and understanding in the synergistic effects of polymer degradation conditions. It is 
very rare for one damaging condition to work alone, the interchange and interaction between environmental conditions is a rich topic for further research.

It is obvious that the current self healing technologies are short from achieving the complete mimic of the perfect process of hemostasis. However, research is progressing rapidly to provide similar healing ability to polymer composites. The ultimate goal for polymer composite self healing is to achieve material stasis through the incorporation of a circulatory system in the polymer composites, similar to the one in the biological process, that continuously supply chemicals and building elements to the damaged site for unlimited repairs [77].

Multiple steps can be taken to advance the self-healing process such as determining the crosslinking reaction mechanisms of the resin at different cross linking agent concentrations and inclusions methods (encapsulations and in access), establishing the variables that govern the recovery rate and conditions at damaged sites as a result of radiation, ion bombardment, mechanical impact or thermal cycle and evaluating the mechanism, rate and the variables that govern the transport of the cross-linking agents from the bulk and surface of the polymer to the damage site.

Fracture mechanics (FM) approach provide insight information for quantifying and predicting strength, durability, reliability, toughness and other mechanical response of polymer structural components that contain cracks or cracks like defects. It is being used to address all major mechanism of material failure; namely ductile and cleavage fracture, creep, fatigue etc. Though FM has under gone major development in metallic materials and ceramics but it is moderately characterized for polymers and polymers composites (PC). 
The major obstacle for PC is their inhomogeneous characteristics unlike metallic materials, which limit the applicability for solid mechanics. On the analytical front, we must expand our efforts to integrate continuum fracture mechanics analysis with micro/nanoscopic or even subatomic process like FFM, QFM or DQFM that governs local fracture at the crack tip. In the area of advanced heterogeneous material, fracture mechanics methods must be further developed and applied to describe novel failure mode. The gain in understanding from multidisciplinary (like mechanics, chemistry and material science) is required to reveal interfacial adhesion, atomic bonding dispersion of additives and critical concentration of fillers. Moreover, numerical and theoretical model should carried out that enables the extrapolation of short term laboratory data in predicting long term service performance of PC. Collectively, research must be carried out that focuses practical life prediction methodology.

\section{Acknowledgement}

The first author would like to acknowledge the financial support from the European Union under the FP7 COFUND Marie Curie Action. 


\section{References}

[1] Pang JWC, Bond IP. A hollow fibre reinforced polymer composite encompassing self-healing and enhanced damage visibility. Composites Science and Technology. 2005;65:1791-9.

[2] Narin JA. Matrix microcracking in composites. In: Talrcja R, Manson J-A, editors. Polymer matrix Composites: Elsevier Science; 2000. p. 1-29.

[3] Dry C. Procedures developed for self-repair of polymer matrix composite materials. Composite Structures. 1996;35:263-9.

[4] Dry C, McMillan W. A novel method to detect crack location and volume in opaque and semi-opaque brittle materials. Smart Materials and Structures. 1997;6:35-9.

[5] Joseph PV, Rabello MS, Mattoso LHC, Joseph K, Thomas S. Environmental effects on the degradation behaviour of sisal fibre reinforced polypropylene composites. Composites Science and Technology. 2002;62:1357-72.

[6] Woo RSC, Chen Y, Zhu H, Li J, Kim J-K, Leung CKY. Environmental degradation of epoxy-organoclay nanocomposites due to UV exposure. Part I: Photo-degradation. Composites Science and Technology. 2007;67:3448-56.

[7] Woo RSC, Zhu H, Leung CKY, Kim J-K. Environmental degradation of epoxy-organoclay nanocomposites due to UV exposure: Part II residual mechanical properties. Composites Science and Technology. 2008;68:2149-55.

[8] Awaja F, Gilbert M, Kelly G, Fox B, Pigram PJ. Adhesion of polymers. Progress in Polymer Science. 2009;34:948-68.

[9] Blaiszik BJ, Kramer SLB, Olugebefola SC, Moore JS, Sottos NR, S.R.White. Self-Healing Polymers and Composites. Annual Review of Materials Research. 2010;40:179-211.

[10] Feldman D. Polymer Weathering: Photo-Oxidation. Journal of Polymers and the Environment. 2002;10:163-73.

[11] Yuan YC, Yin $T$, Rong $M Z$, Zhang $M Q$. Self healing in polymers and polymer composites.Concepts, realization and outlook: A review. Express Polymer Letters. 2008;2:238-50.

[12] Wang CH, Sidhu K, Yang T, Zhang J, Shanks R. Interlayer self-healing and toughening of carbon fibre/epoxy composites using copolymer films. Composites Part A: Applied Science and Manufacturing. 2012;43:512-8.

[13] Awaja F, Riessen Gv, Fox B, Kelly G, Pigram PJ. Time-of-flight Secondary Ion Mass Spectrometry Investigation of Epoxy Resin Curing Behavior in Real Time. Journal of Applied Polymer Science. 2009;113:2765-76.

[14] Awaja F, Riessen Gv, Kelly G, Fox B, Pigram PJ. Tof-sims Investigation of Epoxy Resin Curing Reaction at Different Resin to Hardener Ratios. Journal of Applied Polymer Science. 2008;110:2711-7.

[15] Awaja F, Gilbert M, Fox B, Kelly G, Pigram PJ. Investigation of the Postcure Reaction and Surface Energy of Epoxy Resins Using Time-of-Flight Secondary Ion Mass Spectrometry and Contact-Angle Measurements. Journal ofAppliedPolymer Science. 2009;113: 2755-64

[16] Brown EN, White SR, Sottos NR. Retardation and repair of fatigue cracks in a microcapsule toughened epoxy composite--Part II: In situ self-healing. Composites Science and Technology. 2005;65:2474-80.

[17] Kessler MR, Sottos NR, White SR. Self-healing structural composite materials. Composites Part A: Applied Science and Manufacturing. 2003;34:743-53.

[18] Kessler MR, White SR. Self-activated healing of delamination damage in woven composites. Composites Part A: Applied Science and Manufacturing. 2001;32:683-99. 
[19] Liu X, Lee JK, Yoon SH, Kessler MR. Characterization of diene monomers as healing agents for autonomic damage repair. Journal of Applied Polymer Science. 2006;101:1266-72.

[20] Pang JWC, Bond IP. Bleeding composites-damage detection and self-repair using a biomimetic approach. Composites Part A: Applied Science and Manufacturing. 2005;36:183-8.

[21] Ju J, Morgan RJ. Characterization of Microcrack Development in BMI-Carbon Fiber Composite under Stress and Thermal Cycling. Journal of Composite Materials. 2004;38:2007-24.

[22] Nairn JA. 2.12 - Matrix Microcracking in Composites. In: Zweben AKC, editor. Comprehensive Composite Materials. Oxford: Pergamon; 2000. p. 403-32.

[23] Hiemstra DL, Sottos NR. Thermally Induced Interfacial Microcracking in Polymer Matrix Composites. Journal of Composite Materials. 1993;27:1030-51.

[24] Kim J-K, Mai Y-w. High strength, high fracture toughness fibre composites with interface control-A review. Composite Science and Technology. 1991;41:333-78.

[25] Timmerman JF, Hayes BS, Seferis JC. Cure temperature effects on cryogenic microcracking of polymeric composite materials. Polymer Composites. 2003;24:132-9.

[26] Bafekrpour E, Simon GP, Habsuda J, Naebe M, Yang C, Fox B. Fabrication and characterization of functionally graded synthetic graphite/phenolic nanocomposites. Materials Science and Engineering : A. 2012;545:123-31.

[27] Bafekrpour E, Simon G, Yang C, Habsuda J, Naebe M, Fox B. Effect of compositional gradient on thermal behavior of synthetic graphite-phenolic nanocomposites. Journal of Thermal Analysis and Calorimetry. 2012;109:1169-76.

[28] Ray BC. Study of the influence of thermal shock on interfacial damage in thermosetting matrix aramid fiber composites. Journal of Materials Science Letters. 2003;22:201-2.

[29] Timmerman JF, Tillman MS, Hayes BS, Seferis JC. Matrix and fiber influences on the cryogenic microcracking of carbon fiber/epoxy composites. Composites Part A: Applied Science and Manufacturing. 2002;33:323-9.

[30] Timmerman JF, Hayes BS, Seferis JC. Cryogenic Microcracking of Carbon Fiber/Epoxy Composites: Influences of Fiber-Matrix Adhesion. Journal of Composite Materials. 2003;37:1939-50.

[31] Bechel VT, Fredin MB, Donaldson SL, Kim RY, Camping JD. Effect of stacking sequence on microcracking in a cryogenically cycled carbon/bismaleimide composite. Composites Part A: Applied Science and Manufacturing. 2003;34:663-72.

[32] Awaja F, Moon JB, Gilbert M, Zhang S, Kim CG, Pigram PJ. Surface molecular degradation of selected high performance polymer composites under low earth orbit environmental conditions. Polymer Degradation and Stability. 2011;96:1301-9.

[33] Awaja F, Moon JB, Zhang S, Gilbert M, Kim CG, Pigram PJ. Surface molecular degradation of 3D glass polymer composite under low earth orbit simulated space environment. Polymer Degradation and Stability. 2010;95:987-96.

[34] Shimokawa T, Katoh H, Hamaguchi Y, Sanbongi S, Mizuno H, Nakamura H, et al. Effect of Thermal Cycling on Microcracking and Strength Degradation of High-Temperature Polymer Composite Materials for Use in Next-Generation SST Structures. Journal of Composite Materials. 2002;36:885-95.

[35] Hancox NL. Thermal effects on polymer matrix composites: Part 1. Thermal cycling. Materials and Design. 1998;19:85-91.

[36] Han J-H, Kim C-G. Low earth orbit space environment simulation and its effects on graphite/epoxy composites. Composite Structures. 2006;72:218-26.

[37] Awaja F, Arhatari B, Wiesauer K, Leiss E, Stifter D. An investigation of the accelerated thermal degradation of different epoxy resin composites using X-ray microcomputed tomography and optical coherence tomography. Polymer Degradation and Stability. 2009;94:1814-24. 
[38] Radon JC. Fatigue crack growth in polymers. International Journal of Fracture. 1980;16:533-52.

[39] Wöhler A. Wöhler's experiments on the strength of metals. Engineering. 1867;2:160-1.

[40] Andrews EH. Cracking and crazing in polymeric glasses. In: Haward RN, editor. The Physics of Glassy Polymers: Springer Netherlands; 1973. p. 394-453.

[41] kambour RP. A review of crazing and fracture in thermoplastics. Journal of Polymer Science: Macromolecualr Reviews. 1973;7:1-154.

[42] Manson JA, Hertzberg RW. Fatigue failure in polymers. CRC Critical reviews in Macromolecular Science. 1973;1:433-500.

[43] Plumridge WJ. Review: Fatigue-crack propagation in metallic and polymeric materials. Journal of Materials Science. 1972;7:939-62.

[44] Rabinowitz S, Beardmore P. Craze formation and fracture in glassy polymers. CRC Critical Reviews in Macromolecualr Science. 1972;1:1-45.

[45] Regel VR, Tamuzh VP. Fracture and fatigue of polymers and composites (survey). Polymer Mechanics. 1977;13:392-408.

[46] Schultz JM. Properties of Solid Polymeric Materials. In: Schultz JM, editor. Treaties on Material Science and technology. Orlando: Academic Press; 1977. p. 599-632.

[47] Sauer JA, Richardson GC. Fatigue of polymers. International Journal of Fracture. 1980;16:499-532.

[48] Azimi HR, Pearson RA, Hertzberg RW. Role of crack tip shielding mechanisms in fatigue of hybrid epoxy composites containing rubber and solid glass spheres. Journal of Applied Polymer Science. 1995;58:449-63.

[49] Azimi HR, Pearson RA, Hertzberg RW. Fatigue of hybrid epoxy composites: Epoxies containing rubber and hollow glass spheres. Polymer Engineering \& Science. 1996;36:2352-65.

[50] Becu L, Maazouz A, Sautereau H, Gerard JF. Fracture behavior of epoxy polymers modified with core-shell rubber particles. Journal of Applied Polymer Science. 1997;65:2419-31.

[51] Brown EN, White SR, Sottos NR. Fatigue crack propagation in microcapsule-toughened epoxy. Journal of Materials Science. 2006;41:6266-73.

[52] Jones AS, Rule JD, Moore JS, Scottos NR, White SR. Life extension of self-healing polymers with rapidly growing fatigue cracks. Journal of Royal Society Interface. 2007;4:395-403.

[53] Karger-Kocsis J, Friedrich K. Microstructure-related fracture toughness and fatigue crack growth behaviour in toughened, anhydride-cured epoxy resins. Composites Science and Technology. 1993;48:263-72.

[54] Sautereau H, Maazouz A, Gerard JF, Trotignon JP. Fatigue behaviour of glass bead filled epoxy. Journal of Materials Science. 1995;30:1715-8.

[55] Kawaguchi T, Pearson RA. The moisture effect on the fatigue crack growth of glass particle and fiber reinforced epoxies with strong and weak bonding conditions: Part 2. A microscopic study on toughening mechanism. Composites Science and Technology. 2004;64:1991-2007.

[56] Hayes BS, Seferis JC. Modification of thermosetting resins and composites through preformed polymer particles: A review. Polymer Composites. 2001;22:451-67.

[57] McMurray MK, Amagi S. The effect of time and temperature on flexural creep and fatigue strength of a silica particle filled epoxy resin. Journal of Materials Science. 1999;34:5927-36.

[58] Davis FH, Ellison EG. Hydrodynamic pressure effects of viscous fluid flow in a fatigue crack. Fatigue and Fracture of Engineering Materials and Structures. 1989 12:527-42.

[59] Elber W. Fatigue crack closure under cyclic tension. Engineering of Fractur Mechanics. 1970 2:37-45. [60] Endo K, Okada T, Komai K, Kiyota M. Fatigue crack propagation of steel in oil. Bulletin of the Japan Society of Mechanical Engineers. 1972;15:1316-23. 
[61] Galvin GD, Naylor H. Effect of lubricants on the fatigue of steel and other metals. Proceeding of the Institute of Mechanical Engineers. 1964;179:857-75.

[62] Plumbridge WJ. Mechano-enviornmental effects in fatigue. Materials Science and Engineering. 1977;27:197-208.

[63] Plumbridge WJ, Ross PJ, Parry JSC. Fatigue crack growth in liquids under pressure. Materials Science and Engineering. 1985;68:219-32.

[64] Polk CJ, Murphy WR, Rowe CN. Determining fatigue crack propagation rates in lubricating environments through the application of a fracture mechanics technique. American Society of Lubrication Engineers Transactions. 1975;18:290-8.

[65] Tzou JL, Suresh S, Ritchie RO. Fatigue crack propagation in oil environments: 1. Crack growth behavior in silicone and paraffin oils. Acta Metallurgica. 1985;33:105-16.

[66] Yi KS, Cox BN, Dauskardt RH. Fatigue crack-growth behavior of materials in viscous fluid environment. Journal of Mechanics and Physics of Solids. 1999;47:1843-71.

[67] Faltinsen OM. Hydroelastic slamming. Journal of Marine Science and Technology. 2000;5:49-65.

[68] Caridis PA, Stefanou M. Dynamic elastic/viscoplastic response of hull plating subjected to hydrodynamic wave impact. Journal of Ship Research. 1997;41:130-46.

[69] Wang G, Tang S, Shin Y. Direct Calculation Approach for Designing a Ship-shaped FPSO's Bow Against Wave Slamming Load Proceedings of The Twelfth International Offshore and Polar Engineering Conference. Kitakyushu, Japan2002. p. 35-42.

[70] McGeorge D, Vredeveldt AW. Mode I fracture toughness of secondary bonds of a novel CFRP hull structure. In: Williams JG, Pavan A, editors. Eur Struct Integity Soc: Elsevier; 2000. p. 83-96.

[71] Boyd SW, Blake JIR, Shenoi RA, Kapadia A. Integrity of hybrid steel to composite joints for marine application. Proceedings of the I MECH E Part M: Journal of Engineering for the Maritime Environment; 2004. p. 235-46.

[72] Buckley WH, Stavovy AB, Taylor DW. Progress in the Development of Structural Load Criteria for Extreme Waves. Proc Extreme loads response Symposium. Arlington VA: New York: Soc Naval Architects and Marine Engineers, http://www.shipstructure.org/pdf/81symp06.pdf; 1981. p. 75-88.

[73] Charca S, Shafiq B, Just F. Repeated slamming of sandwich composite panels on water. Journal of Sandwich Structures and Materials. 2009;11:409-24.

[74] Charca S, Shafiq B. Damage assessment due to single slamming of foam core sandwich composites. Journal of Sandwich Structures and Materials. 2010;12:97112.

[75] Sharma N, Gibson RF, Ayorinde EO. fatigue of foam and honeycomb core composite sandwich structures: A tutorial. Journal of Sandwich Structures and Materials. 2006;8:263-319.

[76] Sutherland LS, Soares CG. Impact behaviour of typical marine composite laminates. Composites Part B: Engineering. 2005;37:89-100.

[77] White SR, Sottos NR, Geubelle PH, Moore JS, Kessler MR, Sriram SR, et al. Autonomic healing of polymer composites. Nature. 2001;409:794-7.

[78] Mackerle J. Finite elements in the analysis of pressure vessels and piping, an addendum (19961998). International Journal of Pressure Vessels and Piping. 1999;76:461-85.

[79] Pant M, Singh IV, Mishra BK. A numerical study of crack interactions under thermo-mechanical load using EFGM. J Mech Sci Technol. 2011;25:403-13.

[80] Vikrant KSN, Ramareddy GV, Pavan AHV, Singh K. Estimation of residual life of boiler tubes using steamside oxide scale thickness. International Journal of Pressure Vessels and Piping. 2013;104:69-75.

[81] Ellison EG, Al-Zamily A. Fracture and Life Prediction Under Thermal- Mechanical Strain Cycling. Fatigue Fracture of Engineering Materials and Structures. 1994;17:53-67. 
[82] Halford G. Brief Summary of the Evolution of High-Temperature Creep-Fatigue Life Prediction Models for Crack Initiation. NASA-CP-3230. 1993;1:121-50.

[83] Lansinger J, Hansson T, Clevfors O. Fatigue crack growth under combined thermal cycling and mechanical loading. International Journal of Fatigue. 2007;29:1383-90.

[84] Choi B-H, Chudnovsky A, Sehanobish K. Stress Corrosion Cracking in Plastic Pipes: Observation and Modeling. International Journal of Fracture. 2007;145:81-8.

[85] Choi B-H, Chudnovsky A, Paradkar R, Michie W, Zhou Z, Cham P-M. Experimental and theoretical investigation of stress corrosion crack (SCC) growth of polyethylene pipes. Polymer Degradation and Stability. 2009;94:859-67.

[86] Hogg PJ. A model for stress corrosion crack growth in glass reinforced plastics. Composites Science and Technology. 1990;38:23-42.

[87] Akhtar A, Wong JY. Failure Analysis of Brittle Fracture in Nonceramic Insulators. Journal of Composites Technology and Research. 1987;9:95-100.

[88] Chughtai AR, Smith DM, Kumosa MS. Chemical analysis of a field-failed composite suspension insulator. Composites Science and Technology. 1998;58:1641-7.

[89] Harris SJ, Nobel B, Owen MJ. Metallographic investigation of the damage caused to GRP by the combined action of electrical, mechanical and chemical environments. Journal of Materials Science. 1984;19:1596-604.

[90] Kumosa M, Narayan HS, Qiu Q, Bansal A. Brittle fracture of non-ceramic suspension insulators with epoxy cone end-fittings. Composites Science and Technology. 1997;57:739-51.

[91] Noble B, Harris SJ, Owen MJ. Stress corrosion cracking of GRP pultruded rods in acid environments. Journal of Materials Science. 1983;18:1244-54.

[92] Owen MJ, Harris SJ, Noble B. Failure of high voltage electrical insulators with pultruded glass fibrereinforced plastic cores. Composites. 1986;17:217-26.

[93] Dai J, Yao X, Liang X, Yeh HY. Experimental study of microcracks in stress corrosion of fibre reinforced composites. Polymer Testing. 2006;25:758-65.

[94] Megel M, Kumosa L, Ely T, Armentrout D, Kumosa M. Initiation of stress-corrosion cracking in unidirectional glass/polymer composite materials. Composites Science and Technology. 2001;61:231-46.

[95] Akdemir A, Tarakcioglu N, Avci A. Stress corrosion crack growth in glass/polyester composites with surface crack. Composites Part B: Engineering. 2001;32:123-9.

[96] Kumosa L, Armentrout D, Kumosa M. An evaluation of the critical conditions for the initiation of stress corrosion cracking in unidirectional E-glass/polymer composites. Composites Science and Technology. 2001;61:615-23.

[97] Kumosa L, Armentrout D, Kumosa M. The effect of sandblasting on the initiation of stress corrosion cracking in unidirectional E-glass/polymer composites used in high voltage composite (non-ceramic) insulators. Composites Science and Technology. 2002;62:1999-2015.

[98] Kumosa L, Kumosa M, Armentrout D. Resistance to stress corrosion cracking of unidirectional ECRglass/polymer composites for high voltage composite insulator applications. Composites Part A: Applied Science and Manufacturing. 2003;34:1-15.

[99] Tsotsis TK, Lee SM. Long-term thermo-oxidative aging in composite materials: Failure mechanisms. Composites Science and Technology. 1998;58:355-68.

[100] Olivier L, Ho NQ, Grandidier JC, Lafarie-Frenot MC. Characterization by ultra-micro indentation of an oxidized epoxy polymer: Correlation with the predictions of a kinetic model of oxidation. Polymer Degradation and Stability. 2008;93:489-97.

[101] Colin X, Marais C, Verdu J. A new method for predicting the thermal oxidation of thermoset matrices: Application to an amine crosslinked epoxy. Polymer Testing. 2001;20:795-803. 
[102] Lafarie-Frenot MC, Grandidier JC, Gigliotti M, Olivier L, Colin X, Verdu J, et al. Thermo-oxidation behaviour of composie materials at high temperatures: A review of research activities carried out within the COMEDI program. Polymer Degradation and Stability. 2010;95:965-74.

[103] Bowles KJ, Nowak G. Thermo-oxidative stability studies of celion 6000/PMR-15 unidirectional composites, PMR-15, and celion 6000 Fiber. Journal of Composite Materials. 1988;22:966-85.

[104] Colin X, Marais C, Verdu J. Kinetic modelling of the stabilizing effect of carbon fibres on thermal ageing of thermoset matrix composites. Composites Science and Technology. 2005;65:117-27.

[105] Pochiraju KV, Tandon GP, Schoeppner GA. Evolution of stress and deformations in hightemperature polymer matrix composites during thermo-oxidative aging. Mech Time-Depend Mater. 2008;12:45-68.

[106] Gigliotti M, Olivier L, Vu DQ, Grandidier J-C, Lafarie-Frenot MC. Local shrinkage and stress induced by thermo-oxidation in composite materials at high temperatures. Journal of the Mechanics and Physics of Solids. 2011;59:696-712.

[107] Olivier L, Baudet C, Bertheau D, Grandidier JC, Lafarie-Frenot MC. Development of experimental, theoretical and numerical tools for studying thermo-oxidation of CFRP composites. Composites Part A: Applied Science and Manufacturing. 2009;40:1008-16.

[108] Vu DQ, Gigliotti M, Lafarie-Frenot MC. Experimental characterization of thermo-oxidation-induced shrinkage and damage in polymer-matrix composites. Composites Part A: Applied Science and Manufacturing. 2012;43:577-86.

[109] Colin X, Verdu J. Strategy for studying thermal oxidation of organic matrix composites. Composites Science and Technology. 2005;65:411-9.

[110] Colin X, Mavel A, Marias C, Verdu J. Interaction between cracking and oxidation in organic matrix composites. Journal of Composite Materials. 2005;39:1371-89.

[111] Roy S. Prediction of Anomalous Hygrothermal Effects in Polymer Matrix Composites. Journal of Reinforced Plastics and Composites. 1999;18:1197-207.

[112] Madhukar MS, Bowles KJ, Papadopoulos DS. Thermo-oxidative stability and fiber surface modification effects on the inplane shear properties of graphite/PMR-15 composites Journal of Composite Materials. 1997;31:596-618.

[113] Rouquie S, Lafarie-Frenot MC, Cinquin J, Colombaro AM. Thermal cycling of carbon/epoxy laminates in neutral and oxidative environments. Composites Science and Technology. 2005;65:403-9.

[114] Lafarie-Frenot MC, Rouquie S. Influence of oxidative environments on damage in c/epoxy laminates subjected to thermal cycling. Composite Science and Technology. 2004;64:1725-35.

[115] Tandon GP, Pochiraju KV. Heterogeneous thermo-oxidative behaviour of multidirectional laminated composites. Journal of Composite Materials. 2011;45:415-35.

[116] Vu D-Q, Gigliotti M, Lafarie-Frenot MC. The effect of thermo-oxidation on matrix cracking of crossply [0/90]S composite laminates. Composites Part A: Applied Science and Manufacturing. 2013;44:11421.

[117] Gu X, Michaels C, Drzal P, Jasmin J, Martin D, Nguyen T, et al. Probing photodegradation beneath the surface: a depth profiling study of UV-degraded polymeric coatings with microchemical imaging and nanoindentation. J Coat Technol Res. 2007;4:389-99.

[118] Kumar BG, Singh RP, Nakamura T. Degradation of Carbon Fiber-Reinforced Epoxy Composites by Ultraviolet Radiation and Condensation. Journal of Composite Materials. 2002;36:2713-33.

[119] Awaja F, Nguyen M-T, Zhang S, Arhatari B. The investigation of inner structural damage of UV and heat degraded polymer composites using X-ray micro CT. Composites Part A: Applied Science and Manufacturing. 2011;42:408-18. 
[120] Iskanderova Z, Kleiman J, Gudimenko Y, Tennyson RC, Morison WD. Comparison of surface modification of polymeric materials for protection from severe oxidative environments using different ion sources. Surface and Coatings Technology. 2000;127:18-23.

[121] Xiang J, Wang J, Chen X, Lei J. Formation mechanism of microvoids and microcracks of poly(vinyl chloride) under an artificial aging environment. Journal of Applied Polymer Science. 2012;125:291-9.

[122] Decelle J, Huet N, Bellenger V. Oxidation induced shrinkage for thermally aged epoxy networks. Polymer Degradation and Stability. 2003;81:239-48.

[123] Lafarie-Frenot MC, Rouquié S, Ho NQ, Bellenger V. Comparison of damage development in $\mathrm{C} /$ epoxy laminates during isothermal ageing or thermal cycling. Composites Part A: Applied Science and Manufacturing. 2006;37:662-71.

[124] Chang LN, Chow WS. Accelerated Weathering on Glass Fiber/Epoxy/Organo-montmorillonite Nanocomposites. Journal of Composite Materials. 2010;44:1421-34.

[125] Awaja F, Pigram PJ. Surface molecular characterisation of different epoxy resin composites subjected to UV accelerated degradation using XPS and ToF-SIMS. Polymer Degradation and Stability. 2009;94:651-8.

[126] Aditya PK, Sinha PK. Diffusion Coefficients of Polymeric Composites Subjected to Periodic Hygrothermal Exposure. Journal of Reinforced Plastics and Composites. 1992;11:1035-47.

[127] Sawpan MA, Holdsworth PG, Renshaw P. Glass transitions of hygrothermal aged pultruded glass fibre reinforced polymer rebar by dynamic mechanical thermal analysis. Materials and Design. 2012;42:272-8.

[128] Dag S, Yildirim B, Arslan O, Arman EE. Hygrothermal fracture analysis of orthotropic materials using Jk integral. Journal of Thermal Stresses. 2012;35:596-613.

[129] Robert M, Roy R, Benmokrane B. Environmental effects on glass fibre reinforced polypropylene thermoplastic composites laminates for structural applications. Polymer Composites. 2010;31:604-11.

[130] Aronhime MT, Neumann S, Marom G. The anisotropic diffusion of water in kevlar epoxy composites. Journal of Materials Science. 1987;22:2435-6.

[131] Leman Z, Sapuan SM, Saifol AM, Maleque MA, Ahmad MMHM. Moisture absorption behaviour of sugar plam fibre reinforced epoxy composites. Materials and Design. 2008;29:1666-70.

[132] Jana RN, Bhunia H. Hygrothermal degradation of the composite laminates from woven carbon/SC15 epoxy resin and woven glass/SC-15 epoxy resin. Polymer Composites. 2008;29:664-9.

[133] Ray BC. Temperature effect during humid ageing on interfaces of glass and carbon fibers reinforced epoxy composites. Journal of Colloid and Interface Science. 2006;298:111-7.

[134] Slater C, Davis C, Strangwood M. Compression set of thermoplastic polyurethane under different thermal-mechanical-moisture conditions. Polymer Degradation and Stability. 2011;96:2139-44.

[135] Badia JD, Santonja-Blasco L, Martinez-Felipe A, Ribes-Greus A. Hygrothermal ageing of reprocessed polylactide. Polymer Degradation and Stability. 2012;97:1881-90.

[136] Miller SG, Roberts GD, Bail JL, Kohlman LW, Binienda WK. Effects of hygrothermal cycling on the chemical, thermal, and mechanical properties of 862/W epoxy resin. High Perform Polym. 2012;24:4707.

[137] Phua YJ, Chow WS, Mohd Ishak ZA. The hydrolytic effect of moisture and hygrothermal aging on poly(butylene succinate)/organo-montmorillonite nanocomposites. Polymer Degradation and Stability. 2011;96:1194-203.

[138] Jiang $\mathrm{X}$, Kolstein $\mathrm{H}$, Bijlaard FSK. Moisture diffusion and hygrothermal aging in pultruded fibre reinforced polymer composites of bridge decks. Mater Des. 2012;37:304-12.

[139] Ben Daly H, Ben Brahim H, Hfaied N, Harchay M, Boukhili R. Investigation of water absorption in pultruded composites containing fillers and low profile additives. Polymer Composites. 2007;28:355-64. 
[140] Ben Daly H, Harchay M, Belhadjsalah H, Boukhili R. Experimental Characterization and Numerical Simulation of the Humidity Absorption Process in Glass Reinforced Composites Under Dissymmetric Exposure Conditions. Polymer Composites. 2009;30:1825-36.

[141] Eslami S, Taheri-Behrooz F, Taheri F. Long-term hygrothermal response of perforated GFRP plates with/without application of constant external loading. Polymer Composites. 2012;33:467-75.

[142] Papanicolaou GC, Kosmidou TV, Vatalis AS, Delides CG. Water absorption mechanism and some anomalous effects on the mechanical and viscoelastic behavior of an epoxy system. Journal of Applied Polymer Science. 2006;99:1328-39.

[143] Davies P, Evrard G. Accelerated ageing of polyurethanes for marine applications. Polymer Degradation and Stability. 2007;92:1455-64.

[144] Gac PYL, Saux VL, Paris M, Marco Y. Ageing mechanism and mechanical degradation behaviour of polychloroprene rubber in a marine environment: Comparison of accelerated ageing and long term exposure. Polymer Degradation and Stability. 2012;97:288-96.

[145] Mouritz AP. Environmental durability of z-pinned carbon fibre-epoxy laminate exposed to water. Composites Science and Technology. 2012;72:1568-74.

[146] Visco AM, Campo N, Cianciafara P. Comparison of seawater absorption properties of thermoset resins based composites. Compos Pt A-Appl Sci Manuf. 2011;42:123-30.

[147] Davies P, MazÉas F, Casari P. Sea water aging of glass reinforced composites: Shear behaviour and damage modeling. Journal of Composite Materials. 2001;35:1343-73.

[148] Mouzakis DE, Zoga H, Galiotis C. Accelerated environmental ageing study of polyester/glass fiber reinforced composites (GFRPCS). Composites Part B: Engineering. 2008;39:467-75.

[149] Kawagoe M, Doi Y, Fuwa N, Yasuda T, Takata K. Effects of absorbed water on the interfacial fracture between layers of unsaturated polyester and glass. Journal of Materials Science. 2011;36:51617.

[150] Collette SA, Sutton MA, Miney P, Reynolds AP, Xiaodong L, Colavita PE, et al. Development of patterns for nanoscale strain measurements: I. Fabrication of imprinted Au webs for polymeric materials. Nanotechnology. 2004;15:1812-7.

[151] Gheorghiu C, Labossiére P, Proulx J. Fiber Optic Sensors for Strain Measurement of CFRPstrengthened RC Beams. Structural Health Monitoring. 2005;4:67-80.

[152] Belarbi A, Watkins SE, Chandrashekhara K, Corra J, Konz B. Smart fiber-reinforced polymer rods featuring improved ductility and health monitoring capabilities. Smart Materials and Structures. 2001;10:427-31.

[153] Berfield TA, Patel JK, Shimmin RG, Braun PV, Lambros J, Sottos NR. Fluorescent Image Correlation for Nanoscale Deformation Measurements. Small. 2006;2:631-5.

[154] Lestari W, Qiao P. Damage detection of fiber-reinforced polymer honeycomb sandwich beams. Composite Structures. 2005;67:365-73.

[155] Rizzo P, Scalea FLd. Acoustic emission monitoring of carbon-fiber-reinforced-polymer bridge stay cables in large-scale testing. Experimental Mechanics. 2001;41:282-90.

[156] Ratcliffe CP, Bagaria WJ. Vibration technique for locating delamination in a composite beam. American Institute of Aeronautics and Astronautics. 1998;36:1074-7.

[157] Miceli M, Duke JC, Hornet M. Health monitoring of fiber reinforced polymer bridge decks with infrared thermography. Materials Evaluation. 2002;60:1245-52.

[158] Samuel BA, Demirel MC, Haque A. High resolution deformation and damage detection using fluorescent dyes. Journal of Micromechanics and Microengineering. 2007;17:2324-7. 
[159] Gammon LM. Polymeric composites, morphological characterisation and fracture analysis: Fluorescent, dark field, bright field and polarized light optical microscopy. Microscopy and Microanalysis. 2004;10:740-1.

[160] Hayes BS, Gammon LM. Optical Microscopy of Fiber Reinforced Composites. ASM International; 2010. p. 261.

[161] Huang D, Swanson EA, Lin CP, Schuman JS, Stinson WG, Chang W, et al. Optical Coherence Tomography. Science. 1991;254:1178-81.

[162] Stifter D. Beyond biomedicine: a review of alternative applications and developments for optical coherence tomography. Appl Phys B. 2007;88:337-57.

[163] Wiesauer K, Pircher M, Götzinger E, Hitzenberger CK, Oster R, Stifter D. Investigation of glass-fibre reinforced polymers by polarisation-sensitive, ultra-high resolution optical coherence tomography: Internal structures, defects and stress. Composites Science and Technology. 2007;67:3051-8.

[164] Sato N, Kurauchi T, Sato S, Kamigaito O. SEM observations of the initiation and propagation of cracks in a short fibre-reinforced thermoplastic composite under stress. Journal of Materials Science Letters. 1983;2:188-90.

[165] Purslow D. Fractography of fibre-reinforced thermoplastics, Part 3. Tensile, compressive and flexural failures. Composites. 1988;19:358-66.

[166] Adams RD, Cawley P. A review of defect types and nondestructive testing techniques for composites and bonded joints. NDT International. 1988;21:208-22.

[167] Huguet S, Godin N, Gaertner R, Salmon L, Villard D. Use of acoustic emission to identify damage modes in glass fibre reinforced polyester. Composites Science and Technology. 2002;62:1433-44.

[168] Kinra VK, Ganpatye AS, Maslov K. Ultrasonic Ply-by-Ply Detection of Matrix Cracks in Laminated Composites. Journal of Nondestructive Evaluation. 2006;25:37-49.

[169] Mouritz AP, Townsend C, Shah Khan MZ. Non-destructive detection of fatigue damage in thick composites by pulse-echo ultrasonics. Composites Science and Technology. 2000;60:23-32.

[170] Maslov K, Kim RY, Kinra VK, Pagano NJ. A new technique for the ultrasonic detection of internal transverse cracks in carbon-fibre/bismaleimide composite laminates. Composites Science and Technology. 2000;60:2185-90.

[171] Parnasov VS, Dobromyslov VA. NDT methods, equipment, and technology for polymer composite products. Measurements Techniques. 1997;40:1076-83.

[172] Schilling PJ, Karedla BR, Tatiparthi AK, Verges MA, Herrington PD. X-ray computed microtomography of internal damage in fiber reinforced polymer matrix composites. Composites Science and Technology. 2005;65:2071-8.

[173] Beier U, Fischer F, Sandler JKW, Altstädt V, Weimer C, Buchs W. Mechanical performance of carbon fibre-reinforced composites based on stitched preforms. Composites Part A: Applied Science and Manufacturing. 2007;38:1655-63.

[174] Awaja F, Arhatari BD. X-ray Micro Computed Tomography investigation of accelerated thermal degradation of epoxy resin/glass microsphere syntactic foam. Composites Part A: Applied Science and Manufacturing. 2009;40:1217-22.

[175] Liotier P-J, Alain V, Christine D. Characterization of 3D morphology and microcracks in composites reinforced by multi-axial multi-ply stitched preforms. Composites Part A: Applied Science and Manufacturing. 2010;41:653-62.

[176] Bayraktar E, Bessri K, Bathias C. Deformation behaviour of elastomeric matrix composites under static loading conditions. Engineering Fracture Mechanics. 2008;75:2695-706. 
[177] Sket F, Seltzer R, Molina-Aldareguía JM, González C, Llorca J. Determination of damage micromechanisms and fracture resistance of glass fiber/epoxy cross-ply laminate by means of X-ray computed microtomography. Composites Science and Technology. 2012;72:350-9.

[178] Tan KT, Watanabe N, Iwahori Y. X-ray radiography and micro-computed tomography examination of damage characteristics in stitched composites subjected to impact loading. Composites Part B: Engineering. 2011;42:874-84.

[179] Zhu P, Duvauchelle P, Peix G, Babot D. X-ray Compton backscattering techniques for process tomography: imaging and characterization of materials Measurements Science and Technology 1996;7:281-6.

[180] Babot D, Berodias G, Peix G. Detection and Sizing by X-ray Compton Scattering of Near-surface Cracks under Weld Deposited Cladding. NDT\&E International. 1991;24:247-51.

[181] Lawson L. Compton X-ray Backscatter Depth Profilometry for Aircraft Corrosion Inspection. Materials Evaluation. 1995;53:936-41.

[182] Niemann W, Zahorodny S. Status and Future Aspects of X-ray Backscattering Imaging. Review of Progress in Quantitative Nondestructive Evaluation. 1998;17A:379-85.

[183] Summerscales J. Non-destructive testing of advanced composites: A review of recent advances. British Journal of Non-Destructive Testing. 1990;32:568-77.

[184] Henneke EG, Jones TS. Detection of damage in composite materials by vibrothermography. In: Pipes RB, editor. Nondestructive evaluation andflaw criticality for composite materials: ASTM STP696, (ASTM, Philadelphia); 1979. p. 83-95.

[185] Cho SH, Andersson HM, White SR, Sottos NR, Braun PV. Polydimethylsiloxane-Based Self-Healing Materials. Advanced Materials. 2006;18:997-1000.

[186] Maiti S, Geubelle PH. Cohesive modeling of fatigue crack retardation in polymers: Crack closure effect. Engineering Fracture Mechanics. 2006;73:22-41.

[187] Brown EN, White SR, Sottos NR. Retardation and repair of fatigue cracks in microcapsule toughened epoxy composites-part I: manual infiltration. Composite Science and Technology. 2005;65:2466-73.

[188] Blaiszik BJ, Sottos NR, White SR. Nanocapsules for self-healing materials. Composites Science and Technology. 2008;68:978-86.

[189] Trask RS, Williams HR, Bond IP. Self-healing polymer composites: mimicking nature to enhance performance Bioinspiration and Biomimetics. 2007;2:P1-9.

[190] Bleay SM, Loader CB, Hawyes VJ, Humberstone L, Curtis PT. A smart repair system for polymer matrix composites. Composites, Part A: Applied Science and Manufacturing. 2001;32:1767-76.

[191] Trask RS, Williams GJ, Bond IP. Bioinspired self-healing of advanced composite structures using hollow glass fibres. Journal of Royal Society Interface. 2007; 4:363-71

[192] Bergman SD, Wudl F. Mendable polymers. Journal of Material Chemistry. 2008;18:41-62.

[193] Syrett JA, Becer CR, Haddleton DM. Self-healing and self-mendable polymers. Polymer Chemistry. 2010;1:978-87.

[194] Chen X, Dam MA, Ono K, Mal A, Shen H, Nutt SR, et al. A thermally remendable cross-linked polymeric material. Science. 2002;295:1698-702.

[195] Chen X, Wudl F, Mal AK, Shen H, Nutt SR. New thermally remendable highly cross-linked polymeric materials. Macromolecules. 2003;36:1802-7.

[196] Hayes SA, Zhang W, Branthwaite M, Jones FR. Self-healing of damage in fiber-reinforced polymermatrix composites. Journal of Royal Society Interface. 2007;4:381-87.

[197] Hayes SA, Jones FR, Marshiya K, Zhang W. A self-healing thermosetting composite material. Composites Part A: Applied Science and Manufacturing. 2007;38:1116-20. 
[198] Luo XF, Ou R, Eberly DE, Singhal A, Viratyaporn W, Mather PT. A thermoplastic/thermoset blend exhibiting thermal mending and reversible adhesion. ACS Applied Materials Interfaces. 2009;1:612-20.

[199] Kalista SJ, Ward TC, Oyetunji Z. Self-healing of poly(ethylene-comethacrylic acid) copolymers following projectile puncture. Mechanics of Advanced Materials and Structure. 2007;14:391-97.

[200] Kalista SJ, Ward TC. Thermal characteristics of the self-healing response in poly(ethylenecomethacrylic acid) copolymers. Journal of Royal Society Interface. 2007;4:405-11.

[201] Varley RJ, Zwaag Svd. Towards an understanding of thermally activated self-healing of an ionomer system during ballistic penetration. Acta Material. 2008;56:5737-50.

[202] Varley RJ, Zwaag Svd. Development of a quasi-static test method to investigate the origin of selfhealing in ionomers under ballistic conditions. Polymer Testing. 2008;27:11-9.

[203] Hargou K, Pingkarawat K, Mourtiz AP, Wang CH. Ultrasonic activation of mendable polymer for self-healing carbon-epoxy laminates. Composite Part B: Engineering. 2012;45:1031-9.

[204] Meure S, Furman S, Khor S. Poly[ethylene-co-(methacrylic acid)] healing agent for mendable carbon fibre laminates. Macromolecular Materials and Engineering. 2010;295:420-4.

[205] Varley RJ, Parn GP. Thermally activated healing in a mendable resin using a non woven EMAA fabric. Composite Science and Technology. 2012;72:453-60.

[206] Takeda K, Tanahashi M, Unno H. Self-repairing mechanism of plastics. Science and Technology of Advanced Materials. 2003;4:435-44.

[207] Aramaki K. Preparation of chromate-free, self-healing polymer films containing sodium silicate on zinc pretreated in a cerium(III) nitrate solution for preventing zinc corrosion at scratches in $0.5 \mathrm{M} \mathrm{NaCl}$. Corrosion Science. 2002;44:1375-89.

[208] Chudnovsky A. Slow crack growth, its modeling and crack-layer approach: A review. International Journal of Engineering Science. 2014;83:6-41.

[209] Giesa T, Pugno NM, Wong JY, Kaplan DL, Buehler MJ. What's Inside the Box? - Length-Scales that Govern Fracture Processes of Polymer Fibers. Advanced Materials. 2014;26:412-7.

[210] Griffith AA. The Phenomena of Rupture and Flow in Solids1921.

[211] Taylor D, Cornetti P, Pugno N. The fracture mechanics of finite crack extension. Engineering Fracture Mechanics. 2005;72:1021-38.

[212] Pugno NM. The role of defects in the design of space elevator cable: From nanotube to megatube. Acta Materialia. 2007;55:5269-79.

[213] Pugno NM. Quantized Mechanics of Nanotubes and Bundles. In: Bhushan B, editor. Scanning Probe Microscopy in Nanoscience and Nanotechnology: Springer Berlin Heidelberg; 2010. p. 487-506.

[214] Pugno NM, Ruoff RS. Quantized fracture mechanics. Philosophical Magazine. 2004;84:2829-45.

[215] Rice JR. Fracture Mechanics. Applied Mechanics Reviews. 1985;38:1271-5.

[216] Gross D, Seelig T. Fracture Mechanics: With an Introduction to Micromechanics. Second Edition ed: Springer-Verlag Berlin Heidelberg; 2011.

[217] Friedrich K. Application of Fracture Mechanics to Composite Materials. In: Klaus F, editor. Composite Materials Series: Elsevier; 1989. p. v-vii.

[218] Dharan C. Fracture mechanics of composite materials. Journal of engineering materials and technology. 1978;100:233-47.

[219] Renner K, Móczó J, Pukánszky B. Deformation and failure of PP composites reinforced with lignocellulosic fibers: Effect of inherent strength of the particles. Composites Science and Technology. 2009;69:1653-9.

[220] Tim AO, Georg M. Failure and Damage of Polymers. Materials Science of Polymers for Engineers: Carl Hanser Verlag GmbH \& Co. KG; 2012. p. 423-87. 
[221] Takeno A, Miwa M, Yokoi T, Naito K, Merati AA. A new technique for generating regularly spaced crazes to facilitate piece dyeing of polypropylene filaments. Journal of Applied Polymer Science. 2013;128:3564-9.

[222] Takeno A, Nakagaki N, Miwa M. Anisotropic transparency of polystyrene film with crazes. Advanced Composite Materials. 1998;7:35-46.

[223] Williams JG. Fracture mechanics of polymers. Polymer Engineering \& Science. 1977;17:144-9.

[224] Bucknall CB. New criterion for craze initiation. Polymer. 2007;48:1030-41.

[225] Mills NJ. Craze growth and craze interactions. Journal of Materials Science. 1981;16:1332-42.

[226] Sha Y, Hui CY, Ruina A, Kramer EJ. Continuum and Discrete Modeling of Craze Failure at a Crack Tip in a Glassy Polymer. Macromolecules. 1995;28:2450-9.

[227] Luo W, Liu W. Incubation time to crazing in stressed poly(methyl methacrylate). Polymer Testing. 2007;26:413-8.

[228] Sha Y, Hui CY, Ruina A, Kramer EJ. Detailed simulation of craze fibril failure at a crack tip in a glassy polymer. Acta Materialia. 1997;45:3555-63.

[229] Hui CY, Ruina A, Creton C, Kramer EJ. Micromechanics of crack growth into a craze in a polymer glass. Macromolecules. 1992;25:3948-55.

[230] Hui CY, Kramer EJ. Molecular weight dependence of the fracture toughness of glassy polymers arising from crack propagation through a craze. Polymer Engineering \& Science. 1995;35:419-25.

[231] Cho K, Lee MS, Park CE. The effect of Freon vapour on fracture behaviour of styrene-acrylonitrile copolymer - I. Craze initiation behaviour. Polymer. 1998;39:1357-61.

[232] Henry LF. Prediction and evaluation of the susceptibilities of glassy thermoplastics to environmental stress cracking. Polymer Engineering \& Science. 1974;14:167-76.

[233] van Melick HGH, Bressers OFJT, den Toonder JMJ, Govaert LE, Meijer HEH. A micro-indentation method for probing the craze-initiation stress in glassy polymers. Polymer. 2003;44:2481-91.

[234] Spiegelberg SH, Argon AS, Cohen RE. Measurements of craze velocities in polystyrenepolybutadiene blends. Journal of Applied Polymer Science. 1993;48:85-97.

[235] Trent J, Miles M, Baer E. The mechanical behaviour of high-impact polystyrene under pressure. Journal of Materials Science. 1979;14:789-99.

[236] Breen J, Van Dijk DJ. Environmental stress cracking of PVC: Effects of natural gas with different amounts of benzene. Journal of Materials Science. 1991;26:5212-20.

[237] Maxwell B, Rahm LF. Rheological Properties of Polystyrene below $80^{\circ} \mathrm{C}$. Industrial \& Engineering Chemistry. 1949;41:1988-93.

[238] Sabu T, Gabriel G, Charef H. Micro- and Nanostructured Polymer Blends. Micro- and Nanostructured Multiphase Polymer Blend Systems: CRC Press; 2005. p. 1-42.

[239] Shang S, Chiu K-I, Yuen CWM, Jiang S, Hu E. The potential of yeast as eco-filler for waterborne polyurethane and its reinforcing mechanism. European Polymer Journal. 2014;60:6-13.

[240] Koyanagi J, Sato Y, Sasayama T, Okabe T, Yoneyama S. Numerical simulation of strain-rate dependent transition of transverse tensile failure mode in fiber-reinforced composites. Composites Part A: Applied Science and Manufacturing. 2014;56:136-42.

[241] Sun Z, Zhao L, Chen L, Song Y. Research on failure criterion of composite based on unified macroand micro-mechanical model. Chinese Journal of Aeronautics. 2013;26:122-9.

[242] Ye J, Qiu Y, Chen X, Ma J. Initial and final failure strength analysis of composites based on a micromechanical method. Composite Structures. 2015;125:328-35.

[243] Lee S-Y, Roh J-H. Two-dimensional strain-based interactive failure theory for multidirectional composite laminates. Composites Part B: Engineering. 2015;69:69-75. 
[244] Novozhilov VV. On a necessary and sufficient criterion for brittle strength. Journal of Applied Mathematics and Mechanics. 1969;33: 212-22.

[245] Carpinteri A, Pugno N. Cracks and re-entrant corners in functionally graded materials. Engineering Fracture Mechanics. 2006;73:1279-91.

[246] Dewapriya MAN, Rajapakse RKND, Phani AS. Atomistic and continuum modelling of temperaturedependent fracture of graphene. International Journal of Fracture. 2014;187:199-212.

[247] Pugno NM. Dynamic quantized fracture mechanics. International Journal of Fracture. 2006;140:159-68.

[248] Chen Q, Baino F, Pugno NM, Vitale-Brovarone C. Bonding strength of glass-ceramic trabecular-like coatings to ceramic substrates for prosthetic applications. Materials Science and Engineering: $\mathrm{C}$. 2013;33:1530-8.

[249] Johnson DP, Morton J, Kellas S, Jackson K. Scaling Effects in Sublaminate-Level Scaled Composite Laminates. AIAA Journal. 1998;36:441-7.

[250] Wisnom MR, Khan B, Hallett SR. Size effects in unnotched tensile strength of unidirectional and quasi-isotropic carbon/epoxy composites. Composite Structures. 2008;84:21-8.

[251] Miwa M, Horiba N. Effects of fibre length on tensile strength of carbon/glass fibre hybrid composites. Journal of Materials Science. 1994;29:973-7.

[252] Reis JML, Coelho JLV, Monteiro AH, da Costa Mattos HS. Tensile behavior of glass/epoxy laminates at varying strain rates and temperatures. Composites Part B: Engineering. 2012;43:2041-6.

[253] Shang S, Chiu K-L, Yuen MCW, Jiang S. The potential of cuttlebone as reinforced filler of polyurethane. Composites Science and Technology. 2014;93:17-22.

[254] Saint-Michel F, Pignon F, Magnin A. Rheometric properties of micron-sized CaCO3 suspensions stabilised by a physical polyol/silica gel for polyurethane foams. Rheol Acta. 2005;44:644-53.

[255] Pegoretti A, Dorigato A, Brugnara M, Penati A. Contact angle measurements as a tool to investigate the filler-matrix interactions in polyurethane-clay nanocomposites from blocked prepolymer. European Polymer Journal. 2008;44:1662-72.

[256] Gao X, Zhu Y, Zhou S, Gao W, Wang Z, Zhou B. Preparation and characterization of well-dispersed waterborne polyurethane/CaCO3 nanocomposites. Colloids and Surfaces A: Physicochemical and Engineering Aspects. 2011;377:312-7.

[257] Shang S, Zeng W, Tao X-m. High stretchable MWNTs/polyurethane conductive nanocomposites. Journal of Materials Chemistry. 2011;21:7274-80.

[258] Chen G, Zhou S, Gu G, Yang H, Wu L. Effects of surface properties of colloidal silica particles on redispersibility and properties of acrylic-based polyurethane/silica composites. Journal of Colloid and Interface Science. 2005;281:339-50.

[259] Ciobanu C, Ungureanu M, Ignat L, Ungureanu D, Popa VI. Properties of lignin-polyurethane films prepared by casting method. Industrial Crops and Products. 2004;20:231-41.

[260] El-Shekeil YA, Sapuan SM, Jawaid M, Al-Shuja'a OM. Influence of fiber content on mechanical, morphological and thermal properties of kenaf fibers reinforced poly(vinyl chloride)/thermoplastic polyurethane poly-blend composites. Mater Des. 2014;58:130-5.

[261] Zhu X-K, Joyce JA. Review of fracture toughness (G, K, J, CTOD, CTOA) testing and standardization. Engineering Fracture Mechanics. 2012;85:1-46.

[262] Launey ME, Ritchie RO. On the Fracture Toughness of Advanced Materials. Advanced Materials. 2009;21:2103-10.

[263] Kanchanomai C, Rattananon S, Soni M. Effects of loading rate on fracture behavior and mechanism of thermoset epoxy resin. Polymer Testing. 2005;24:886-92. 
[264] Boesl BP, Bourne GR, Sankar BV. Insitu multiscale analysis of fracture mechanisms in nanocomposites. Composites Part B: Engineering. 2011;42:1157-63.

[265] Brighenti R, Carpinteri A, Scorza D. Stress-intensity factors at the interface edge of a partially detached fibre. Theoretical and Applied Fracture Mechanics. 2013;67-68:1-13.

[266] Subramaniyan AK, Sun CT. Toughening polymeric composites using nanoclay: Crack tip scale effects on fracture toughness. Composites Part A: Applied Science and Manufacturing. 2007;38:34-43.

[267] Alicia Salazar, Yatish Patel, Williams JG. Influence of crack sharpness on the fracture toughness of epoxy resins. 13th International Conference on Fracture. Beijing, China2013. p. 1-10.

[268] Krishnan A, Roy Xu L. An experimental study on the crack initiation from notches connected to interfaces of bonded bi-materials. Engineering Fracture Mechanics. 2013;111:65-76.

[269] O'Brien DJ, Parquette B. Polymer toughness transfer in a transparent interpenetrating glasspolymer composite. Composites Science and Technology. 2012;73:57-63.

[270] Lee J, Yee AF. Role of inherent matrix toughness on fracture of glass bead filled epoxies. Polymer. 2000;41:8375-85.

[271] Argon AS, Cohen RE. Toughenability of polymers. Polymer. 2003;44:6013-32.

[272] Chasiotis I, Knauss WG. The mechanical strength of polysilicon films: Part 2. Size effects associated with elliptical and circular perforations. Journal of the Mechanics and Physics of Solids. 2003;51:1551-72. [273] Schapery RA. On some path independent integrals and their use in fracture of nonlinear viscoelastic media. In: Knauss WG, Rosakis AJ, editors. Non-Linear Fracture: Springer Netherlands; 1990. p. 189-207.

[274] Varna J, Joffe R, Berglund LA. Interfacial toughness evaluation from the single-fiber fragmentation test. Composites Science and Technology. 1996;56:1105-9.

[275] Rice JR. A Path Independent Integral and the Approximate Analysis of Strain Concentration by Notches and Cracks. Journal of Applied Mechanics. 1968;35:379-86.

[276] Rice JR, Paris PC, Merkle JG. Some Further Results of J-Integral Analysis and Estimates. Progress in Flaw Growth and Fracture Toughness Testing1973. p. 231-45.

[277] Rink M, Andena L, Marano C. The essential work of fracture in relation to J-integral. Engineering Fracture Mechanics. 2014;127:46-55.

[278] Salazar A, Rodríguez J, Segovia A, Martínez AB. Influence of the notch sharpening technique on the fracture toughness of bulk ethylene-propylene block copolymers. Polymer Testing. 2010;29:49-59.

[279] Bárány T, Czigány T, Karger-Kocsis J. Application of the essential work of fracture (EWF) concept for polymers, related blends and composites: A review. Progress in Polymer Science. 2010;35:1257-87.

[280] Wetzel B, Rosso P, Haupert F, Friedrich K. Epoxy nanocomposites - fracture and toughening mechanisms. Engineering Fracture Mechanics. 2006;73:2375-98.

[281] Ma J, Mo M-S, Du X-S, Rosso P, Friedrich K, Kuan H-C. Effect of inorganic nanoparticles on mechanical property, fracture toughness and toughening mechanism of two epoxy systems. Polymer. 2008;49:3510-23.

[282] Johnsen BB, Kinloch AJ, Mohammed RD, Taylor AC, Sprenger S. Toughening mechanisms of nanoparticle-modified epoxy polymers. Polymer. 2007;48:530-41.

[283] Hsieh TH, Kinloch AJ, Taylor AC, Kinloch IA. The effect of carbon nanotubes on the fracture toughness and fatigue performance of a thermosetting epoxy polymer. Journal of Materials Science 2011;46:7525-35.

[284] Tark Han J, Cho K. Layered Silicate-Induced Enhancement of Fracture Toughness of Epoxy Molding Compounds over a Wide Temperature Range. Macromolecular Materials and Engineering. 2005;290:1184-91. 
[285] Kinloch AJ, Taylor AC. The mechanical properties and fracture behaviour of epoxy-inorganic microand nano-composites. Journal of materials Science 2006;41:3271-97.

[286] Chandrasekaran S, Sato N, Tölle F, Mülhaupt R, Fiedler B, Schulte K. Fracture toughness and failure mechanism of graphene based epoxy composites. Composites Science and Technology. 2014;97:90-9.

[287] Albdiry MT, Yousif BF. Role of silanized halloysite nanotubes on structural, mechanical properties and fracture toughness of thermoset nanocomposites. Mater Des. 2014;57:279-88.

[288] Reis JML, Chianelli-Junior R, Cardoso JL, Marinho FJV. Effect of recycled PET in the fracture mechanics of polymer mortar. Construction and Building Materials. 2011;25:2799-804.

[289] Ziadeh M, Fischer B, Schmid J, Altstädt V, Breu J. On the importance of specific interface area in clay nanocomposites of PMMA filled with synthetic nano-mica. Polymer. 2014;55:3770-81.

[290] Soundararajah QY, Karunaratne BSB, Rajapakse RMG. Montmorillonite polyaniline nanocomposites: Preparation, characterization and investigation of mechanical properties. Materials Chemistry and Physics. 2009;113:850-5.

[291] Talbott MF, Springer GS, Berglund LA. The Effects of Crystallinity on the Mechanical Properties of PEEK Polymer and Graphite Fiber Reinforced PEEK. Journal of Composite Materials. 1987;21:1056-81.

[292] Kurtz SM, Devine JN. PEEK Biomaterials in Trauma, Orthopedic, and Spinal Implants. Biomaterials. 2007; 28:4845-69.

[293] Crick RA, Leach DC, Meakin PJ, Moore DR. Interlaminar fracture morphology of carbon fibre/PEEK composites. Journal of Materials Science. 1987;22:2094-104.

[294] Gao S-L, Kim J-K. Cooling rate influences in carbon fibre/PEEK composites. Part 1. Crystallinity and interface adhesion. Composites Part A: Applied Science and Manufacturing. 2000;31:517-30.

[295] Morgan P. Carbon fibers and their composites. USA: Boca Raton FL: Taylor and Francis; 2005. p. 1200.

[296] Pingkarawat K, Wang CH, Varley RJ, Mouritz AP. Self-healing of delamination fatigue cracks in carbon fibre-epoxy laminate using mendable thermoplastic. Journal of Materials Science. 2012;47:444956.

[297] Takeda T, Shindo Y, Watanabe S, Narita F. Three-dimensional stress analysis of cracked satin woven carbon fiber reinforced/polymer composites under tension at cryogenic temperatures. Cryogenics. 2012;52:784-92.

[298] Manjunatha CM, Taylor AC, Kinloch AJ, Sprenger S. The tensile fatigue behaviour of a silica nanoparticle-modified glass fibre reinforced epoxy composite. Composites Science and Technology. 2010;70:193-9.

[299] Poowadin T, Panin SV, Sergeev VP, Kornienko LA, Ivanova LR. Wear resistance of UHMWPE-based carbon nanocomposite subsequent AlBx ion implantation. Strategic Technology (IFOST),7th International Forum, IEEE. Russia 2012 p. 1-5.

[300] Kurtz SM. UHMWPE biomaterials handbook. In: Kurtz SM, editor. USA: Academic press, Elsevier; 2009. p. 543.

[301] Nizamuddin S, Merah N, Khan Z, Al-Sulaiman F, Mehdi MS. Crude Oil and Outdoor Temperature Effects on The Tensile and Creep Properties of Glass Fiber Reinforced Vinylester Composite Pipes. Advanced Materials Research. 2010;83-86:457-64.

[302] Li W, Cho Y, Achenbach JD. Detection of thermal fatigue in composites by second harmonic Lamb waves Smart Materials and Structures. 2012;21:085019.

[303] Guerjouma RE, Baboux JC, Ducret D, Godin N, Guy P, Huguet S, et al. Non-Destructive Evaluation of Damage and Failure of Fibre Reinforced Polymer Composites Using Ultrasonic Waves and Acoustic Emission. Advanced Engineering Materials. 2001; 3:601-8. 
[304] Kumosa M, Hull D, Price JN. Acoustic emission from stress corrosion cracks in aligned GRP. Journal of Materials Science. 1987;22:331-6.

[305] Hill R, Cowking A, Carswell WS. An acoustic emission study of stress corrosion in a chopped strand mat GFRP composite. Composites. 1989; 20:215-22.

[306] Nagy PB. Fatigue damage assessment by nonlinear materials characterization. Ultrasonics. 1998;36:375-81.

[307] Mian A, Han X, Islam S, Newaz G. Fatigue damage detection in graphite/epoxy composites using sonic infrared imaging technique. Composites Science and Technology. 2004;64:657-66.

[308] Garnier C, Pastor M-L, Eyma F, Lorrain B. The detection of aeronautical defects in situ on composite structures using Non Destructive Testing. Composite Structures. 2011;93:1328-36.

[309] Seale MD, Smith BT, Prosser WH. Lamb wave assessment of fatigue and thermal damage in composites Journal of the Acoustical Society of America. 1998;103:2416-24.

[310] Schmidt F, Rheinfurth M, Horst P, Busse G. Multiaxial fatigue behaviour of GFRP with evenly distributed or accumulated voids monitored by various NDT methodologies. International Journal of Fatigue. 2012;43:207-16.

[311] Schmidt F, Rheinfurth M, Protz R, Horst P, Busse G, Gude M, et al. Monitoring of multiaxial fatigue damage evolution in impacted composite tubes using non-destructive evaluation. Composites Part A: Applied Science and Manufacturing. 2012;43:537-46.

[312] Kessler SS, Spearing SM, Soutis C. Damage detection in composite materials using Lamb wave methods. Smart Materials and Structures. 2002; 11:269-78

[313] Usamentiaga R, Venegas P, Guerediaga J, Vega L, López I. Automatic detection of impact damage in carbon fiber composites using active thermography. Infrared Physics \& Technology. 2013;58:36-46.

[314] Chu W, Karbhari V. Effect of Water Sorption on Performance of Pultruded E-Glass/Vinylester Composites. Journal of Materials in Civil Engineering. 2005;17:63-71.

[315] Bao L-R, Yee AF. Effect of temperature on moisture absorption in a bismaleimide resin and its carbon fiber composites. Polymer. 2002;43:3987-97.

[316] Stifter D, Wiesauer K, Wurm M, Schlotthauer E, Kastner J, Pircher M, et al. Investigation of polymer and polymer/fibre composite materials with optical coherence tomography. Measurement Science and Technology. 2008;19:074011-74018.

[317] Stock SR. X-ray microtomography of materials. International Materials Reviews. 1999;44:141-64.

[318] Cantwell WJ, Morton J. The significance of damage and defects and their detection in composite materials: A review. The Journal of Strain Analysis for Engineering Design. 1992;27:29-42.

[319] Kapadia A. Non destructive testing of composite materials. Cambridge UK: National Composite Network, http://www.compositesuk.co.uk/LinkClick.aspx?fileticket=14Rxzdzdkjw=\&; 2008. p. 1-35.

[320] Song Y, Li YJ. The portable intelligent coin-tap test system of civil aircraft composite structures. IEEE Confedrence on Piezoelectricity, Acoustic Waves, and Device Applications2008. p. 570-4.

[321] Huang M, L. Jiang, P. K. Liaw, C. R. Brooks, R. Seeley, Klarstrom DL. Using Acoustic Emission in Fatigue and Fracture Materials Research. JOM. 1998;50:1-4.

[322] Scholey JJ, Wilcox PD, Lee CK, Friswell MI, Wisnom MR. Acoustic Emission in Wide Composite Specimens. Advanced Materials Research. 2006;13-14:325-32.

[323] Cohen YB. Ultrasonic NDE of composites- A review. In: Achenbach JD, Rajapakse Y, editors. Solid mechanics for quantitative non-destructive evaluation. Dordrecht NL: Martinus Nijhoff; 1987. p. 187-201. [324] Serabian S. Composite characterisation techniques:Ultrasonics. Mantech Journal. 1985;10:11-23.

[325] Harris B. Fatigue in Composites: science and technology of the fatigue response of fibre-reinforced plastics. Cambridge: Woodhead Publishing 2003. p. 727. 
[326] Summerscales J. Non-destructive testing of fibre-reinforced plastics composites In: Summerscales J, editor. Barking UK: Elsevier Applied Science; 1990. p. 512.

[327] Ghosh KK, Karbhari VM. A critical review on infrared thermography as a method for nondestructive evaluation of FRP rehabilitated structures. International Journal of Materials and Product. 2006;25:241-66.

[328] Junyan L, Liqiang L, Yang W. Experimental study on active infrared thermography as a NDI tool for carbon-carbon composites. Composites Part B: Engineering. 2013;45:138-47.

[329] Nikishkov Y, Airoldi L, Makeev A. Measurement of voids in composites by X-ray Computed Tomography. composites science and technology,. 2013;89:89-97.

[330] Bull DJ, Sinclair I, Spearing SM. Partial volume correction for approximating crack opening displacements in CFRP material obtained from micro-focus X-ray CT scans. Composites Science and Technology. 2013;81:9-16.

[331] Bull DJ, Spearing SM, Sinclair I, Helfen L. Three-dimensional assessment of low velocity impact damage in particle toughened composite laminates using micro-focus $\mathrm{X}$-ray computed tomography and synchrotron radiation laminography. Composites Part A: Applied Science and Manufacturing. 2013;52:62-9.

[332] Fidan S, Sınmazçelik T, Avcu E. Internal damage investigation of the impacted glass/glass aramid fiber reinforced composites by micro-computerized tomography. NDT\&E International. 2012;51:1-7.

[333] Kaouache B, Addiego F, Hiver J-M, Ferry O, Toniazzo V, Ruch D. In Situ Mechanical Characterization of Short Vegetal Fibre-Reinforced High-Density Polyethylene Using X-Ray Tomography. Macromolecular Materials and Engineering. 2013;298:1269-74.

[334] Seltzer R, González C, Muñoz R, LLorca J, Blanco-Varela T. X-ray microtomography analysis of the damage micromechanisms in 3D woven composites under low-velocity impact. Composites Part A: Applied Science and Manufacturing. 2013;45:49-60.

[335] Sket F, Enfedaque A, Alton C, González C, Molina-Aldareguia JM, Llorca J. Automatic quantification of matrix cracking and fiber rotation by X-ray computed tomography in shear-deformed carbon fiberreinforced laminates. Composites Science and Technology. 2014;90:129-38.

[336] Dunkers JP, Phelan FR, Sanders DP, Everett MJ, Green WH, Hunston DL, et al. The application of optical coherence tomography to problems in polymer matrix composites. Optics and Lasers in Engineering. 2001;35:135-47.

[337] Duncan M, Bashkansky M, Reintjes J. Subsurface defect detection in materialsusing optical coherence tomography. Opt Express. 1998;2:540-5.

[338] Beattie AG. Acoustic emission, principles and instrumentation. Journal of Acoustic Emission 1983;2(1/2):95-128.

[339] Brown EN, Kessler MR, Sottos NR, White SR. In situ poly(urea-formaldehyde) microencapsulation of dicyclopentadiene. Journal of microencapsulation. 2003;20:719-30.

[340] Jung D, Hegeman A, Sottos NR, Geubelle PH, White SR. Self-healing composites using embedded microspheres. In: Composites and functionally graded materials. ASME International Mechanical Engineering Congress and Exposition. Dallas, USA1997. p. 265-75.

[341] Yuan L, Liang G-Z, Xie J-Q, Guo J, Li L. Thermal stability of microencapsulated epoxy resins with poly(urea-formaldehyde). Polymer Degradation and Stability. 2006;91:2300-6.

[342] Rule JD, Brown EN, Sottos NR, White SR, Moore JS. Wax-Protected Catalyst Microspheres for Efficient Self-Healing Materials. Advanced Materials. 2005;17:205-8.

[343] Kumar A, Stephenson LD. Self healing coatings using microcapsules. (Individual U) US:2006042504A1, 
.2006.

[344] Plaisted TA, Vakil Amirkhizi A, Arbelaez D, Nemat-Nasser SC, Nemat-Nasser S. Self-healing structural composites with electromagnetic functionality. 2003. p. 372-81.

[345] Liu Y-L, Chen Y-W. Thermally Reversible Cross-Linked Polyamides with High Toughness and SelfRepairing Ability from Maleimide- and Furan-Functionalized Aromatic Polyamides. Macromolecular Chemistry and Physics. 2007;208:224-32.

[346] Higaki Y, Otsuka H, Takahara A. Dynamic Formation of Graft Polymers via Radical Crossover Reaction of Alkoxyamines. Macromolecules. 2004;37:1696-701.

[347] Zako M, Takano N. Intelligent Material Systems Using Epoxy Particles to Repair Microcracks and Delamination Damage in GFRP. Journal of Intelligent Material Systems and Structures. 1999;10:836-41.

[348] Jones F, Hayes SA. Self-healing composite material. The University Of Sheffield; 2006.

[349] Outwater JO, Gerry DJ. On the Fracture Energy, Rehealing Velocity and Refracture Energy of Cast Epoxy Resin. J Adhes. 1969;1:290-8.

[350] Ho CT. Reactive two-part polyurethane compositions and optionally self-healable and scratchresistant coatings prepared therefrom. Minnesota Mining \& Mfg: Google Patents; 1996.

[351] Naeisawa I, Ishikawa M, Ogawa H. Fracture and crazing in the indenting of glassy polystyrene and styrene-acrylonitrile copolymer. Philosophical Magazine A. 1980;41:331-51.

[352] Faye A, Parmeswaran V, Basu S. Mechanics of Dynamic Fracture in Polycarbonate. Procedia Materials Science. 2014;3:1304-9.

[353] Luo W, Wang C, Zhao R, Tang X, Tomita Y. Creep behavior of poly(methyl methacrylate) with growing damage. Materials Science and Engineering: A. 2008;483-484:580-2.

[354] Boonyapookana A, Nagata K, Mutoh Y. Fatigue crack growth behavior of silica particulate reinforced epoxy resin composite. Composites Science and Technology. 2011;71:1124-31.

[355] Shtein M, Nadiv R, Lachman N, Daniel Wagner H, Regev O. Fracture behavior of nanotubepolymer composites: Insights on surface roughness and failure mechanism. Composites Science and Technology. 2013;87:157-63.

[356] Aïssa B, Therriault D, Haddad E, Jamroz W. Self-Healing Materials Systems: Overview of Major Approaches and Recent Developed Technologies. Advances in Materials Science and Engineering. 2012;2012:17.

[357] Abdullah SI, Ansari MNM. Mechanical properties of graphene oxide (GO)/epoxy composites. HBRC Journal. 2014;in press.

[358] Sun T, Wu Z, Zhuo Q, Liu X, Wang Z, Fan H. Microstructure and mechanical properties of aminated polystyrene spheres/epoxy polymer blends. Composites Part A: Applied Science and Manufacturing. 2014;66:58-64.

[359] Lim M-Y, Kim HJ, Baek SJ, Kim KY, Lee S-S, Lee J-C. Improved strength and toughness of polyketone composites using extremely small amount of polyamide 6 grafted graphene oxides. Carbon. 2014;77:366-78. 
Table 1. Some applications of fibre reinforced composites and their crack susceptibility

\begin{tabular}{|c|c|c|c|c|}
\hline Composite type & Qualities & Application & Sources for cracks & Ref \\
\hline Carbon fibre/ PEEK & $\begin{array}{l}\text { Biocompatible, low wear } \\
\text { rate, chemical stability, } \\
\text { imaging capability, } \\
\text { tailored stiffness }\end{array}$ & $\begin{array}{l}\text { Medical Implants, } \\
\text { aerospace structures }\end{array}$ & Impact load & $\begin{array}{l}{[292-} \\
294]\end{array}$ \\
\hline Carbon fibre/Eepoxy & Light, stiff, strong & $\begin{array}{l}\text { military and civil aircrafts } \\
\text { parts, crogenic fuel tanks }\end{array}$ & $\begin{array}{l}\text { Fatigue crack is a major threat } \\
\text { for structure in this application, } \\
\text { Permeation of liquid and } \\
\text { gaseous fuel, gas leakage }\end{array}$ & $\begin{array}{l}{[295-} \\
297]\end{array}$ \\
\hline Glass fibre/Epoxy & $\begin{array}{l}\text { Cost-effective } \\
\text { manufacturing } \\
\text { replacement for steel tube } \\
\text { susceptible to corrosion, }\end{array}$ & $\begin{array}{l}\text { Liners in oil directional } \\
\text { wells, ship hulls, wind } \\
\text { turbines }\end{array}$ & $\begin{array}{l}\text { Harsh environment, losing } \\
\text { structural integrity, then } \\
\text { durability becomes an issue, } \\
\text { fatigue crack }\end{array}$ & $\begin{array}{l}{[141,} \\
298]\end{array}$ \\
\hline Carbon fibre/UHMWPE & $\begin{array}{l}\text { Low moisture absorption, } \\
\text { resistance to corrosive } \\
\text { chemical, high abrasion } \\
\text { resistance and high } \\
\text { impact strength }\end{array}$ & Medical implants & Delamination cracks & $\begin{array}{l}{[299,} \\
300]\end{array}$ \\
\hline Glass fibre/Vinylester & $\begin{array}{l}\text { Good chemical stability } \\
\text { in seawater, low cost }\end{array}$ & $\begin{array}{l}\text { Fishing and patrol boats, } \\
\text { submarine domes, water } \\
\text { and crude oil pipes }\end{array}$ & Environmental induced crack & $\begin{array}{l}{[146,} \\
301]\end{array}$ \\
\hline Glass fibre/Polyester & $\begin{array}{l}\text { Low cost, good chemical } \\
\text { stability in seawater }\end{array}$ & $\begin{array}{l}\text { Boat hull, wind turbine } \\
\text { blades }\end{array}$ & $\begin{array}{lll}\text { Irreversible } & \text { damage } & \text { to } \\
\text { composite as a result of }\end{array}$ & $\begin{array}{l}{[139,} \\
140,\end{array}$ \\
\hline
\end{tabular}




\begin{tabular}{|l|l|l|l|l|}
\hline & & & environmental ageing & $148]$ \\
\hline
\end{tabular}

\section{Table 2. Some examples of various causes of defects in composites and their detection methods}

\begin{tabular}{|c|c|c|c|}
\hline Type of damage & Composites/polymer & Detection method & Ref \\
\hline Thermal fatigue cracking & Carbon fibre/epoxy & Ultrasonic & {$[302]$} \\
\hline Hygrothermal ageing cracks & E glass/epoxy & Acoustic emission/Ultrasonic & [303] \\
\hline Stress corrosion cracks & Glass fibre/polyester & Acoustic emission & {$[304]$} \\
\hline Stress corrosion cracks & E Glass fibre/polyester & Acoustic emission & [305] \\
\hline Mechanical fatigue cracking & Poly Carbonate, Polyvinyl Chloride & Ultrasonic & [306] \\
\hline Mechanical fatigue cracking & Carbon fibre/epoxy & Ultrasonic/Infra-red thermography & $\begin{array}{l}{[307-} \\
309]\end{array}$ \\
\hline Thermal stress cracking & Carbon fibre/epoxy & Ultrasonic & [309] \\
\hline Thermo-oxidation cracks & Carbon fibre/epoxy & Scanning electron microscopy & [108] \\
\hline $\begin{array}{l}\text { Mechanical fatigue and impact } \\
\text { cracking }\end{array}$ & E glass/epoxy & $\begin{array}{l}\text { Scanning electron microscopy, Infra-red } \\
\text { thermography }\end{array}$ & $\begin{array}{l}{[310,} \\
311]\end{array}$ \\
\hline Delamination cracking & Carbon fibre/epoxy & Ultrasonic & {$[312]$} \\
\hline Impact damage & Carbon fibre/epoxy & Infrared thermography & [313] \\
\hline
\end{tabular}


Table 3: Thermal and Oxidative shrinkage in polymer composites

\begin{tabular}{|c|c|c|c|}
\hline Composite & Thermo oxidative condition & Shrinkage & Ref \\
\hline PMR-15 resin & $\begin{array}{l}\text { argon aging } \text { environments of } \\
288^{\circ} \mathrm{C}, 200 \mathrm{~h}\end{array}$ & $\begin{array}{l}\text { Volume averaged } \\
0.152 \%\end{array}$ & {$[105]$} \\
\hline PMR-15 resin & Oxygen aging, $288^{\circ} \mathrm{C}, 200 \mathrm{~h}$ & $\begin{array}{l}\text { Volume averaged } \\
0.66 \%\end{array}$ & {$[105]$} \\
\hline $\begin{array}{l}\text { Unidirectional IM7/977-2 carbon-fiber reinforced } \\
\text { composite }\end{array}$ & $\begin{array}{l}150{ }^{\circ} \mathrm{C} \text {, atmospheric air, pressure } \\
1.7 \text { bars, } 1000 \mathrm{~h}\end{array}$ & $\begin{array}{l}\text { Matrix averaged } \\
7.6 \%\end{array}$ & [108] \\
\hline $\begin{array}{l}\text { Unidirectional IM7/977-2 carbon-fiber reinforced } \\
\text { composite }\end{array}$ & $\begin{array}{l}150{ }^{\circ} \mathrm{C} \text {, oxygen, pressure } 1.7 \text { bars, } \\
49.5 \mathrm{~h}\end{array}$ & $\begin{array}{l}\text { Matrix } \quad \text { averaged } \\
6.83 \%\end{array}$ & {$[108]$} \\
\hline $\begin{array}{l}\text { Aromatic epoxy crosslinked by the diamino } \\
\text { diphenylsulphone, } 70 \mu \mathrm{m} \text { film }\end{array}$ & $\begin{array}{l}\text { at } 180{ }^{\circ} \mathrm{C} \text {, oxygen, atmospheric } \\
\text { pressure, } 1000 \mathrm{~h}\end{array}$ & $\begin{array}{l}\text { Volume variation } \\
4.9 \%\end{array}$ & {$[122]$} \\
\hline
\end{tabular}


Table 4: Hydrolysis aging of polymer composites

\begin{tabular}{|c|c|c|c|}
\hline Composite & Hydrolysis aging conditions & Ageing effect & Ref \\
\hline $\begin{array}{l}\text { Unidirectional composite laminate of } \\
\text { glass fibre/carbon fibre }\end{array}$ & $\begin{array}{l}32 \text { weeks: } 48 \mathrm{~h}(10 \% \text { humidity, } \\
\left.74.5^{\circ} \mathrm{C}\right), 48 \mathrm{~h}(100 \% \text { humidity, } \\
\left.23.5^{\circ} \mathrm{C}\right), 64 \mathrm{~h}(100 \% \text { humidity, } \\
\left.39^{\circ} \mathrm{C}\right)\end{array}$ & $\begin{array}{l}\text { Delamination damage tolerance } \\
\text { reduction on } 39 \text { and } 34 \% \text { for glass } \\
\text { epoxy and carbon expose, } \\
\text { respectively }\end{array}$ & {$[132]$} \\
\hline $\begin{array}{llll}\text { Polyactide glass/carbon fibre epoxy } \\
\text { composite }\end{array}$ & Humidity $95 \%, 70{ }^{\circ} \mathrm{C}, 35 \mathrm{~h}$ & $\begin{array}{l}\text { Moisture uptake carbon/epoxy } 1.2 \% \\
\text { Moisture uptake glass/epoxy } 2.5 \%\end{array}$ & {$[133]$} \\
\hline Polylactide 2002D & Water, $75^{\circ} \mathrm{C}, 5 \mathrm{~h}$ & Moisture uptake $1.75 \%$ & {$[135]$} \\
\hline $\begin{array}{l}\text { Reinforced with E glass fibre polyester } \\
\text { resin }\end{array}$ & $\begin{array}{l}\text { Water, } 85^{\circ} \mathrm{C}, 4 \text { months } \\
\text { Sea water, } 85^{\circ} \mathrm{C}, 4 \text { months }\end{array}$ & $\begin{array}{l}\text { Moisture uptake } 0.571 \% \\
\text { Moisture uptake } 0.465 \%\end{array}$ & {$[139]$} \\
\hline $\begin{array}{l}\text { Reinforced with E glass fibre }(51.5 \%) \\
\text { polyester resin }\end{array}$ & $\begin{array}{l}\text { Water, } 65^{\circ} \mathrm{C}, 5000 \mathrm{~h} \\
\text { Sea water, } 65^{\circ} \mathrm{C}, 5000 \mathrm{~h}\end{array}$ & $\begin{array}{l}\text { Moisture uptake } 0.38 \% \\
\text { Moisture uptake } 0.28 \%\end{array}$ & {$[140]$} \\
\hline Glass fiber-reinforced plastic & Water, $60^{\circ} \mathrm{C}, 10$ days & Moisture uptake $28 \%$ & {$[141]$} \\
\hline $\begin{array}{l}\text { Epoxy resin, diglycidyl ether of } \\
\text { bisphenol A resin } \text { with } \\
\text { diethylenetriamine }\end{array}$ & Water, $80^{\circ} \mathrm{C}, 1536 \mathrm{~h}$ & Moisture uptake $2.6 \%$ & {$[142]$} \\
\hline Polyurethane, XB5073 & Sea water, $100^{\circ} \mathrm{C}, 2$ years & Weight change $2.4 \%$ after drying & {$[143]$} \\
\hline Polychloroprene rubber & Sea water, $80^{\circ} \mathrm{C}, 50$ days & $\begin{array}{l}\text { Nominal stress increase to } 11.1 \mathrm{MPa} \\
\text { at nominal strain of } 420 \%\end{array}$ & {$[144]$} \\
\hline z-pinned carbon fibre-epoxy laminate & $\begin{array}{l}\text { Water, } 70{ }^{\circ} \mathrm{C}, 300 \text { days } \\
\text { Air, humidity } 85 \%, 70{ }^{\circ} \mathrm{C}, 300 \\
\text { days }\end{array}$ & $\begin{array}{l}\text { Moisture uptake } 3 \% \\
\text { Moisture uptake } 1 \%\end{array}$ & {$[145]$} \\
\hline $\begin{array}{l}\text { isophthalic polyester resin (Synolite } \\
\text { 0288 PA) }\end{array}$ & Sea water, $60^{\circ} \mathrm{C}, 1400 \mathrm{~h}$ & Moisture uptake 1.18 & {$[146]$} \\
\hline Vinyl ester resin (Atlac 580) & Sea water, $60^{\circ} \mathrm{C}, 1400 \mathrm{~h}$ & Moisture uptake $0.83 \%$ & {$[146]$} \\
\hline $\begin{array}{l}5 \text { layers of reinforcement (a glass fibre } \\
\text { fabric) with isophthalic resin laminate }\end{array}$ & Sea water, $60^{\circ} \mathrm{C}, 1400 \mathrm{~h}$ & Moisture uptake $1.3 \%$ & {$[146]$} \\
\hline E-glass/vinylester composite & Water, $80^{\circ} \mathrm{C}, 75$ weeks & Moisture uptake $0.623 \%$ & {$[314]$} \\
\hline $\begin{array}{l}\text { Carbon fibre reinforced three- } \\
\text { component modifed BMI (Cytec 5250-4 } \\
\text { RTM) }\end{array}$ & Water, $90^{\circ} \mathrm{C}, 10$ days & Moisture uptake $4.5 \%$ & {$[315]$} \\
\hline
\end{tabular}


Table 5: Comparison of different non-destructive testing methods for composites

\begin{tabular}{|c|c|c|c|}
\hline Inspection Method & Major detected defects & Strength and limitation & Ref \\
\hline Visual inspection & $\begin{array}{l}\text { Surface crack, delamination, } \\
\text { impact damage }\end{array}$ & $\begin{array}{l}\text { Simple, rapid, inexpensive, Sub-surface } \\
\text { flaws cannot be detected, should be used } \\
\text { along with other detection methods }\end{array}$ & [160] \\
\hline $\begin{array}{l}\text { Optical Coherence Tomography } \\
\text { (OCT) }\end{array}$ & Cracks, delamination, voids & $\begin{array}{l}\text { 3D high resolution imaging, Not suitable for } \\
\text { carbon fibre composites due to making the } \\
\text { object opaque for imaging }\end{array}$ & {$[316,317]$} \\
\hline $\begin{array}{l}\text { Microscopy (light microscopy, } \\
\text { SEM) }\end{array}$ & $\begin{array}{l}\text { Cracks, voids, delamination, } \\
\text { fibre breakage }\end{array}$ & $\begin{array}{l}\text { Evaluation of crack initiation and } \\
\text { propagation, SEM sample preparation takes } \\
\text { time, infield inspection not possible, small } \\
\text { sample size studied }\end{array}$ & {$[160,318]$} \\
\hline Tap test & Delamination, cracking & $\begin{array}{l}\text { Can be used for moisture sensitive } \\
\text { composites, simple, inexpensive, } \\
\text { Insufficient sensivity for field applications }\end{array}$ & {$[319,320]$} \\
\hline Acoustic emission & $\begin{array}{l}\text { Cracks, delamination, Fibre } \\
\text { breakage }\end{array}$ & $\begin{array}{l}\text { Suitable for field tests, high sensitivity, only } \\
\text { suitable for detection growing flaws, defect } \\
\text { size and location difficult to obtain, } \\
\text { sensitivity affected by surrounding noise, } \\
\text { not suitable for thick specimen }\end{array}$ & $\begin{array}{l}{[171,321,} \\
322]\end{array}$ \\
\hline Ultrasonic & $\begin{array}{l}\text { Cracks, delamination, voids } \\
\text { and foreign objects }\end{array}$ & $\begin{array}{l}\text { Depth and location of flaws can be } \\
\text { determined, can be used when only one side } \\
\text { access to composite is possible, hard to } \\
\text { detect the defects in region near the probe }\end{array}$ & {$[323,324]$} \\
\hline
\end{tabular}




\begin{tabular}{|c|c|c|c|}
\hline X-ray radiography & $\begin{array}{l}\text { Foreign inclusions, Cracks, } \\
\text { voids, fibre alignment, fibre } \\
\text { splitting }\end{array}$ & $\begin{array}{l}\text { thick section of composite can be inspected, } \\
\text { Poor image contrast, High cost due to } \\
\text { OH\&S associated with ionising radiation }\end{array}$ & {$[171,325]$} \\
\hline $\begin{array}{l}\text { X-ray computed micro- } \\
\text { tomography }\end{array}$ & $\begin{array}{l}\text { Cracks and micro-cracks, } \\
\text { voids }\end{array}$ & $\begin{array}{l}\text { 3D images reveals the nature and shape of } \\
\text { defects, in service damages including } \\
\text { delamination hard to detect without } \\
\text { penetrant, higher cost due to OH\&S }\end{array}$ & {$[183,326]$} \\
\hline $\begin{array}{l}\text { Compton backscattering } \\
\text { diffraction }\end{array}$ & $\begin{array}{l}\text { Cracks and micro-cracks, } \\
\text { voids, porosity, fibre } \\
\text { misalignment }\end{array}$ & $\begin{array}{l}\text { One-sided inspection possible as well as } \\
\text { tomographic imaging, layer-by-layer } \\
\text { inspection of object, Higher cost associated } \\
\text { to the control exposure of personnel to } \\
\text { ionising radiation. }\end{array}$ & {$[171,319]$} \\
\hline Infrared thermography & $\begin{array}{l}\text { Voids, cracks, foreign } \\
\text { inclusions, delamination, } \\
\text { impact damage }\end{array}$ & $\begin{array}{l}\text { Rapid area coverage, remote sensing } \\
\text { possible, one-sided inspection possible, } \\
\text { anisotropy masks indications }\end{array}$ & {$[327,328]$} \\
\hline
\end{tabular}




\section{Table 6: Quantitative measurements of defects in polymer composites using x-ray}

\section{tomography}

\begin{tabular}{|c|c|c|c|c|}
\hline Composite type & $\begin{array}{l}\text { Measured } \\
\text { quantity }\end{array}$ & Resolution & Notes & Ref \\
\hline $\begin{array}{lr}\text { Unidirectional } & \\
\text { Carbon/Epoxy } & \text { tape } \\
\text { composite, } & \text { and } \\
\text { Carbon/Epoxy } & \text { fabric } \\
\text { specimens with } & \text { porosity } \\
\text { defects. } & \end{array}$ & voids & $\begin{array}{l}0.08-0.18 \\
\mathrm{~mm}\end{array}$ & $\begin{array}{l}\text { The proposed method uses a sub-pixel contour } \\
\text { generation for the average of the air and } \\
\text { material gray values obtained in CT scans. }\end{array}$ & [329] \\
\hline $\begin{array}{l}\text { Different fibre } \\
\text { polymer matrix } \\
\text { materials }\end{array}$ & $\begin{array}{l}\text { damage and internal } \\
\text { flaws, including } \\
\text { delamination and } \\
\text { microcracking }\end{array}$ & $\sim 4 \mu \mathrm{m}$ & $\begin{array}{l}\text { It was possible to characterize the three- } \\
\text { dimensional configuration of internal cracks } \\
\text { and microcracks with some limitations that are } \\
\text { related to the damage configuration. }\end{array}$ & {$[172]$} \\
\hline $\begin{array}{ll}\text { Carbon } & \text { fibre/epoxy } \\
\text { composite } & \end{array}$ & $\begin{array}{l}\text { Impact damage, crack } \\
\text { opening displacement }\end{array}$ & $\begin{array}{l}5.24,4.3,14 \\
\mu \mathrm{m}\end{array}$ & $\begin{array}{l}\text { Using partial volume correction technique that } \\
\text { applies measurement weighting based on gray } \\
\text { scale intensity values proved to be a viable } \\
\text { method to obtain quantitative estimates of crack } \\
\text { opening displacements in CF/epoxy composite }\end{array}$ & {$[330]$} \\
\hline $\begin{array}{l}\text { Carbon fibre composite with } \\
\text { and without particle } \\
\text { toughened epoxy resin }\end{array}$ & $\begin{array}{l}\text { Impact damage, intra- } \\
\text { and inter-laminar } \\
\text { cracks }\end{array}$ & $0.7,4.3 \mu \mathrm{m}$ & $\begin{array}{l}\text { Combination of } \mu \mathrm{CT} \text { and synchrotron } \\
\text { radiation computed laminography allowed } \\
\text { investigation of the } 3 \mathrm{D} \text { characteristics of } \\
\text { impact damage and to study particle toughening } \\
\text { micro-mechanisms, }\end{array}$ & {$[331]$} \\
\hline $\begin{array}{l}\text { Stitched carbon fibre/ epoxy } \\
\text { composite laminate }\end{array}$ & Impact damage & $\begin{array}{l}2048 \times 2048 \\
\text { pixels }\end{array}$ & $\begin{array}{l}\text { 3D internal damage distribution of matrix } \\
\text { cracks and delamination damage pattern } \\
\text { differences due to the effect of stitching (stitch } \\
\text { density and thread thickness) was } \\
\text { demonstrated. }\end{array}$ & {$[115]$} \\
\hline $\begin{array}{l}\text { Glass and glass+ aramid } \\
\text { fibre/polyester composite }\end{array}$ & $\begin{array}{l}\text { Impact damage } \\
\text { ( delamination, fibre } \\
\text { breakage, matrix } \\
\text { cracking) }\end{array}$ & $12.5 \mu \mathrm{m}$ & $\begin{array}{l}\text { Internal damages of impacted composite was } \\
\text { determined. Cross-sectional views showed } \\
\text { detailed through-thickness delamination } \\
\text { distribution and 3D delamination damage } \\
\text { pattern. }\end{array}$ & {$[332]$} \\
\hline $\begin{array}{l}\text { Glass and carbon } \\
\text { fibre/epoxy composites }\end{array}$ & $\begin{array}{l}\text { Voids, cracks and } \\
\text { microcracks }\end{array}$ & $6 \mu \mathrm{m}$ & $\begin{array}{l}\text { Changes in the inner structure of epoxy } \\
\text { composites could be determined using this } \\
\text { technique. }\end{array}$ & [119] \\
\hline $\begin{array}{l}\text { Short hemp fibre/HDPE } \\
\text { composites }\end{array}$ & $\begin{array}{l}\text { Voids, microcracks, } \\
\text { fibre-matrix } \\
\text { debonding }\end{array}$ & $\sim 4 \mu \mathrm{m}$ & $\begin{array}{l}\text { 3D- and 2D-imaging reconstruction } \\
\text { of the meso-scale structure of the material } \\
\text { allowed study the debonding mechanisms } \\
\text { during the in-situ tensile testing. }\end{array}$ & {$[333]$} \\
\hline $\begin{array}{l}\text { 3D woven carbon and glass } \\
\text { fibre/epoxy composites }\end{array}$ & $\begin{array}{lr}\text { Impact } & \text { damage, } \\
\text { delamination, } & \text { fibre } \\
\text { breakage, } & \text { tow } \\
\text { splitting, } & \text { resin }\end{array}$ & $5-10 \mu \mathrm{m}$ & $\begin{array}{l}\text { Quantitative micro-mechanism of impact } \\
\text { damage was studies. }\end{array}$ & {$[334]$} \\
\hline
\end{tabular}

91 


\begin{tabular}{|l|l|l|l|l|}
\hline & cracking & & & \\
\hline $\begin{array}{l}\text { Glass } \\
\text { composites }\end{array}$ & fiber/epoxy & $\begin{array}{l}\text { Intraply cracking, } \\
\text { fibre kinking, interply } \\
\text { delamination }\end{array}$ & $\begin{array}{l}\text { A very detailed picture of the cracking } \\
\text { sequence was provided as well as the } \\
\text { interaction among the different failure } \\
\text { mechanisms. }\end{array}$ & $\begin{array}{l}\text { [177] } \\
\text { theorithms were developed for the automatic } \\
\text { quantification of matrix cracking and fiber } \\
\text { rotation in each ply from the tomograms. }\end{array}$ \\
\hline $\begin{array}{l}\text { Carbon cracking, } \\
\text { composites }\end{array}$ & $\begin{array}{l}\text { Matrix } \\
\text { interplay } \\
\text { delamination }\end{array}$ & $10 \mu \mathrm{m}$ & \\
\hline
\end{tabular}


Table 7: Comparisons of crack detections for polymer structures and composites

\begin{tabular}{|c|c|c|c|c|c|}
\hline Cracks detection technique & resolution & accuracy & ease & detected defects & Ref \\
\hline Optical Coherence Tomography & up to $\mu \mathrm{m}$ scale & High & No & Cracks, delamination, voids & {$[336,337]$} \\
\hline $\begin{array}{l}\text { optical and fluorescence } \\
\text { microscopy }\end{array}$ & up to $\mu \mathrm{m}$ scale & Medium & Yes & $\begin{array}{l}\text { Cracks, voids, delamination, } \\
\text { fibre breakage }\end{array}$ & {$[159,160]$} \\
\hline SEM & up to nm scale & Very High & No & $\begin{array}{l}\text { Cracks, voids, delamination, } \\
\text { fibre breakage }\end{array}$ & {$[164,165]$} \\
\hline Sonic testing & cm scale & Low & Yes & $\begin{array}{l}\text { Cracks, delamination, fibre } \\
\text { breakage }\end{array}$ & $\begin{array}{ll}{[238,} & 239, \\
249-251] & \end{array}$ \\
\hline Tap testing & cm scale & Low & Yes & Delamination, cracking & $\begin{array}{l}{[166],[258,} \\
259]\end{array}$ \\
\hline Acoustic emission & mm scale & Medium & Yes & $\begin{array}{l}\text { Cracks, delamination, Fibre } \\
\text { breakage }\end{array}$ & {$[155,338]$} \\
\hline Ultrasonic testing & mm scale & Medium & Yes & $\begin{array}{l}\text { Cracks, delamination, voids } \\
\text { and foreign objects }\end{array}$ & $\begin{array}{l}{[251],} \\
{[264,272]}\end{array}$ \\
\hline Conventional X-ray radiography & up to $\mu \mathrm{m}$ scale & High & No & $\begin{array}{l}\text { Foreign inclusions, cracks, } \\
\text { voids, fibre alignment, fibre } \\
\text { splitting }\end{array}$ & {$[171,275]$} \\
\hline $\begin{array}{ll}\text { X-ray } & \text { computed } \\
\text { microtomography } & \end{array}$ & up to nm scale & Very high & No & $\begin{array}{l}\text { Cracks and micro-cracks, } \\
\text { voids }\end{array}$ & {$[191,276]$} \\
\hline $\begin{array}{ll}\text { Compton } & \text { backscattering } \\
\text { diffraction } & \end{array}$ & up to nm scale & Very high & No & $\begin{array}{l}\text { Cracks and micro-cracks, } \\
\text { voids, porosity, fibre } \\
\text { misalignment }\end{array}$ & {$[171,258]$} \\
\hline $\begin{array}{l}\text { Electric impedance and } \\
\text { thermography }\end{array}$ & mm scale & Low & Yes & $\begin{array}{l}\text { Voids, cracks, foreign } \\
\text { inclusions, delamination, } \\
\text { impact damage }\end{array}$ & {$[150-157,254]$} \\
\hline fiber optic and fluorescent probe & mm scale & Medium & No & $\begin{array}{l}\text { Cracks and micro-cracks, } \\
\text { voids }\end{array}$ & {$[4,151,158]$} \\
\hline
\end{tabular}


Table 8: Cracks and Micro cracks self-repair and healing mechanisms

\begin{tabular}{|c|c|c|c|c|}
\hline Composite & Healing agent & Test method & $\begin{array}{l}\text { Healing } \\
\text { efficiency }\end{array}$ & Ref \\
\hline $\begin{array}{l}\text { Unidirectional carbon fiber- } \\
\text { reinforced epoxy composite }\end{array}$ & $\begin{array}{l}30 \text { wt } \% \text { DCPD microcapsules and } 2.5 \mathrm{wt} \% \\
\text { Grubbs' catalyst }\end{array}$ & Tensile test & $19 \%$ & [339] \\
\hline Polyester resin & styrene-based healing system & Tensile test & $75 \%$ & [340] \\
\hline Neat epoxy & ROMP of DCPD & Fracture test & $75-90 \%$ & $\begin{array}{l}{[187,} \\
341]\end{array}$ \\
\hline $\begin{array}{l}\text { Fiber-reinforced } \quad \text { epoxy } \\
\text { composites }\end{array}$ & ROMP of DCPD & Fracture test & $66 \%$ & {$[16]$} \\
\hline Neat epoxy resin & $\begin{array}{l}5-25 \mathrm{wt} \% \text { microencapsulated DCPD } \\
\text { monomer and } 2.5 \mathrm{wt} \% \text { Grubbs catalyst }\end{array}$ & Fracture test & $60 \%$ & [77] \\
\hline Neat epoxy resin & $\begin{array}{l}5 \mathrm{wt} \% \text { DCPD microcapsules and } 0.75 \mathrm{wt} \% \\
\text { the catalyst in the microcapsules with wax }\end{array}$ & Fracture test & $93 \%$ & {$[342]$} \\
\hline Neat epoxy resin & $\begin{array}{l}12 \text { wt } \% \text { PDMS, } 4 \text { wt } \% \\
\text { methylacryloxypropyl triethoxysilane, and } \\
\text { 3.6wt\% DBTL microcapsules }\end{array}$ & Fracture test & $46 \%$ & [185] \\
\hline $\begin{array}{l}\text { Epoxy laminate reinforced } \\
\text { with woven E-glass fabric }\end{array}$ & cyanoacrylate-based microcapsules & Fracture test & $12 \%$ & {$[18]$} \\
\hline $\begin{array}{l}\text { Carbon fiber-reinforced } \\
\text { epoxy laminate }\end{array}$ & $\begin{array}{l}20 \mathrm{wt} \% \text { DCPD microcapsules and } 5 \mathrm{wt} \% \text { of } \\
\text { Grubbs' catalyst }\end{array}$ & Fracture test & $45 \%$ & {$[343]$} \\
\hline Epoxy resin & $\begin{array}{l}20 \mathrm{wt} \% 180 \mathrm{~mm} \text { DCPD microcapsules and } \\
2.5 \mathrm{wt} \% \text { Grubbs' catalyst }\end{array}$ & Fatigue test & $89 \%$ & {$[18]$} \\
\hline $\begin{array}{l}\text { Thermally reversible } \\
\text { crosslinked polymer }\end{array}$ & Cross-linking by Diels-Alder (DA) reaction & Fracture tests & $\begin{array}{l}50 \% \text { at } 150 \\
{ }^{\circ} \mathrm{C}\end{array}$ & {$[194]$} \\
\hline Fiber-reinforced composites & Cross-linking by Diels-Alder (DA) reaction & Qualitative test & $\begin{array}{l}100 \% \text { at } 80 \\
{ }^{\circ} \mathrm{C}\end{array}$ & {$[344]$} \\
\hline $\begin{array}{l}\text { Epoxy of multifunctional } \\
\text { furan and maleimide } \\
\text { monomers }\end{array}$ & Cross-linking by Diels-Alder (DA) reaction & Qualitative test & $\begin{array}{l}\text { Cracks } \\
\text { disappear at } \\
120^{\circ} \mathrm{C}\end{array}$ & [345] \\
\hline $\begin{array}{l}2,2,6,6- \\
\text { tetramethylpiperidine-1-oxy }\end{array}$ & Cross-linking by alkoxyamine derivatives & Qualitative test & $\begin{array}{l}\text { Cracks } \\
\text { disappear at } \\
100{ }^{\circ} \mathrm{C}\end{array}$ & [346] \\
\hline $\begin{array}{l}\text { Glass fiber-reinforced epoxy } \\
\text { composite }\end{array}$ & 40 vol\% of thermoplastic epoxy particles & Tensile fatigue test & $\begin{array}{l}100 \% \text { at } 120 \\
{ }^{\circ} \mathrm{C}\end{array}$ & [347] \\
\hline Epoxy resin & $\begin{array}{l}\text { Thermoplastic component of } 25 \mathrm{wt} \% \text { of } \\
\text { polybisphenol-A-co-epichlorohydrin }\end{array}$ & $\begin{array}{l}\text { Compact tension } \\
\text { fracture }\end{array}$ & $\begin{array}{l}\text { About } 30 \% \\
\text { at } 140{ }^{\circ} \mathrm{C}\end{array}$ & [348] \\
\hline Glass fiber-reinforced epoxy & Thermoplastic component of $10 \mathrm{wt} \%$ of & Visual test & $30-50 \%$ & [197] \\
\hline
\end{tabular}




\begin{tabular}{|l|l|l|l|l|}
\hline composite & polybisphenol-A-co-epichlorohydrin & $140{ }^{\circ} \mathrm{C}$ & \\
\hline Epoxy resin & $\begin{array}{l}\text { Chain rearrangement of diglycidyl ether of } \\
\text { bisphenol-A, nadic methyl anhydride and } \\
\text { benzyl dimethylamine }\end{array}$ & $\begin{array}{l}\text { Double torsion } \\
\text { fracture testing }\end{array}$ & $\begin{array}{l}100 \% \text { at 150 } \\
{ }^{\circ} \mathrm{C}\end{array}$ & {$[349]$} \\
\hline Polyurethane & $\begin{array}{l}\text { Chain rearrangement in presence of 2- } \\
20 \mathrm{wt} \% \text { of siloxane or fluorinated segments }\end{array}$ & Visual test & $\begin{array}{l}100 \% \text { at <10 } \\
{ }^{\circ} \mathrm{C}\end{array}$ & {$[350]$} \\
\hline
\end{tabular}


Table 9: Craze initiation stress (MPa) for different polymers (from left to right are Polypropylene, polystyrene, polycarbonate, polyvinyl chloride, poly-methyl methacrylate) and composites

\begin{tabular}{|c|c|c|c|}
\hline $\begin{array}{l}\text { Polymer } \\
\text { /Polymer composite }\end{array}$ & Testing Method & $\begin{array}{c}\text { Craze initiation } \\
\text { stress (MPa) }\end{array}$ & Reference \\
\hline poly(propylene) (PP) & $\begin{array}{l}\text { Bending Test (self-designed } \\
\text { and fabricated apparatus) }\end{array}$ & 6.00 & [221] \\
\hline Polystyrene & $\begin{array}{l}\text { plane-strain } \\
\text { indentation }+ \text { hydrostatic } \\
\text { stress criterion }\end{array}$ & 25.00 & [351] \\
\hline $\begin{array}{l}\text { Quenched Polystyrene (PS) } \\
\text { Annealed Polystyrene (PS) } \\
20 \% \text { PPO + PS } \\
40 \% \text { PPO + PS, }\end{array}$ & $\begin{array}{l}\text { Micro-indentation }+ \\
\text { hydrostatic stress criterion }\end{array}$ & $\begin{array}{l}40.00 \\
40.00 \\
50.00 \\
55.00\end{array}$ & [233] \\
\hline $\begin{array}{l}\text { Polystyrene (PS) in air condition } \\
\text { Polystyrene (PS) in Freon condition }\end{array}$ & three-point bending (TPB) & $\begin{array}{c}20.00 \\
6.00\end{array}$ & [231] \\
\hline $\begin{array}{l}\text { Styrene }+5 \% \text { Acronitrile } \\
\text { Styrene }+13 \% \text { Acronitrile } \\
\text { Styrene }+24 \% \text { Acronitrile } \\
\text { Styrene }+28 \% \text { Acronitrile } \\
\text { Styrene }+33 \% \text { Acronitrile }\end{array}$ & three-point bending (TPB) & $\begin{array}{c}7.00 \\
9.00 \\
13.00 \\
14.00 \\
20.00\end{array}$ & [231] \\
\hline Polycarbonate & $\begin{array}{l}\text { Single edge notched (SEN) } \\
\text { a) Static loading- } \\
\text { b) Dynamic loading- }\end{array}$ & $\begin{array}{c}80.00 \\
100.00\end{array}$ & {$[352]$} \\
\hline poly(methyl methacrylate) (PMMA) & Uniaxial stress applied & 10.00 & [353] \\
\hline $\begin{array}{l}\text { poly(methyl methacrylate) (PMMA) } \\
\text { time elapsed (seconds) } \\
400 \\
600 \\
1000 \\
2000 \\
4000 \\
6000 \\
8000\end{array}$ & Uniaxial stress applied & $\begin{array}{l}41.00 \\
39.00 \\
36.00 \\
32.00 \\
31.00 \\
28.20 \\
27.00\end{array}$ & [227] \\
\hline
\end{tabular}

96 


\begin{tabular}{|l|l|c|l|}
\hline 10000 & & 25.80 & \\
\hline $\begin{array}{l}\text { (polyvinylchloride }+10 \% \text { chlorinated } \\
\text { polyethylene) PVC+CPE } \\
\text { PVC+ Benzene vapor }\end{array}$ & Tapered test strip & 44.00 & {$[236]$} \\
\hline
\end{tabular}

Table 10: Fracture toughness of Epoxy polymer composite tested from different methods.

Fracture toughness shows here represent the mean values from different literatures.

\begin{tabular}{|c|c|c|c|}
\hline $\begin{array}{l}\text { Polymer } \\
\text { /Polymer composite }\end{array}$ & Testing Method & $\begin{array}{l}\text { Fracture } \\
\text { toughness } \\
\left(\mathrm{Mpa}(\mathrm{m})^{1 / 2}\right)\end{array}$ & Reference \\
\hline $\begin{array}{l}\text { Pure epoxy } \\
\text { Epoxy + silica }\end{array}$ & $\begin{array}{l}\text { Tensile test } \\
\text { (Servo-hydraulic fatigue testing) }\end{array}$ & $\begin{array}{l}1.1 \\
2.5\end{array}$ & [354] \\
\hline $\begin{array}{l}\text { Epoxy } \\
\text { Epoxy+1\%volZnO } \\
\text { Epoxy }+2 \% \text { volZnO } \\
\text { Epoxy }+3 \% \text { volZnO } \\
\text { Epoxy }+4 \% \text { volZnO }\end{array}$ & $\begin{array}{l}\text { Macroscale testing } \\
\text { method } \\
\text { Mini Bionix II MTS } \\
\text { testing } \\
\text { ASTM E1820 }\end{array}$ & $\begin{array}{r}1.5 \\
2.25 \\
2.5 \\
2.8 \\
2.8\end{array}$ & [264] \\
\hline $\begin{array}{l}\text { Epoxy }+10 \% \text { volAlumina } \\
\text { Epoxy }+10 \% \text { volTitania }\end{array}$ & Three-point bending tests & $\begin{array}{l}1.15 \\
0.85\end{array}$ & [280] \\
\hline $\begin{array}{l}\text { Ероху+0.01 wt\%TRGO } \\
\text { Еpoxy+0.05 wt\%TRGO } \\
\text { Еpoxy+0.1wt\%TRGO } \\
\text { Еpoxy+0.25wt\%TRGO } \\
\text { Epoxy+0.5 wt\%TRGO }\end{array}$ & $\begin{array}{l}\text { 3P-ENB test } \\
\text { ASTM E397 }\end{array}$ & $\begin{array}{r}0.55 \\
0.625 \\
0.71 \\
0.75 \\
0.8\end{array}$ & {$[286]$} \\
\hline $\begin{array}{l}\text { Epoxy+0.05 wt\%GNP } \\
\text { Epoxy+0.1 wt\%GNP } \\
\text { Epoxy+0.25 wt\%GNP } \\
\text { Epoxy+0.5 wt\%GNP } \\
\text { Epoxy+1wt\%GNP } \\
\text { Epoxy+2wt } \% \mathrm{GNP}\end{array}$ & $\begin{array}{l}\text { 3P-ENB test } \\
\text { ASTM E397 }\end{array}$ & $\begin{array}{r}0.51 \\
0.55 \\
0.62 \\
0.7 \\
0.8 \\
0.75 \\
\end{array}$ & [286] \\
\hline
\end{tabular}

97 


\begin{tabular}{|c|c|c|c|}
\hline $\begin{array}{l}\text { Epoxy+0.05wt\%MWNT } \\
\text { Epoxy+0.1wt\%MWNT } \\
\text { Epoxy+0.25wt\%MWNT } \\
\text { Epoxy+0.5wt\%MWNT }\end{array}$ & $\begin{array}{l}\text { 3P-ENB test } \\
\text { ASTM E397 }\end{array}$ & $\begin{array}{r}0.52 \\
0.55 \\
0.6 \\
0.62\end{array}$ & {$[286]$} \\
\hline $\begin{array}{l}\text { Epoxy+mortar } \\
\text { Epoxy+mortar+5\%wt PET } \\
\text { Epoxy+mortar+10\%wt PET } \\
\text { Epoxy+mortar+15\%wt PET } \\
\text { Epoxy+mortar+20\%wt PET }\end{array}$ & Three-point bending tests & $\begin{array}{l}1.98 \\
1.62 \\
1.54 \\
1.43 \\
1.22\end{array}$ & {$[288]$} \\
\hline $\begin{array}{l}\text { Epoxy } \\
\text { Epoxy+0.03 WS2NTvol\% } \\
\text { Epoxy+0.08 WS2NTvol\% } \\
\text { Epoxy+0.1 WS2NTvol\% } \\
\text { Epoxy+0.12 WS2NTvol\% } \\
\text { Epoxy+0.126 WS2NTvol\% } \\
\text { Epoxy+0.15 WS2NTvol\% } \\
\text { Epoxy+0.18 WS2NTvol\% } \\
\text { Epoxy+0.226 WS2NTvol\% }\end{array}$ & $\begin{array}{l}\text { compact tension } \\
\text { ASTM D 5045-91 }\end{array}$ & $\begin{array}{r}0.85 \\
1 \\
1.15 \\
1.46 \\
2.06 \\
1.3 \\
1.3 \\
1.24 \\
1.26 \\
\end{array}$ & {$[355]$} \\
\hline $\begin{array}{l}\text { Epoxy+0.07vol\% CNT } \\
\text { Epoxy+0.08vol\% CNT } \\
\text { Epoxy+0.09vol\% CNT } \\
\text { Epoxy+0.1vol\% CNT } \\
\text { Epoxy+0.12vol\% CNT } \\
\text { Epoxy+0.13vol\% CNT } \\
\text { Epoxy+0.16vol\% CNT } \\
\text { Epoxy+0.07vol\% CNT }\end{array}$ & $\begin{array}{l}\text { compact tension } \\
\text { ASTM D 5045-91 }\end{array}$ & $\begin{array}{r}0.8 \\
1.3 \\
1.44 \\
2 \\
1.15 \\
1.3 \\
1.22\end{array}$ & {$[355]$} \\
\hline $\begin{array}{l}\text { (DER)Epoxy resins/4,4'- } \\
\text { diaminodiphenylsulphone (DDS) } \\
\text { DER 332/ (DDS) } \\
\text { DER 661/ (DDS) } \\
\text { DER 664/ (DDS) } \\
\text { DER 667/ (DDS) }\end{array}$ & Single Edge Notced (SEN) & $\begin{array}{r}1.09 \\
1.5 \\
1.99 \\
2.54\end{array}$ & [270] \\
\hline $\begin{array}{l}\text { (DER)Epoxy resins/4,4'- } \\
\text { diaminodiphenylsulphone (DDS) } \\
\text { DER } 332+10 \% \text { VolG } \\
\text { DER } 661+10 \% \text { VolG } \\
\text { DER } 664+10 \% \text { VolG } \\
\text { DER } 667+10 \% \text { VolG } \\
\end{array}$ & Single Edge Notced (SEN) & $\begin{array}{r}1.09 \\
1.5 \\
1.99 \\
2.54\end{array}$ & [270] \\
\hline
\end{tabular}



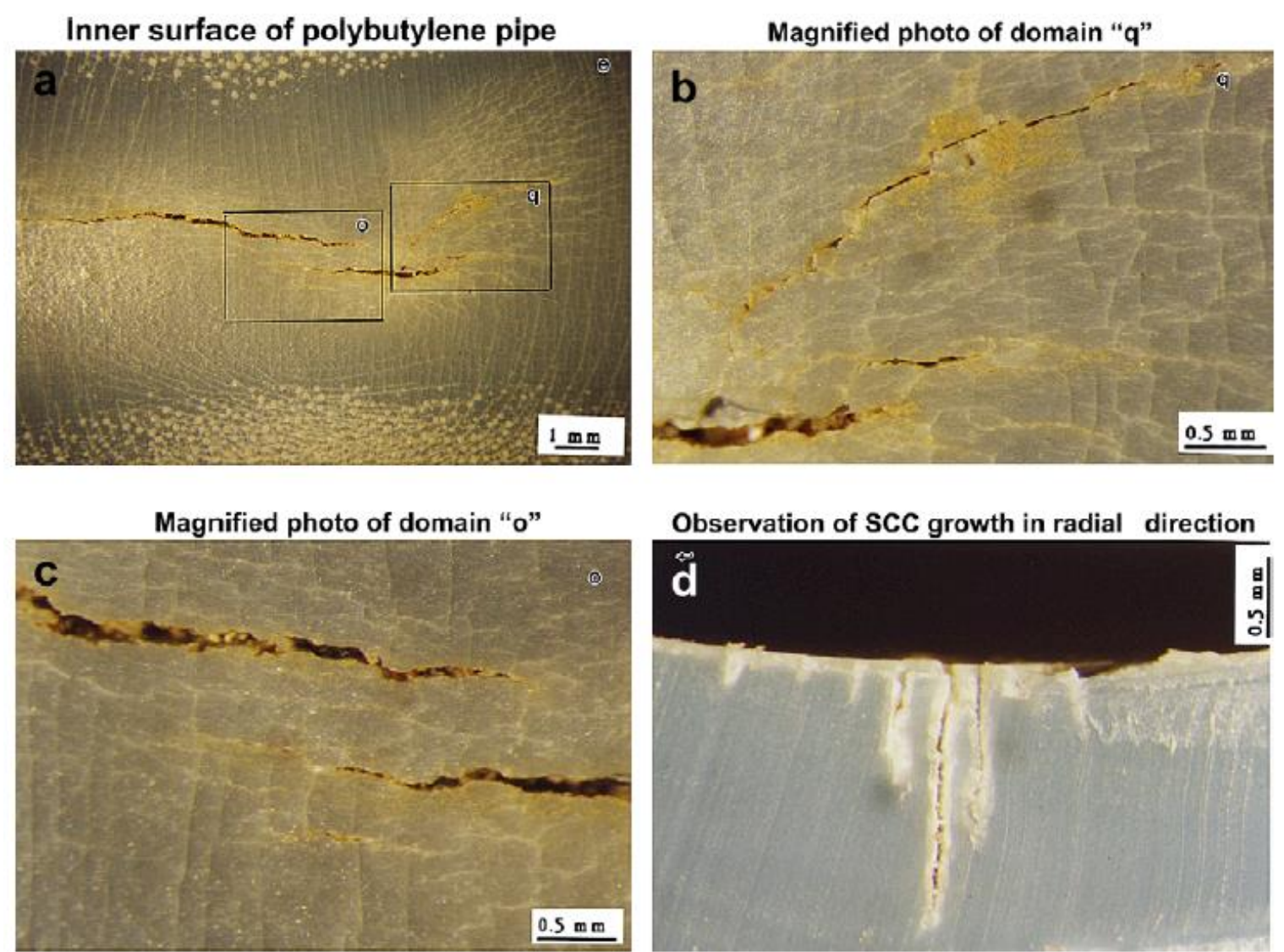

Figure 1 Stress corrosion cracks formation in combined aggressive chemical environment and mechanical stress. Copyright 2014. Reprint from [85]. 


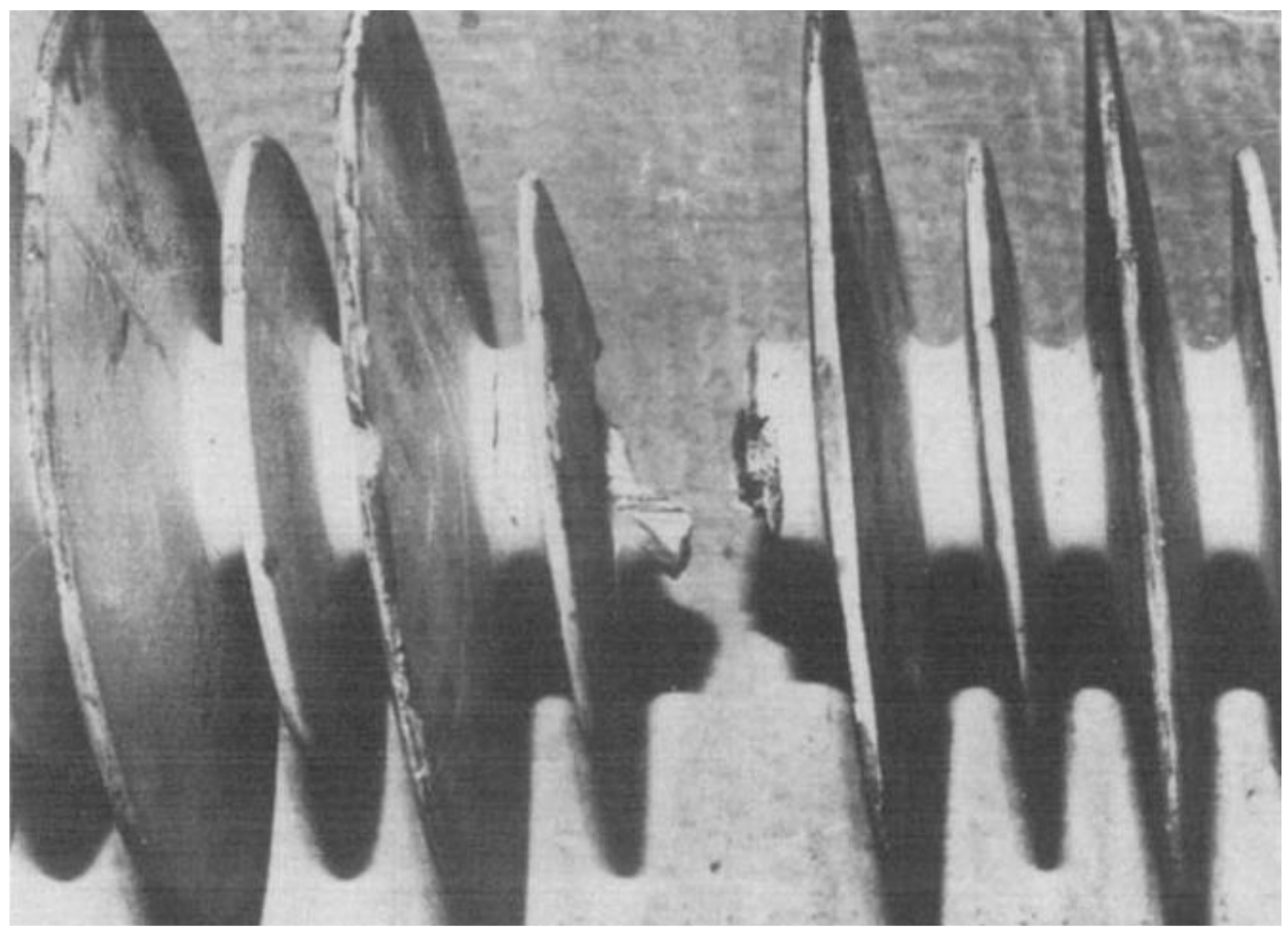

Figure 2 Destruction of high voltage insulator due to action of moisture, electrical field and acidic environment. Copyright 2014. Reprint from [92]. 


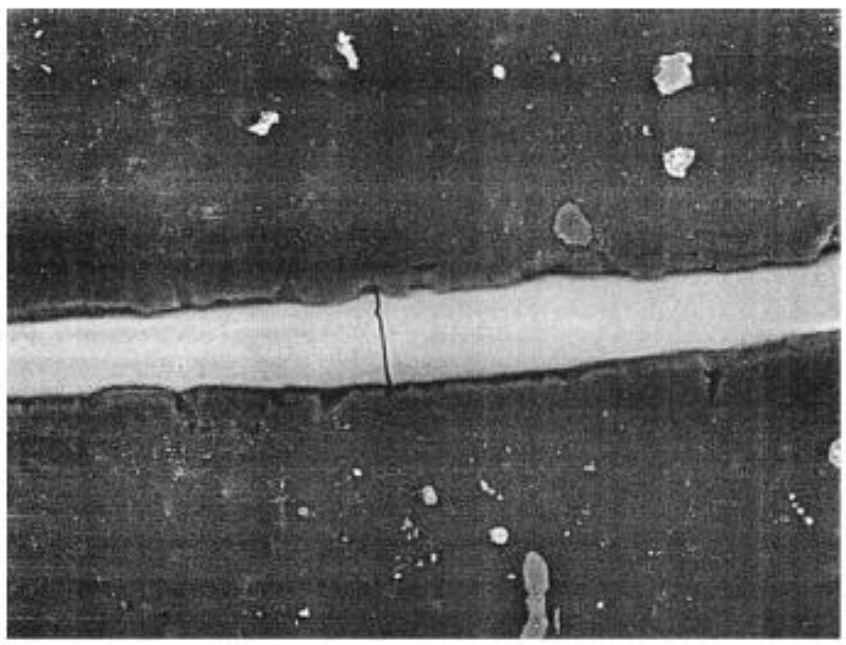

(a)

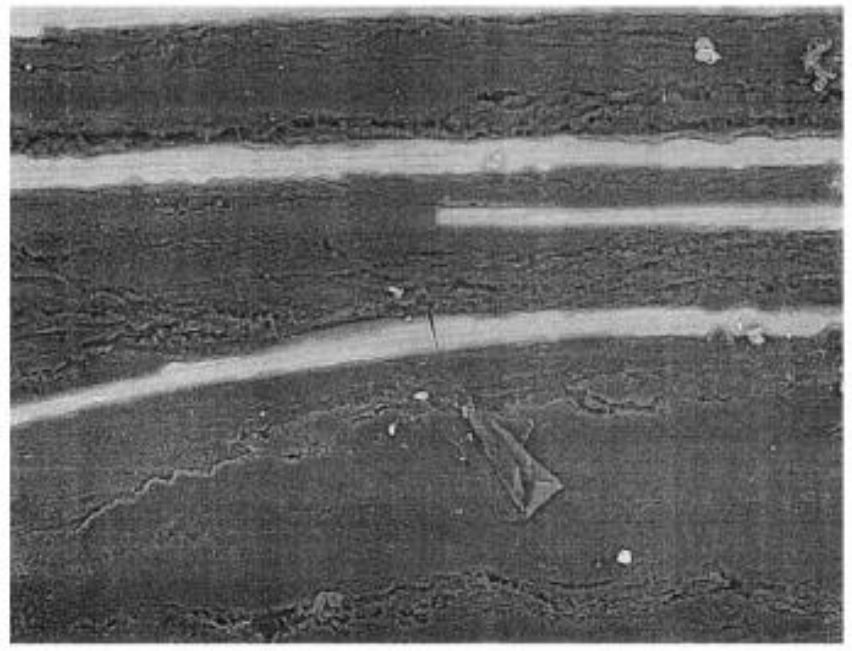

(c)

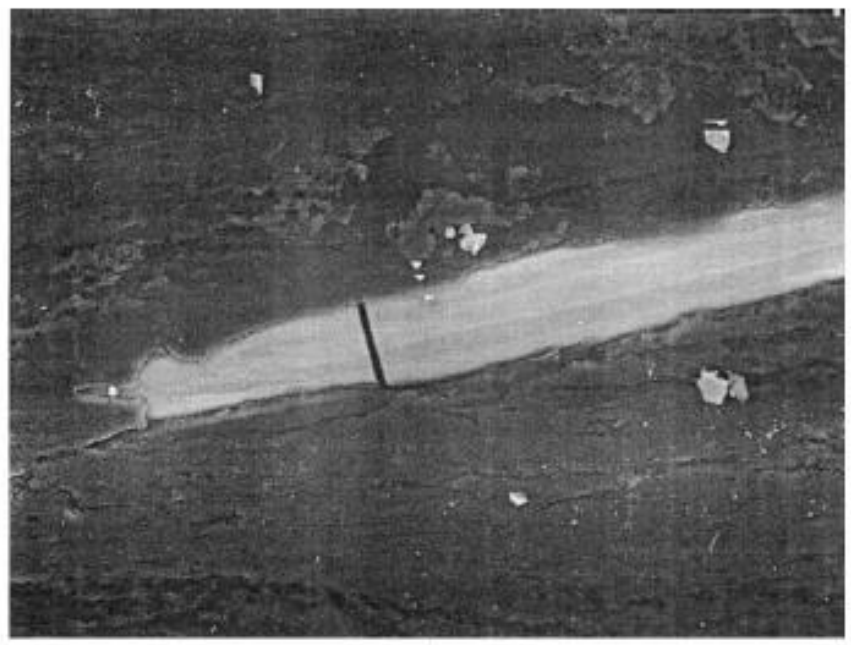

(b)

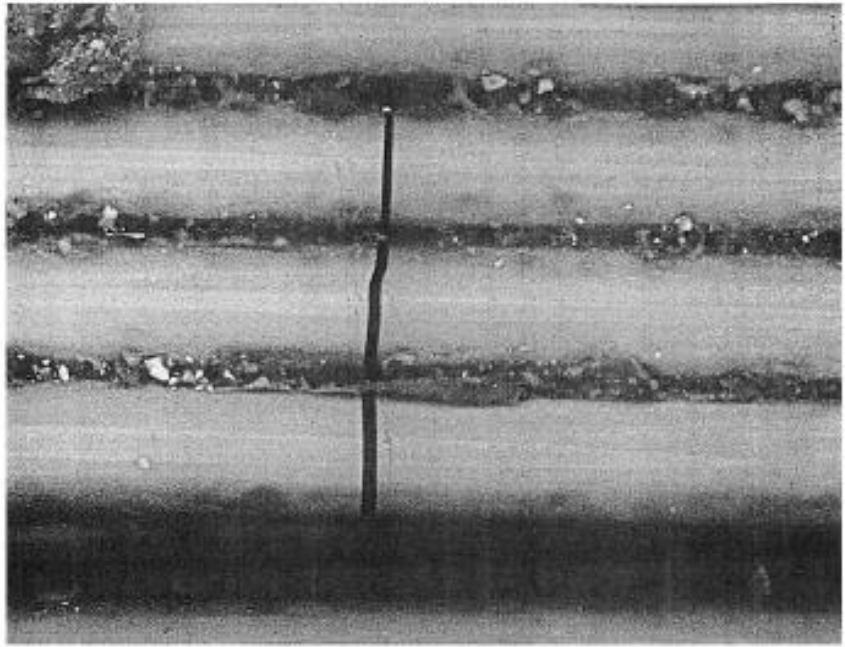

(d)

Figure 3 Stress-corrosion cracks after $336 \mathrm{~h}$ of acid exposure of E-glass/vinil ester without mechanical load. a,b,c) single fiber crack, and d) multiple fiber crack zone. Copyright 2014. Reprint from [96]. 


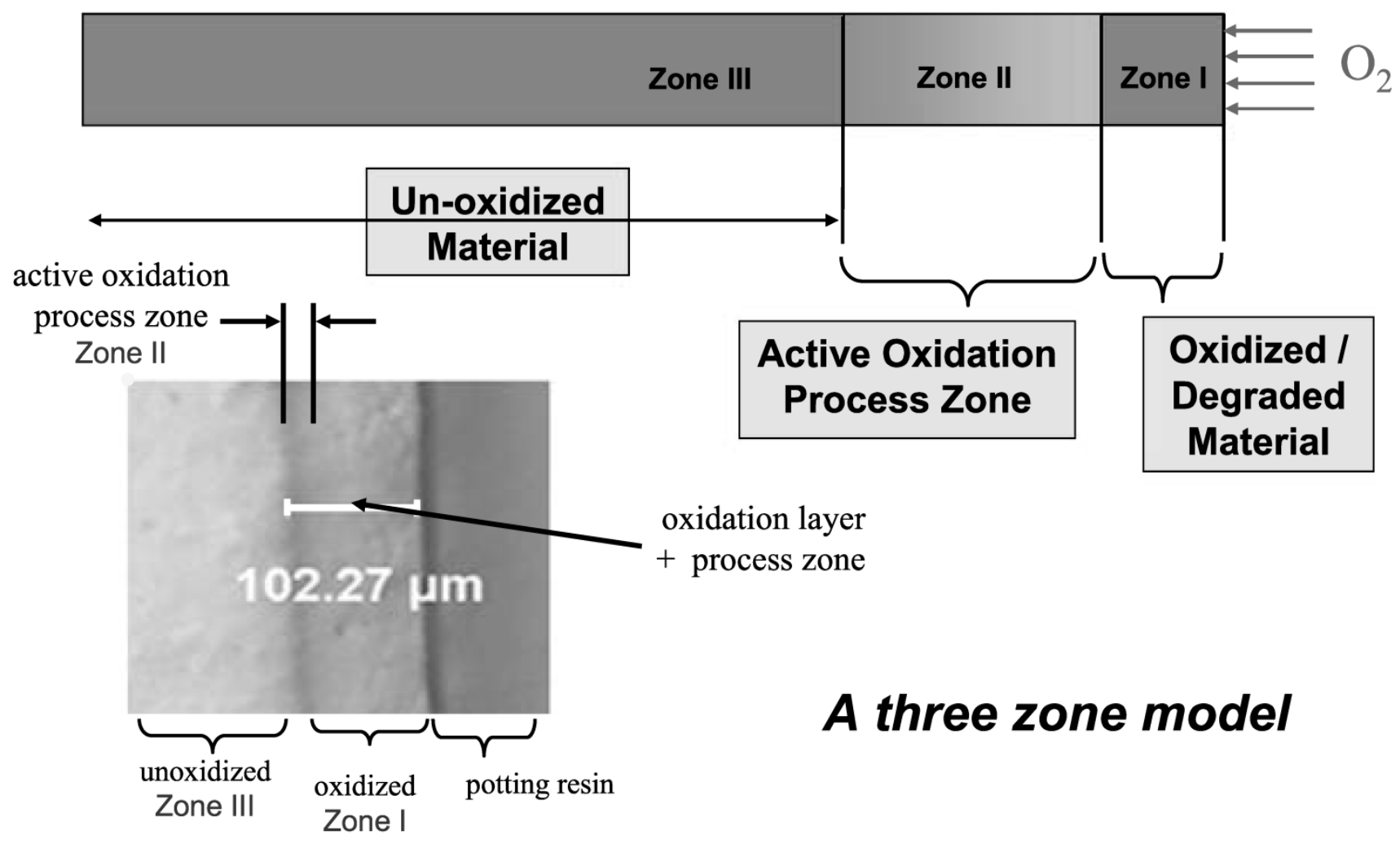

Figure 4 A three zone model of thermo-oxidative aging. Copyright 2014. Reprint from [105]. 


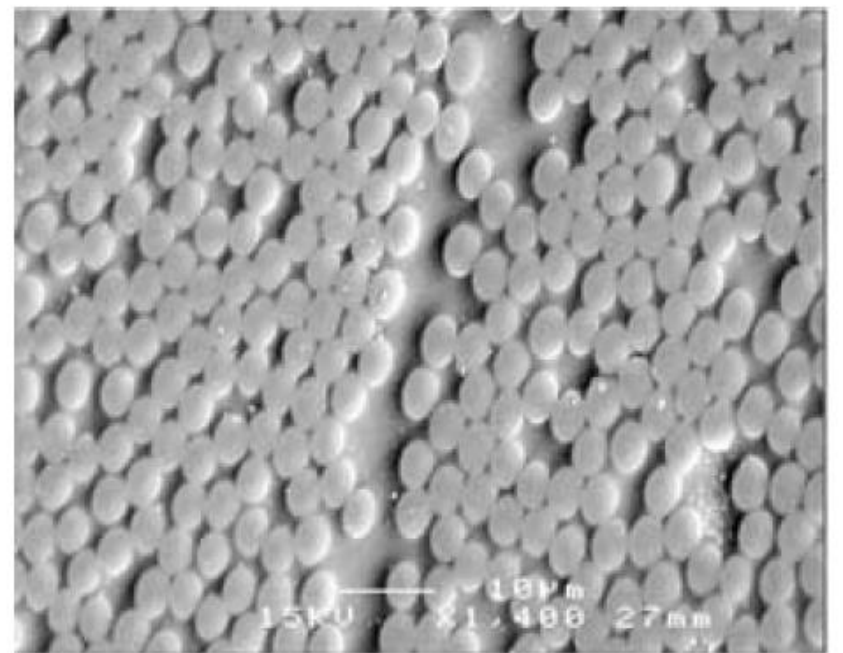

(a) $\mathrm{N}_{2}: 500$ thermal cycles

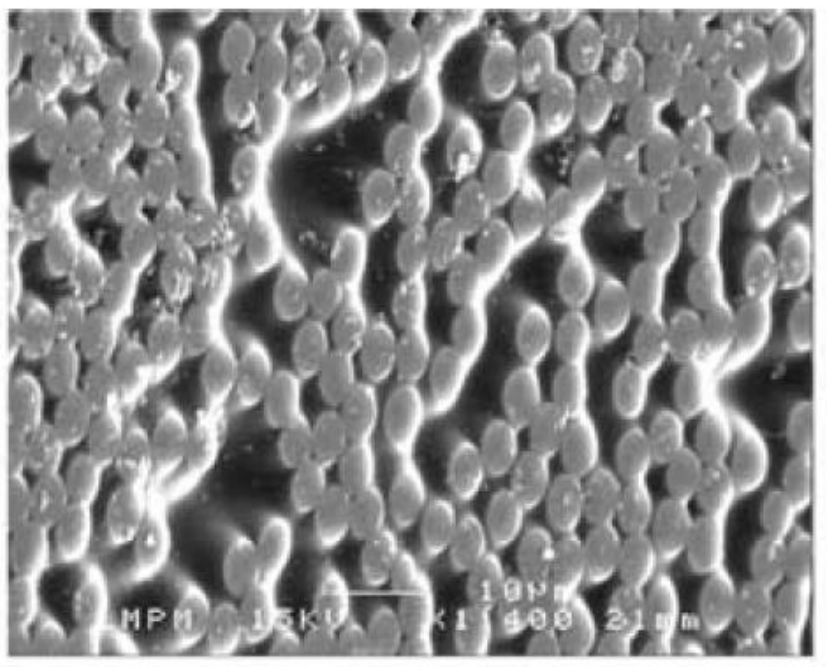

(b) air: 500 thermal cycles

Figure 5 Damage development in polymer after aging in nitrogen and air environment.

Copyright 2014. Reprint from [123]. 


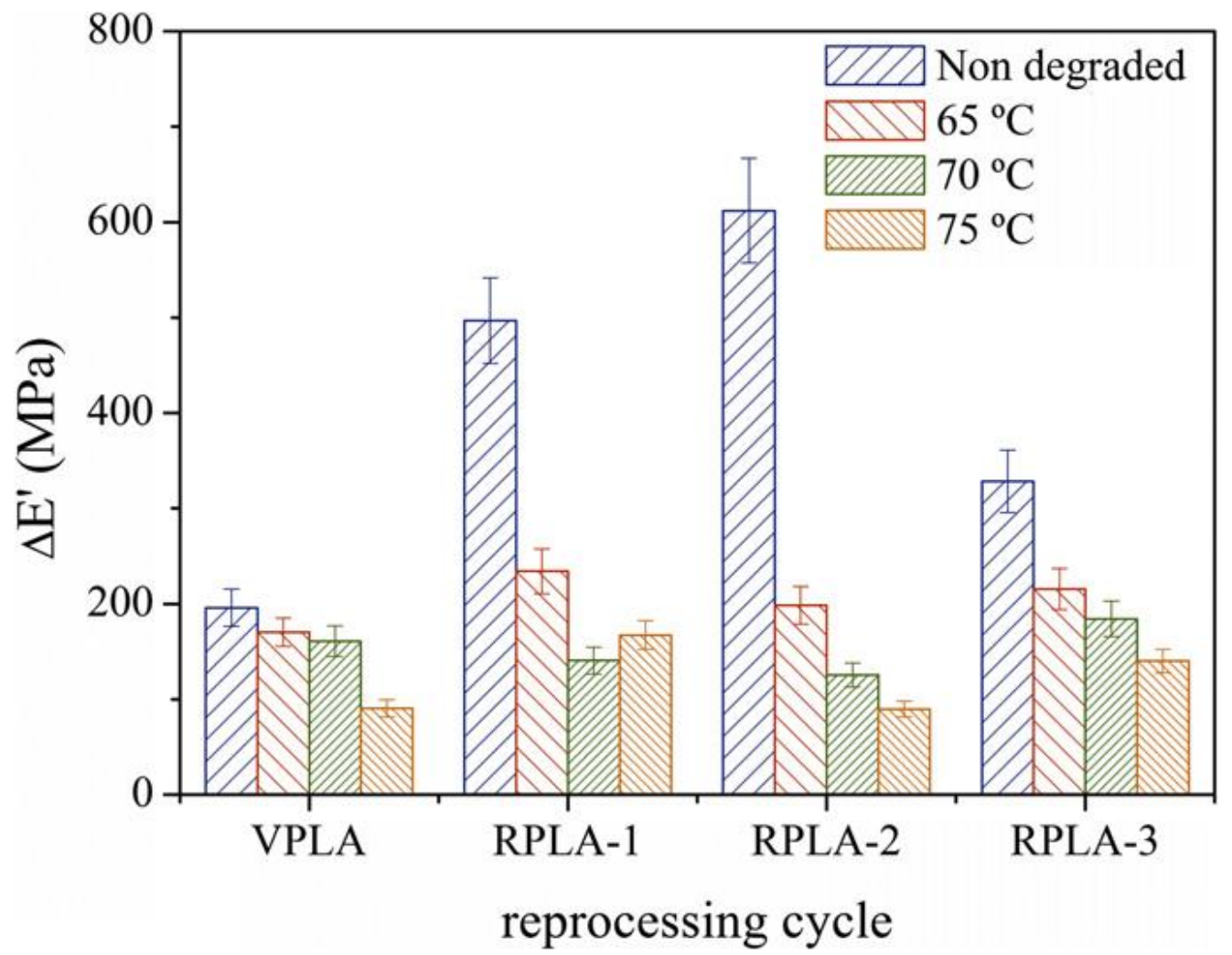

Figure 6 Development of mechanical stress in polylactide samples for different hydrothermal aging temperatures. VPLA and RPLA-i corresponds to virgin polymer and polymer after $i$ processing cycles, respectively. Copyright 2014. Reprint from [135]. 
Microencapsulated healing agent

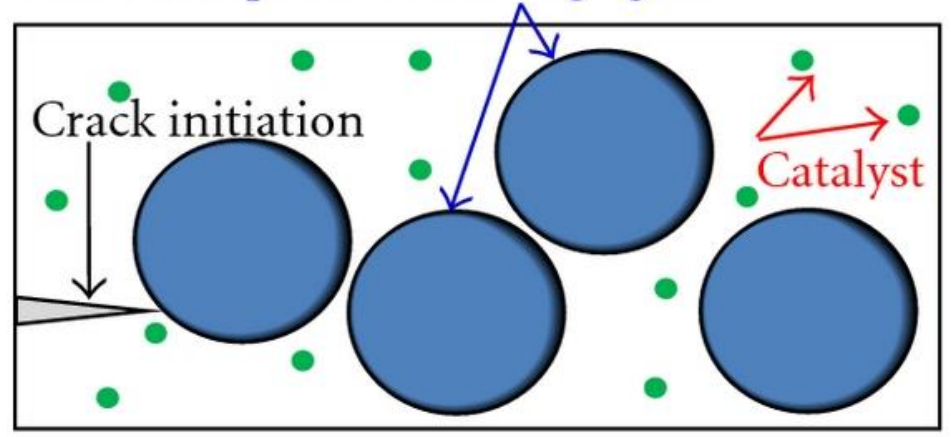

(i)

Healing agent

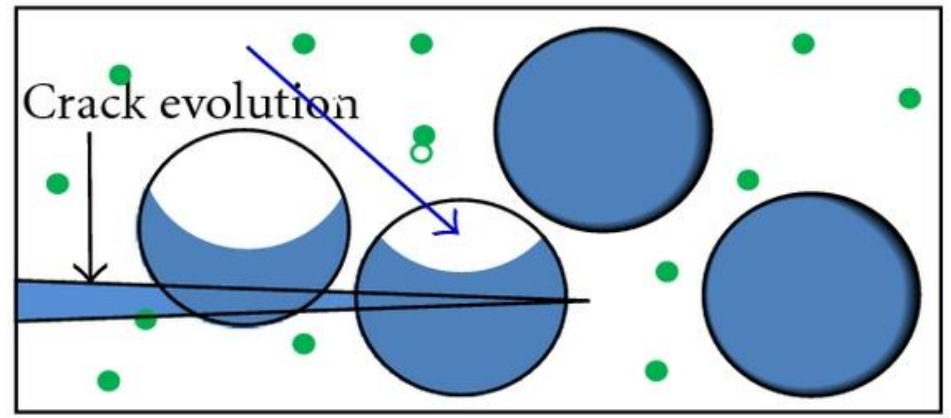

(ii)

Polymerized healing agent

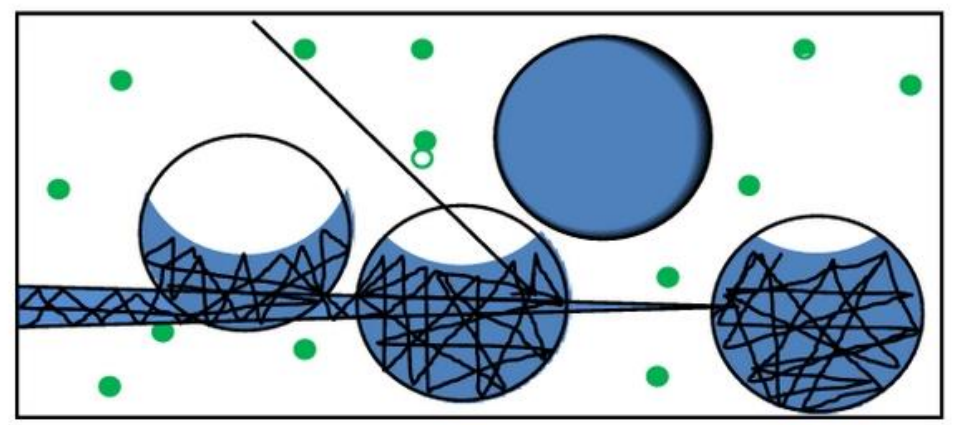

(iii)

Figure 7 Schematic of self-healing using microcapsules. Copyright 2014. Reprint from [356]. 


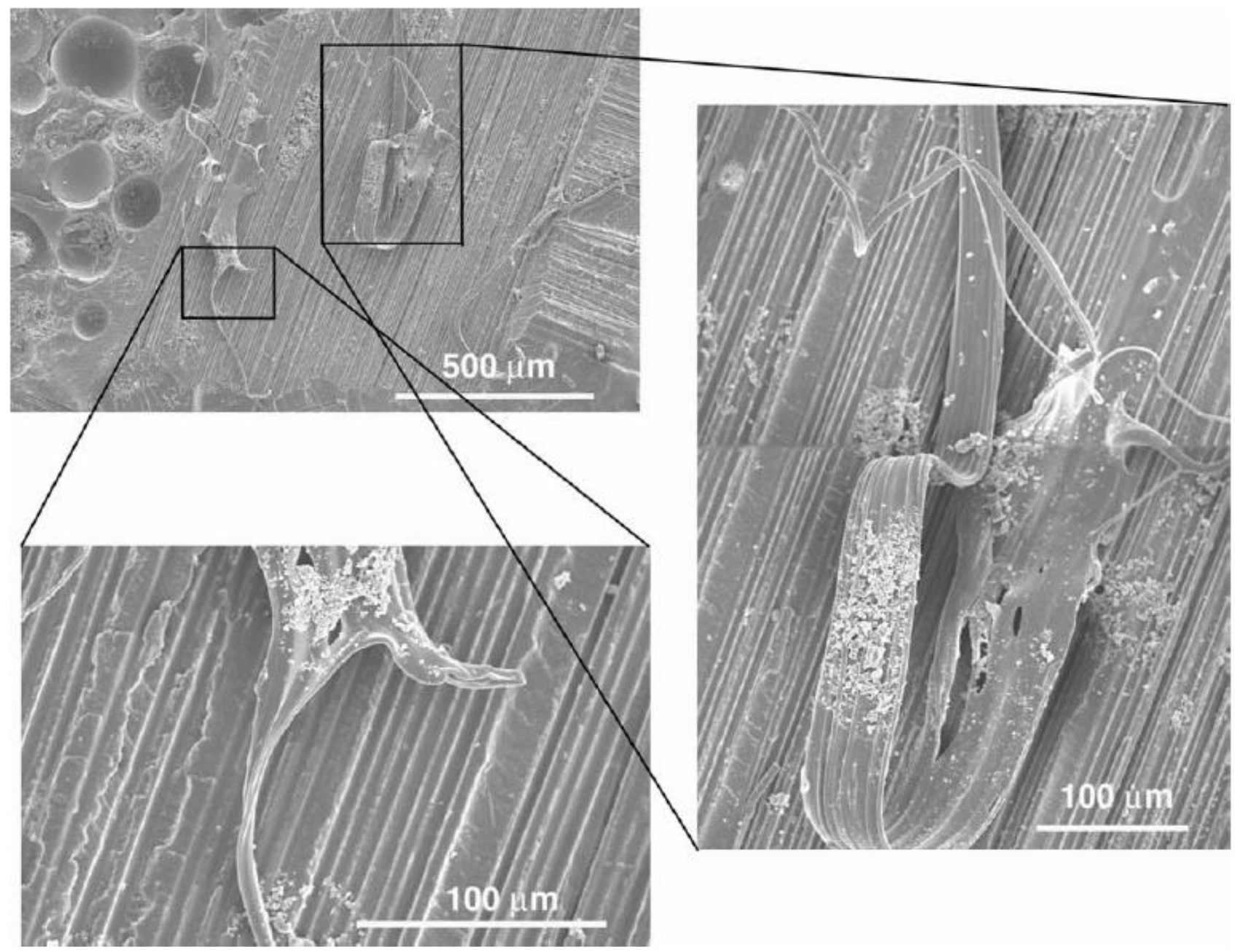

Figure 8 SEM image of the healed surface of composite fiber-reinforced polymer after 30 min healing time. Copyright 2014. Reprint from [17]. 


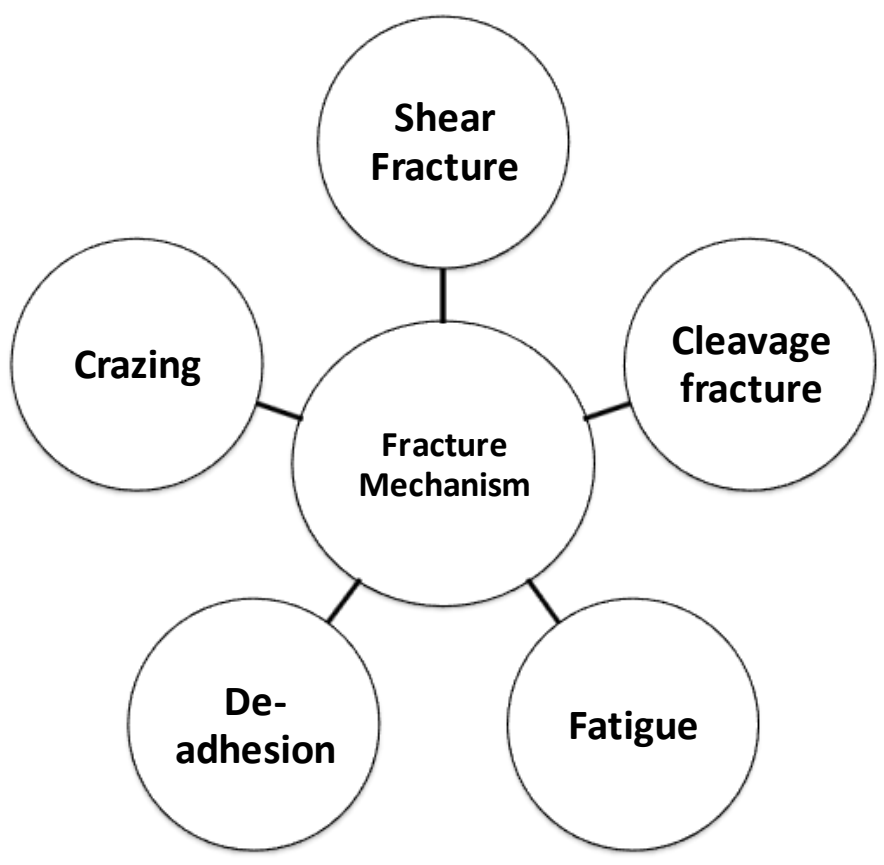

Figure 9 Types of fracture mechanism that generally distinguished for initiation and propogation 


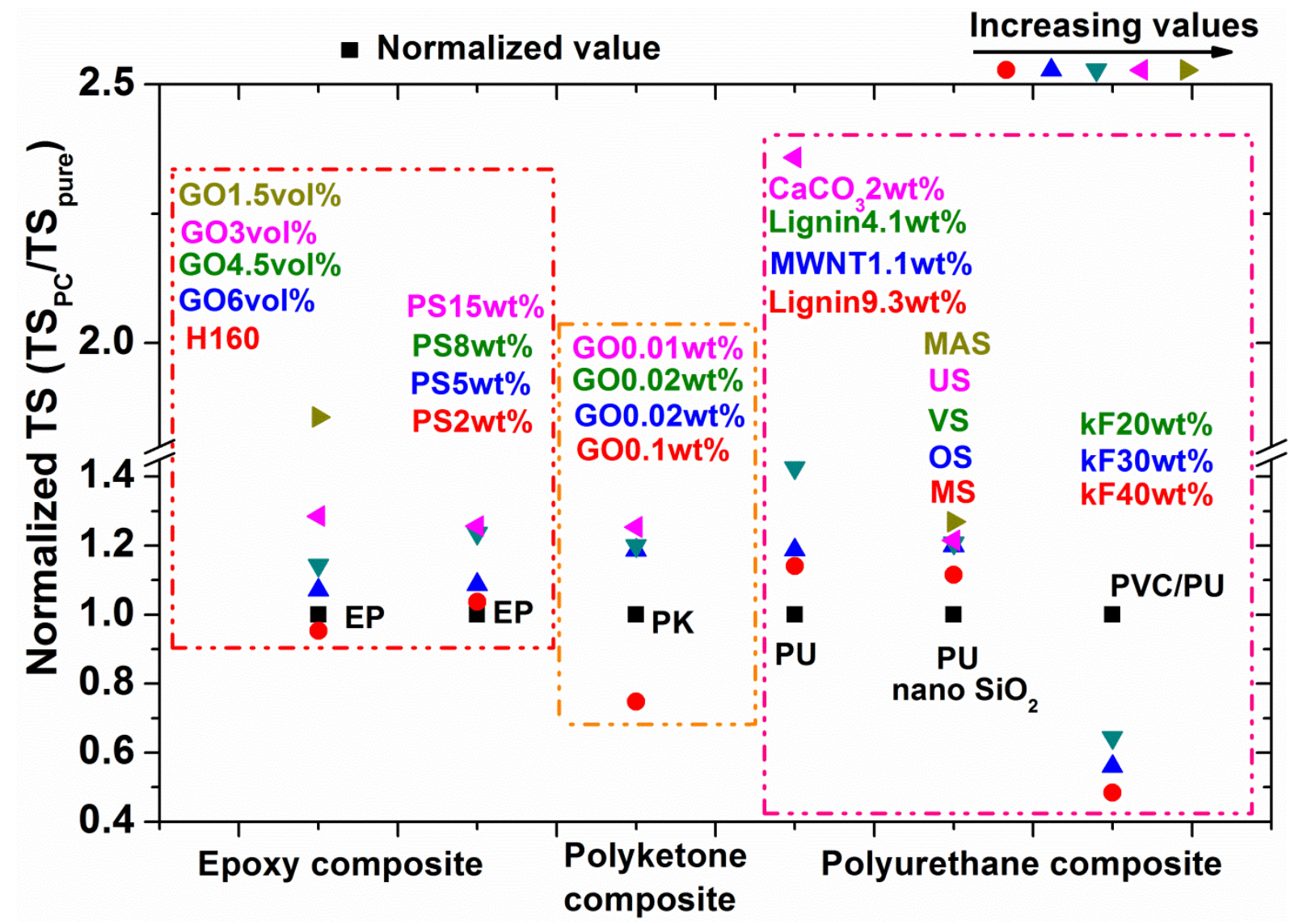

Figure 10 Normalized Tensile strength (TS) of different polymer composites, all values are normalized to its pure state (TSpc/TSPure). Inset shows increasing trend from red circle to angular dark yellow triangle [256-260, 357-359]. 


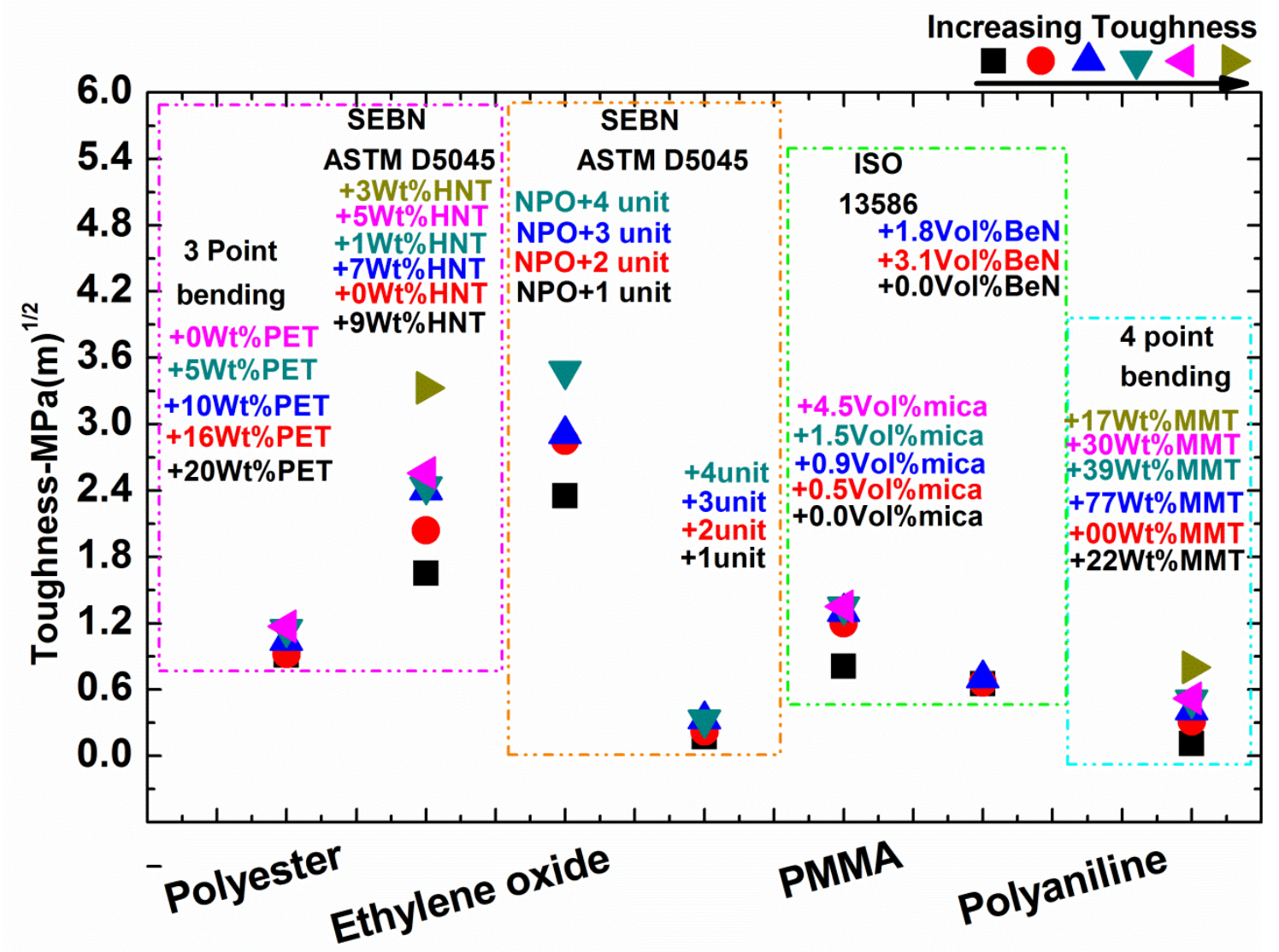

Figure 11 Toughness measurement of different polymers (Polyester, Ethylene oxid, PMMA, Emeraldine salt) correspond with different modifiers (PET, HNT, mica, Bentone (Ben),(MMT) concentration[269, 287-290]. 